Pós-Graduação em Desenvolvimento Sustentável

\title{
A Gestão de Resíduos Sólidos Urbanos na RIDE-DF: \\ A geração e a coleta seletiva
}

Mikaela Soares Silva Cardoso

Dissertação de Mestrado

Brasília-DF, maio de 2016

UNIVERSIDADE DE BRASÍLIA - UnB

CENTRO DE DESENVOLVIMENTO SUSTENTÁVEL - CDS 
UNIVERSIDADE DE BRASÍLIA

CENTRO DE DESENVOLVIMENTO SUSTENTÁVEL

\section{A Gestão de Resíduos Sólidos Urbanos na RIDE-DF: \\ A geração e a coleta seletiva}

Mikaela Soares Silva Cardoso

Orientador: Elimar Pinheiro do Nascimento

Dissertação de Mestrado

Brasília-DF, maio de 2016 
UNIVERSIDADE DE BRASÍLIA

CENTRO DE DESENVOLVIMENTO SUSTENTÁVEL

\title{
A Gestão de Resíduos Sólidos Urbanos na RIDE-DF: A geração e a coleta seletiva
}

\author{
Mikaela Soares Silva Cardoso
}

Dissertação de Mestrado submetida ao Centro de Desenvolvimento Sustentável da Universidade de Brasília, como parte dos requisitos necessários para a obtenção do Grau de Mestre em Desenvolvimento Sustentável, área de concentração Política e Gestão da Sustentabilidade.

Aprovado por:

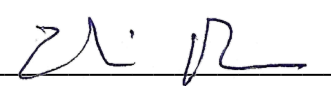

Elimar Pinheiro do Nascimento - Doutor (CDS-UnB)

(Orientador)

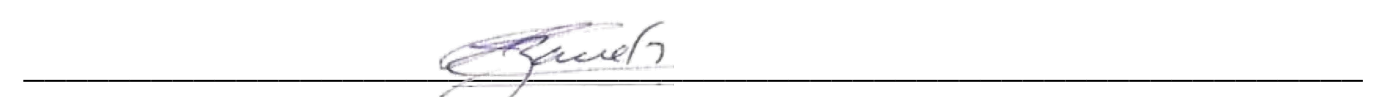

Izabel Cristina Bruno Bacellar Zaneti - Doutora (CDS - UnB)

(Examinadora Interna)

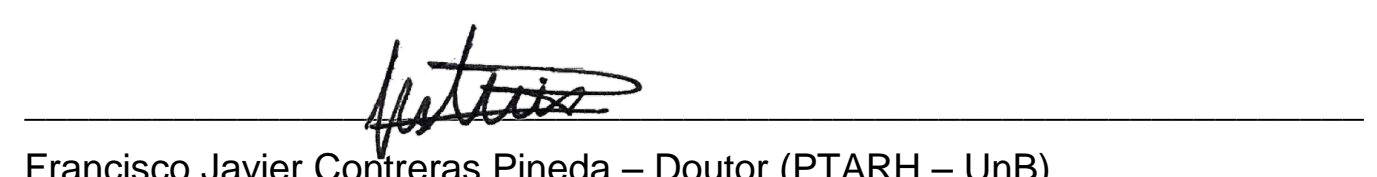

Francisco Javier Contreras Pineda - Doutor (PTARH - UnB)

(Examinador Externo)

Frederic Adelin Georges Mertens - (CDS - UnB)

(Suplente)

Brasília-DF, 20 de maio de 2016. 


\section{AGRADECIMENTOS}

A Deus, por permitir a realização deste trabalho.

Ao Dr. Elimar Pinheiro do Nascimento pela orientação.

Ao Dr. José Aroudo Mota, pelas contribuições como primeiro orientador.

Ao Centro de Desenvolvimento Sustentável da Universidade de Brasília (CDS/UnB), por todo o aprendizado adquirido.

À Coordenação de Aperfeiçoamento de Pessoal de Nível Superior (CAPES), pelo apoio a esta pesquisa

Aos professores membros da banca, por suas valiosas colaborações.

Ao Dr. Francisco Javier Contreras Pineda, pelas sugestões que fizeram toda a diferença no trabalho.

À família, em especial aqueles que acreditam e me ensinaram o valor da educação.

Aos amigos, que sempre estiveram presentes na torcida e no apoio;

À minha amiga Ângela Bussinguer, pela grande ajuda;

Ao marido, Márcio, pelo apoio, carinho, amor e, principalmente, pela paciência;

Às pessoas amadas que partiram desta vida;

Ao amigo, cujo caminho já não coincide, pelo apoio no início desta caminhada. Obrigada! 


\section{RESUMO}

Esta dissertação tem como objeto a questão quanto à sustentabilidade do tratamento de resíduos sólidos na região de Brasília e seu entorno. É composta por três capítulos, todos em formato de artigo científico. No primeiro capítulo são analisados os fatores socioeconômicos que influenciaram a geração de resíduos sólidos domiciliares no Distrito Federal durante o período de 2003 a 2014. A metodologia utilizada foi a Análise de Componentes Principais aliada à Análise de Cluster. Este capítulo não foi estendido aos municípios que integram a Região Integrada de Desenvolvimento do Distrito Federal e Entorno devido à ausência dos dados necessários para a realização das análises. A Análise de Componentes Principais resultou em dois componentes principais, onde o primeiro absorveu $95,029 \%$ da variância inicial. Os maiores escores encontrados foram para o Produto Interno Bruto $(0,993)$, o consumo de energia $(0,992)$ e o consumo de bens e produtos $(0,988)$, mostrando que os fatores relacionados à renda e ao consumo apresentaram forte relação com a geração dos Resíduos Sólidos Domésticos. As variáveis relacionadas ao crescimento populacional também apresentaram relação significativa com a geração dos resíduos sólidos no Distrito Federal. O segundo capítulo aborda aspectos da eficiência ambiental do manejo dos Resíduos Sólidos Urbanos desenvolvido no Distrito Federal e em três municípios integrantes da RIDE-DF. Utilizou-se o método proposto por Zaman (2011), que avalia o impacto dos resíduos sólidos no consumo energético, no consumo de água, na utilização de matérias-primas e na emissão de gás carbônico. Os maiores valores de Zero Waste Index foram encontrados para Luziânia, Goiás, seguidos do Distrito Federal, Formosa (também no Estado de Goiás) e Unaí, Minas Gerais. Estes valores, calculados para Região Integrada de Desenvolvimento do Distrito Federal e Entorno, estão muito abaixo dos valores obtidos por Zaman (2013). Um valor baixo de Zero Waste Index indica que o tratamento adotado (aterramento ou disposição em lixões) é ambientalmente ineficaz. O terceiro capítulo consiste na avaliação dos programas de coleta seletiva desenvolvidos na Região Integrada de Desenvolvimento do Distrito Federal e Entorno, no ano de 2014. A metodologia utilizada foi a aplicação de dois índices de sustentabilidade, propostos por Besen (2011) e Fechine (2014). Os resultados indicaram que todos os programas de coleta seletiva analisados apresentaram "baixa ou muito baixa sustentabilidade". Os resultados obtidos pelos dois índices diferiram para a maioria das localidades estudadas. Os resultados obtidos nos três capítulos permitem concluir que a gestão dos Resíduos Sólidos Urbanos na Região Integrada de Desenvolvimento do Distrito Federal e Entorno é insustentável.

Palavras-Chave: Análise de Componentes Principais; Zero Waste Index; Índices de sustentabilidade; Coletiva Seletiva; Gestão de resíduos sólidos. 


\begin{abstract}
This work as object the question about the sustainability of solid waste treatment in Brasilia and its surrounding region. This thesis is composed of three chapters, all in scientific article format. In the first chapter, the socioeconomic factors that influenced the generation of solid waste in the Distrito Federal during the period 2003 to 2014 are analyzed. The methodology used was the Principal Component Analysis (PCA) combined with Cluster Analysis (CA). This chapter has not been extended to the municipalities of the Integrated Region of Development of the Distrito Federal and Surrounding Areas (RIDE-DF) due to the lack of data needed to perform the analyzes. The PCA resulted in two main components, where the first absorbed $95.029 \%$ of the initial variance. The highest scores were found to GDP (0.993), energy consumption (0.992) and consumption of goods and products (0.988), showing that factors related to income and consumption showed a strong relationship with the generation of USW. The variables related to population growth also have significant relationship with the generation of solid waste in DF. Chapter 2 approaches the aspects of environmental efficiency of the management of urban solid waste developed in the DF and three municipalities members of RIDEDF. It was used the method proposed by Zaman (2011), which assesses the impact of solid waste on energy consumption, water consumption, the use of raw materials and carbon dioxide emissions. The largest ZWI values were found to Luziânia (GO), followed by the Distrito Federal (DF), Formosa (GO) and Unaí (MG). These values, calculated for RIDE-DF, are much lower than the values obtained by Zaman (2013). A low value of ZWI indicates that the treatment adopted (landfill or disposal in dumpsites) is environmentally ineffective. Chapter 3, consists in the assessment of selective collection programs developed in the RIDE-DF, in 2014. The methodology used was the application of two sustainability indexes proposed by Besen (2011) and Fechine (2014). The results indicated that all of selective waste collection programs analyzed exhibited low or very low sustainability. The results obtained by the two indexes differed from most locations studied.
\end{abstract}

Keywords: Principal component analysis. Zero Waste Index. Sustainability índices. Selective collective. Solid waste management. 


\section{LISTA DE ILUSTRAÇÕES}

Figura 1.1 - As Regiões Administrativas distribuídas em lotes.

Figura 2.1 - A Região Integrada de Desenvolvimento do Distrito Federal e Entorno e os locais de estudo

Figura 3.1 - Localidades da Região Integrada de Desenvolvimento do Distrito Federal e Entorno que declararam realizar Coleta Seletiva (2014).

Figura 3.2 - Avaliação da tendência à sustentabilidade (radar da sustentabilidade) da Coleta Seletiva.

Figura 3.3 - Rota da Coleta Seletiva no Distrito Federal..........................................................

Figura 3.4 - Imagem do jogo Clean City Curitiba.............................................................. 90

Figura 3.5 - Funcionamento do programa ECOELCE............................................................. 91 


\section{LISTA DE TABELAS}

Tabela 1.1 - Variáveis que influenciam a geração de Resíduos Sólidos Urbanos...................... 24

Tabela 1.2 - Testes de KMO e Barlett................................................................................. 28

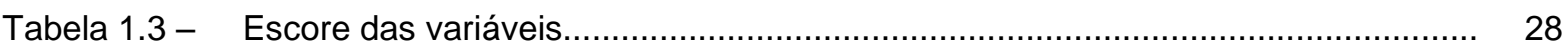

Tabela 1.4 - Geração mensal de Resíduos Sólidos Urbanos (toneladas) no Distrito Federal,

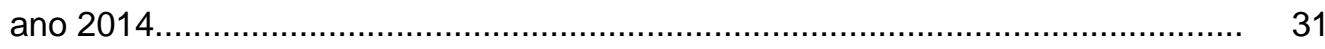

Tabela 2.1 - Dados das quatro áreas de estudo................................................................. 40

Tabela 2.2 - Valores de substituição para o Zero Waste Index............................................... 41

Tabela 2.3 - O Zero Waste Index para o ano de 2013........................................................ 42

Tabela 2.4 - O Zero Waste Index para o Distrito Federal (2003 a 2013)................................. 43

Tabela 2.5 - O Zero Waste Index em Luziânia, Goiás............................................................ 47

Tabela 3.1 - Resíduo Sólido Urbano coletado nas áreas de estudo............................................ 64

Tabela 3.2 - A coleta convencional no município de Padre Bernardo, Goiás............................ 66

Tabela 3.3 - I Índices de sustentabilidade da Coleta Seletiva ................................................... 81

Tabela 3.4 - Abrangência da Coleta Seletiva.................................................................. 82

Tabela 3.5 - Indicadores ambientais......................................................................... 84

Tabela 3.6 - Aspectos sociais.................................................................................. 86

Tabela 3.7 - Aspectos econômicos sobre a gestão dos Resíduos Sólidos Urbanos.................. 88

Tabela 3.8 - C Custo da coleta diferenciada de Resíduos Sólidos da Saúde............................... 89 


\section{LISTA DE QUADROS}

Quadro 1.0 - Legislação sobre resíduos sólidos.

Quadro 3.1 - Disposição final de Resíduos Sólidos Urbanos na Região Integrada de Desenvolvimento do Distrito Federal e Entorno................................................. 65

Quadro 3.2 - Matriz de indicadores de sustentabilidade para a Coleta Seletiva.......................... 68

Quadro 3.3 - Matriz para a Dimensão Institucional/Operacional............................................... 70

Quadro 3.4 - Matriz para a Dimensão Econômica....................................................................... 71

Quadro 3.5 - Matriz para a Dimensão Ambiental................................................................... 72

Quadro 3.6 - Matriz para a Dimensão Sociocultural............................................................ 73

Quadro 3.7 - Grau de sustentabilidade da coleta seletiva...................................................... 73

Quadro 3.8 - Organizações de catadores de materiais recicláveis no Distrito Federal.............. 76 


\section{LISTA DE GRÁFICOS}

Gráfico 1.1 - Resíduos domiciliares coletados anualmente no Distrito Federal....................... 26

Gráfico 1.2 - Densidade demográfica e população total..................................................... 26

Gráfico 1.3 - Composição gravimétrica dos Resíduos Sólidos Urbanos no Brasil e no

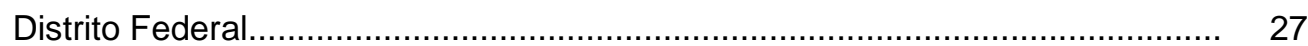

Gráfico 1.4 - Análise de Cluster................................................................................ 30

Gráfico 2.1 - O Zero Waste Index no Distrito Federal............................................................ 43

Gráfico 2.2 - $\quad$ A reciclagem no Distrito Federal (2003-2013)............................................... 43

Gráfico 2.3 - Matéria prima (tonelada) poupada anualmente pela reciclagem nos resíduos

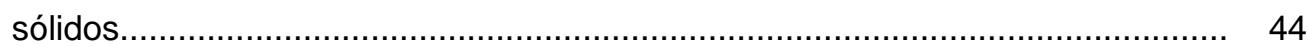

Gráfico 2.4 - Energia economizada em Giga Joules....................................................... 44

Gráfico 2.5 - Redução e emissão de $\mathrm{CO}_{2}$ (toneladas) pelo manejo dos resíduos sólidos no Distrito Federal......................................................................................... 45

Gráfico 2.6 - Economia ou demanda de água (litros) ..................................................... 46

Gráfico 2.7 - A reciclagem no Município de Formosa, Goiás, em 2013................................ 47

Gráfico 2.8 - Q Quantidade de Resíduos Sólidos Urbanos reciclados em Luziânia, Goiás........ 48

Gráfico 2.9 - Matéria prima economizada......................................................................... 48

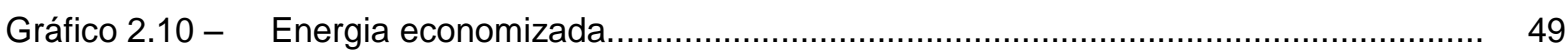

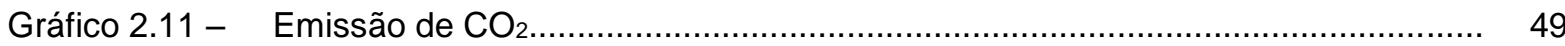

Gráfico 2.12 - Utilização de água (economia e gasto)........................................................ 50

Gráfico 2.13 - Resíduos sólidos reciclados em Unaí, Minas Gerais (2009)............................... 50 


\section{LISTA DE ABREVIATURAS}

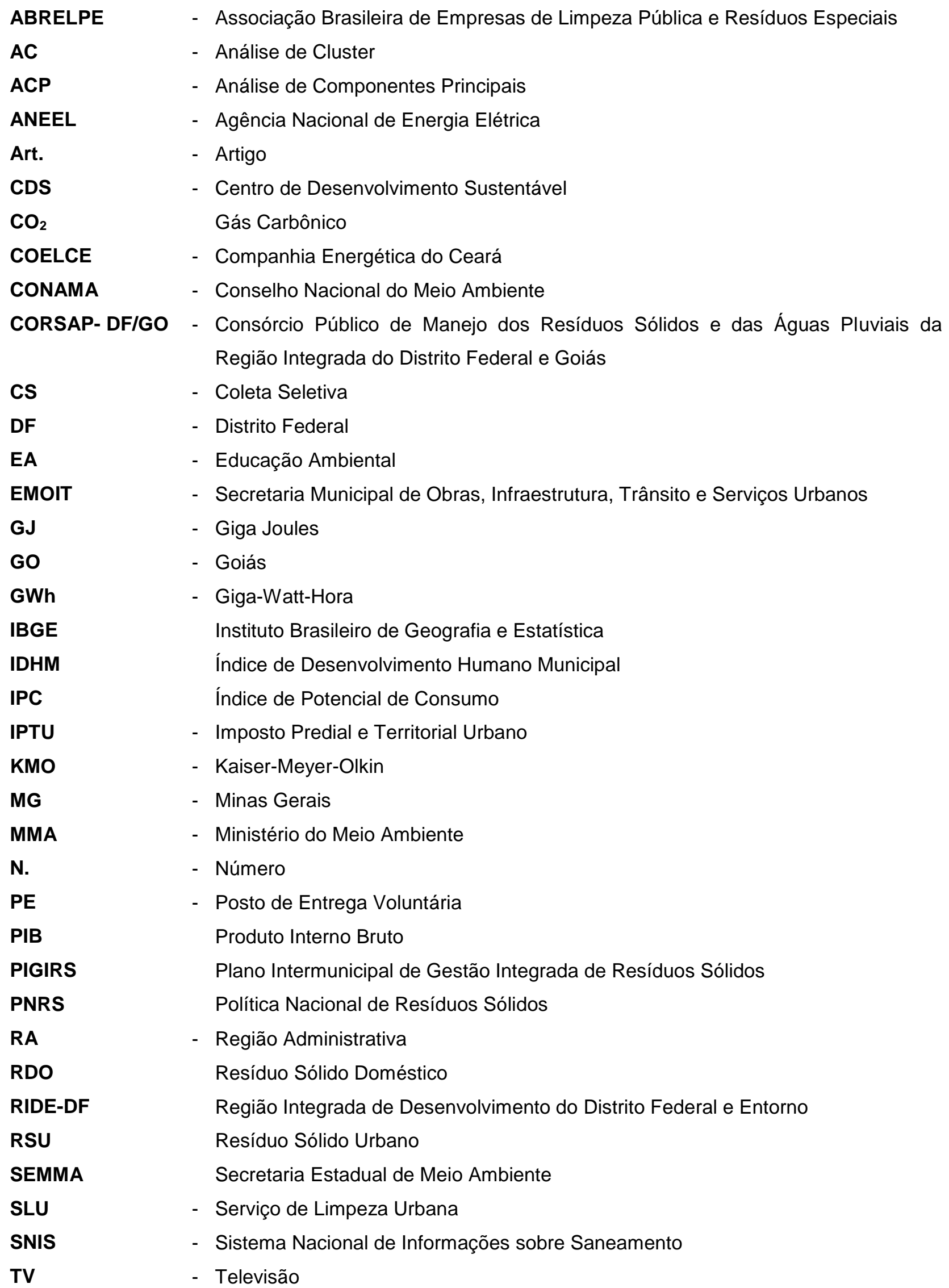


UnB

ZWI
- Universidade de Brasília

- Zero Waste Index 


\section{SUMÁRIO}

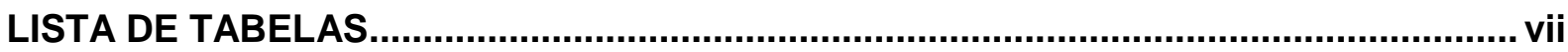

LISTA DE QUADROS ............................................................................................ viii

LISTA DE GRÁFICOS......................................................................................... ix

LISTA DE ABREVIATURAS ….................................................................................

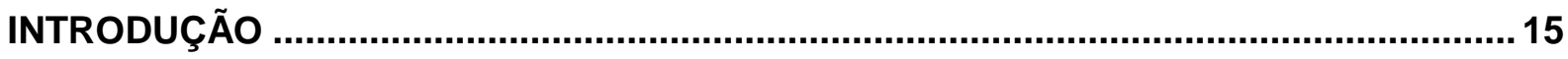

1 ANÁLISE DA GERAÇÃO DOS RESídUOS SÓLIDOS DOMÉSTICOS NO DISTRITO

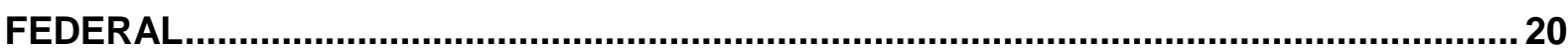

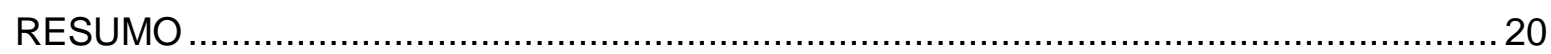

ABSTRACT

INTRODUÇÃO

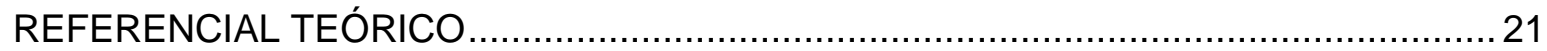

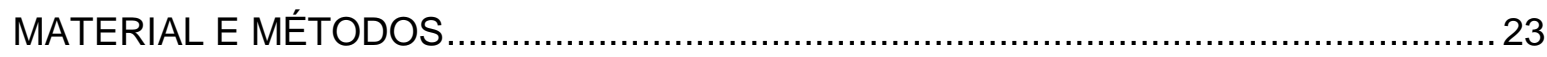

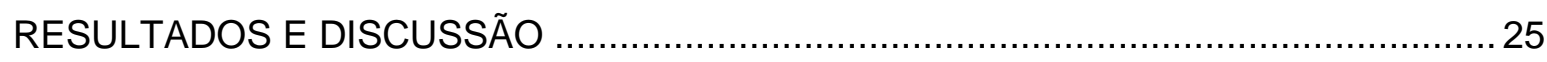

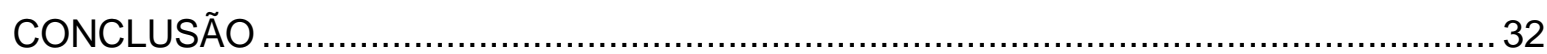

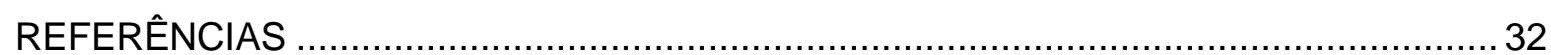

20 ZERO WASTE INDEX NA REGIÃO INTEGRADA DE DESENVOLVIMENTO DO DISTRITO FEDERAL E ENTORNO A PARTIR DE DADOS DO SISTEMA NACIONAL DE INFORMAÇÃO SOBRE SANEAMENTO: UMA ANÁLISE DO GERECIAMENTO DOS

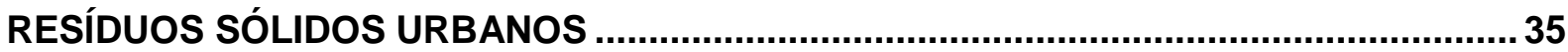

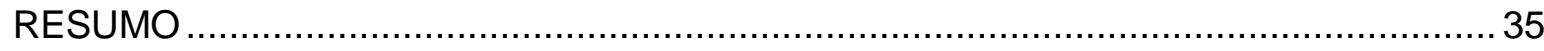

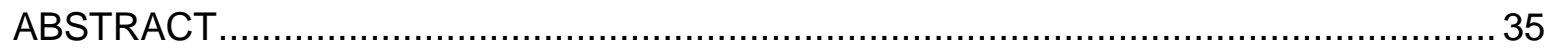

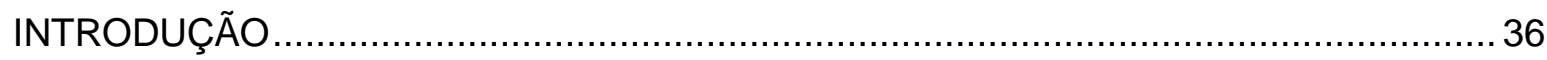

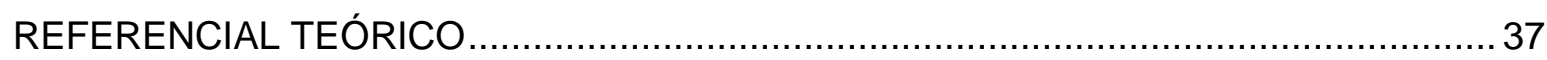

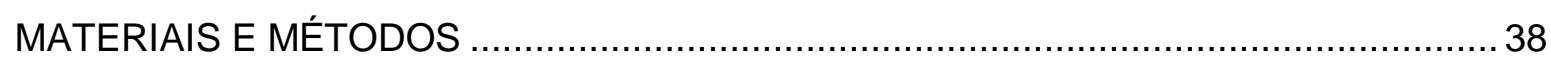

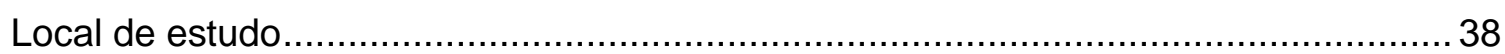

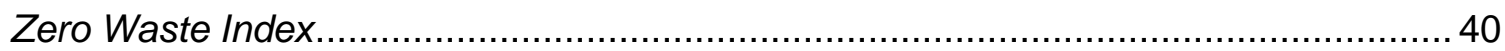

Sistema Nacional de Informação sobre Saneamento ................................................. 41

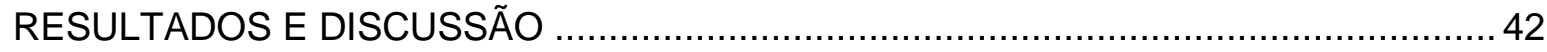

O Zero Waste Index para o Distrito Federal ............................................................... 42

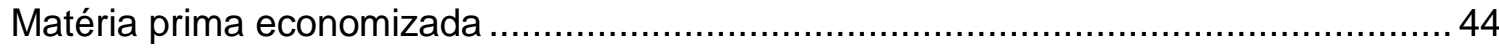

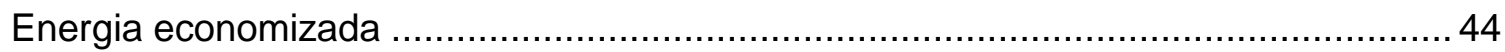

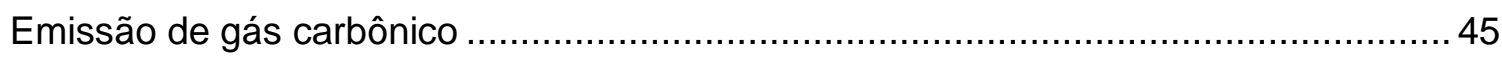


Água economizada .45

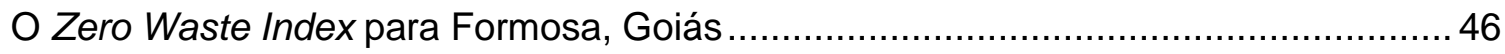

O Zero Waste Index para Luziânia, Goiás................................................................... 47

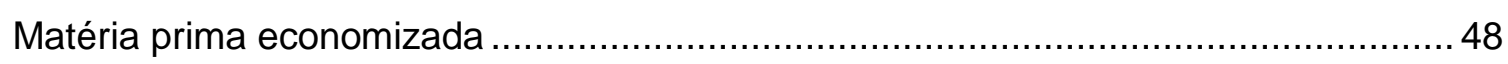

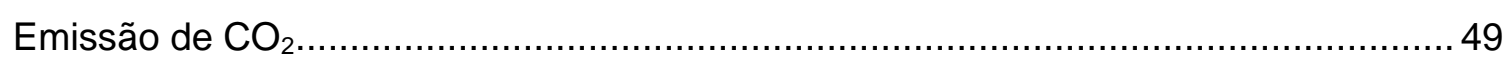

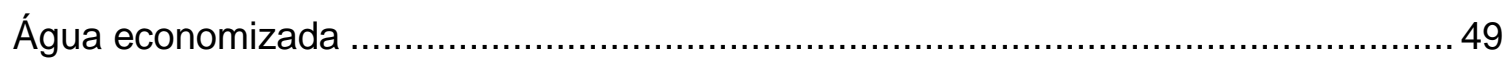

O Zero Waste Index para Unaí, Minas Gerais .......................................................... 50

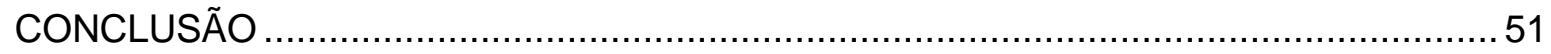

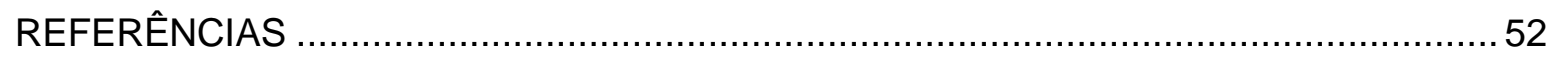

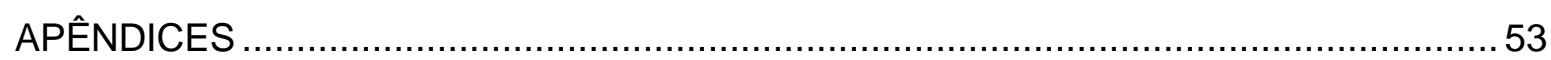

Apêndice "A" - O Zero Waste Index no Distrito Federal ................................................5 53

Apêndice "B" - O Zero Waste Index em Formosa, Goiás.............................................57

Apêndice "C" - O Zero Waste Index em Luziânia, Goiás ..............................................58

Apêndice "D" - O Zero Waste Index em Unaí, Minas Gerais ......................................60 60

3 AVALIAÇÃo DA COLETA SELETIVA NA REGIÃO INTEGRADA DE DESENVOLVIMENTO DO DISTRITO FEDERAL E ENTORNO A PARTIR DE DOIS

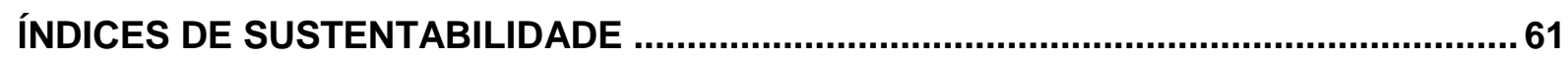

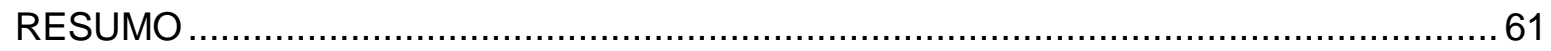

ABSTRACT

INTRODUÇÃO

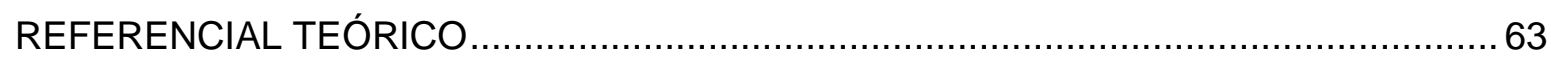

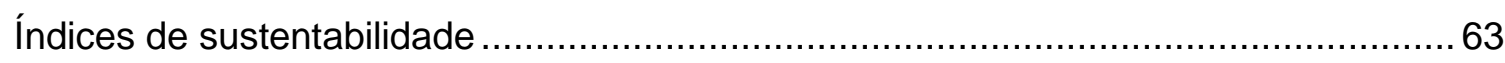

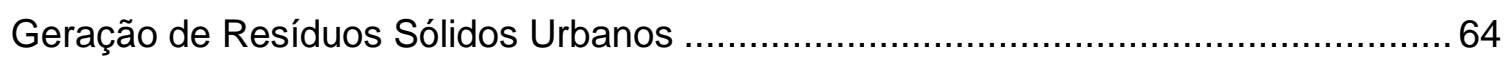

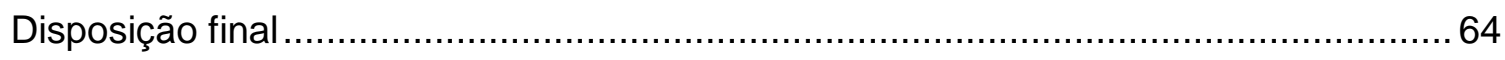

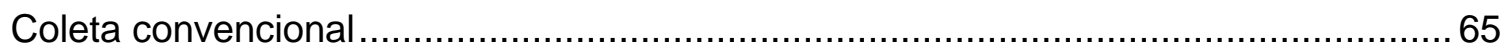

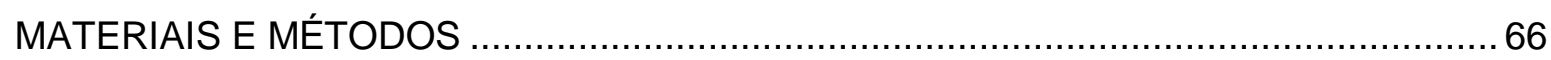

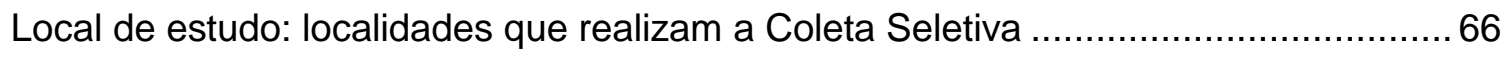

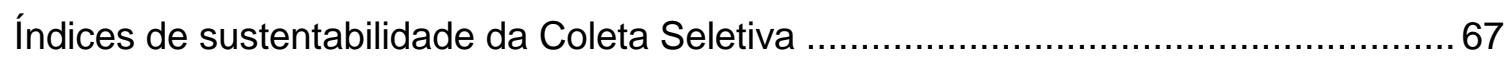

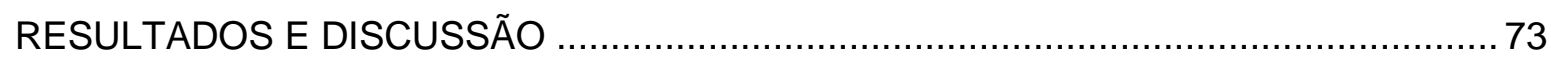

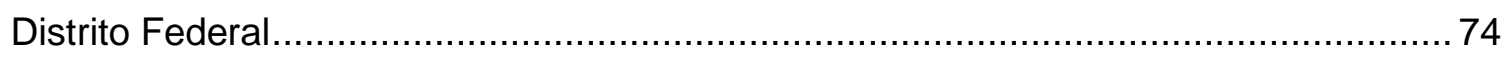

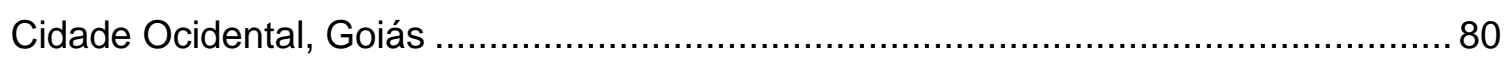

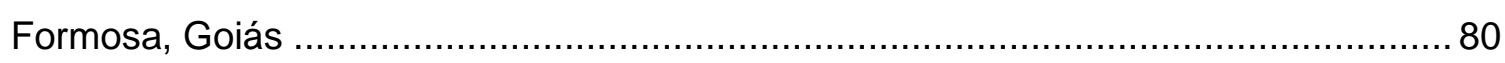

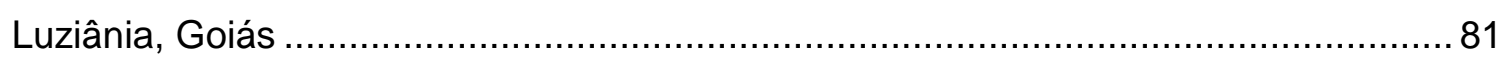




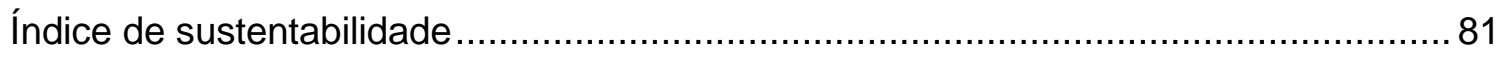

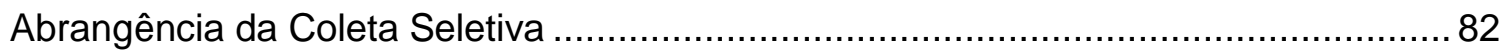

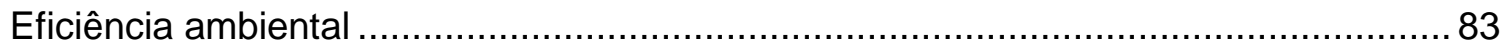

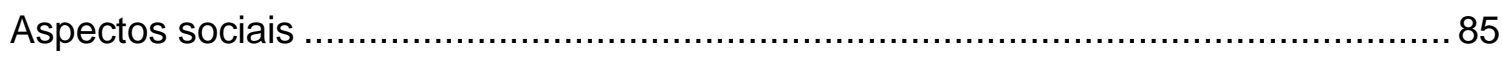

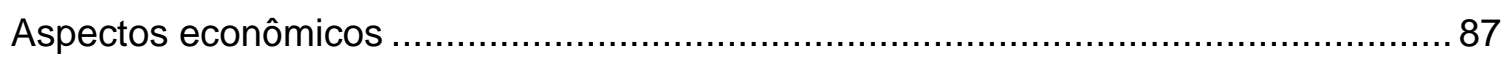

Resíduos da saúde

Educação Ambiental: campanhas e divulgação da Coleta Seletiva.............................. 89

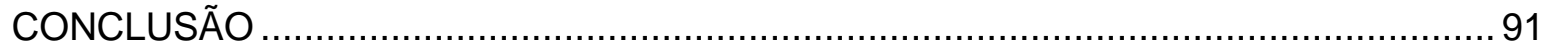

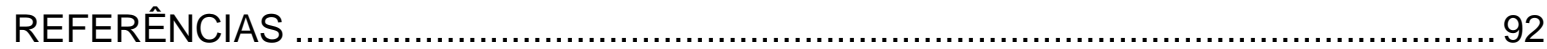

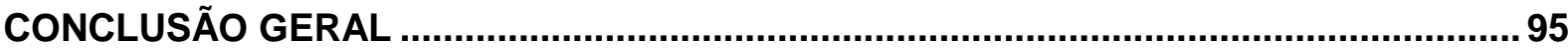

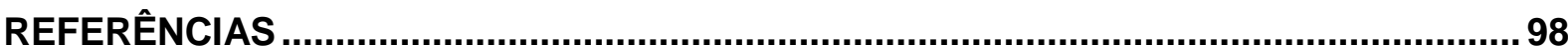




\section{INTRODUÇÃO}

O aumento da geração de Resíduos Sólidos Urbanos (RSUs) pode ser observado em diversos centros urbanos. Este fenômeno demanda mais atenção nos países em desenvolvimento, onde o gerenciamento destes resíduos apresenta baixa eficácia. $\mathrm{Na}$ Holanda cerca de $90 \%$ dos RSUs gerados recebem tratamento adequado como reciclagem, compostagem ou aproveitamento energético. O restante é disposto em aterros sanitários (EPE, 2008). No Brasil, observa-se que a coleta convencional, atividade mais básica no gerenciamento dos RSUs, ainda não possui cobertura total. Estima-se que cerca de $10 \%$ do total de RSUs produzidos não é sequer coletado, sendo depositado em lixões clandestinos (ABRELPE, 2014). Além disso, a maior parte dos RSUs coletados no Brasil é disposta, sem qualquer tratamento, em lixões e aterros controlados inadequados (IBGE, 2014, s. d.).

Na Região Integrada de Desenvolvimento do Distrito Federal e Entorno (RIDE-DF) também se observa o aumento na geração de RSUs no Distrito Federal (DF) e na maioria dos municípios. Em Padre Bernardo, Goiás (GO), a geração de resíduos sólidos foi de 2.504 toneladas, no ano de 2009, e de 4.745 toneladas em 2013 (SNIS, 2016).

A Política Nacional de Resíduos Sólidos (PNRS) reúne os princípios, as diretrizes, os objetivos, os instrumentos, as metas e as ações a serem adotados pela União isoladamente ou em parceria com os estados, o Distrito Federal, os municípios e os entes privados, visando à gestão integrada e ao gerenciamento ambientalmente adequado dos resíduos sólidos.

A PNRS institui a obrigatoriedade de todos os municípios desenvolverem o Plano Municipal de Resíduos Sólidos como documento norteador da Política Municipal de Resíduos Sólidos. Os municípios que optarem por soluções consorciadas podem desenvolver Plano Intermunicipal, cumprindo os conteúdos mínimos do art. 19 e estarão dispensados de elaboração de Plano Municipal.

Para a RIDE-DF será desenvolvido um Plano Intermunicipal de Gestão Integrada de Resíduos Sólidos (PIGIRS) por meio do Consórcio Público de Manejo dos Resíduos Sólidos e das Águas Pluviais da Região Integrada do Distrito Federal e Goiás (CORSAP-DF/GO), que elaborou um termo de referência para a contratação de consultoria técnica especializada para a elaboração do PIGIRS. Dentre as etapas constantes no termo de referência está previsto o Diagnóstico Regional com Detalhamento Municipal, que deverá contemplar:

a) Diagnóstico da Gestão;

b) Caracterização Socioeconômica; 
c) Atividades Geradoras;

d) Situação dos Resíduos; e

e) Iniciativas Relevantes.

A Política Nacional do Meio Ambiente, instituída pela Lei n. 6.938/1981, pode ser considerada uma das primeiras leis federais que abordam aspectos do manejo de resíduos sólidos. No código 17 do anexo VIII são designadas as atividades com potencial poluidor:

Produção de energia termoelétrica; tratamento e destinação de resíduos industriais líquidos e sólidos; disposição de resíduos especiais tais como: de agroquímicos e suas embalagens; usadas e de serviço de saúde e similares; destinação de resíduos de esgotos sanitários e de resíduos sólidos urbanos, inclusive aqueles provenientes de fossas; dragagem e derrocamentos em corpos d'água; recuperação de áreas contaminadas ou degradadas.

A Lei n. 11.445/2007, que institui a Política Nacional de Saneamento Básico (PNSB), também consiste em um marco regulatório relativo à gestão de resíduos sólidos. Na PNSB são definidas as diretrizes para prestação dos serviços públicos de limpeza urbana e manejo de resíduos sólidos: o planejamento, a regulação e fiscalização, a prestação de serviços com regras, a exigência de contratos precedidos de estudo de viabilidade técnica e financeira, definição de regulamento por lei, definição de entidade de regulação, e controle social assegurado.

O principal normativo brasileiro que dispõe sobre resíduos sólidos é a Lei $\mathrm{n}$. 12.305/2010, que institui a PNRS. Esta Política foi regulamentada mediante a edição do Decreto n. 7.404/2010. O processo de discussão da Lei que instituiu a PNRS levou cerca de 20 anos, dada a complexidade do tema. Deste amplo processo resultou uma Lei considerada moderna pelos especialistas. A Lei estabelece princípios, objetivos, instrumentos e diretrizes para a gestão integrada e o gerenciamento dos resíduos sólidos, visando a redução da geração de resíduos sólidos, propondo um conjunto de instrumentos para promover a destinação ambientalmente adequada dos resíduos como a reciclagem, a reutilização e a disposição ambientalmente adequada dos rejeitos. Além disso, a Lei prevê o estímulo a práticas de consumo sustentável e de responsabilidade socioambiental.

A Lei n. 12.305/2010 traz, como grande avanço, o conceito de logística reversa e da responsabilidade compartilhada entre fabricantes, consumidores, distribuidores, importadores, entre outros. A PNRS estipulou, ainda, prazo para o fechamento dos lixões e determinou que os resíduos sólidos recebessem tratamento adequado e que apenas rejeitos sejam depositados em aterro sanitário, quando esgotadas as alternativas de tratamento.

Apenas alguns estados brasileiros possuem Plano Estadual de Resíduos Sólidos. Em relação aos estados em análise, o estado de Goiás (GO) instituiu a Política Estadual de 
Resíduos Sólidos mediante a promulgação da Lei Estadual n. 14.248/2002. O DF instituiu a Política Distrital de Resíduos Sólidos através da Lei Distrital n. 3.232/2003.

O Quadro 1, a seguir, aborda as principais normas, resoluções e leis acerca do manejo de resíduos sólidos.

\begin{tabular}{|c|c|c|}
\hline Ano & Legislação & Disposição \\
\hline 1981 & Lei n. 6.938 & Dispõe sobre a Política Nacional do Meio Ambiente. \\
\hline 1988 & Constituição Federal & $\begin{array}{l}\text { Aborda a participação e a responsabilidade da sociedade civil e do } \\
\text { poder público ao determinar que todos têm direito a um ambiente } \\
\text { ecologicamente equilibrado. }\end{array}$ \\
\hline 1990 & Decreto n. 9.274 & $\begin{array}{l}\text { Regulamenta a Lei n. } 6.902 \text {, de } 27 \text { de abril de } 1981 \text {, e a Lei } n . \\
6.938 \text {, de } 31 \text { de agosto de } 1981 .\end{array}$ \\
\hline 1998 & Lei n. 9.605 & $\begin{array}{l}\text { Dispõe sobre as sanções penais e administrativas derivadas de } \\
\text { condutas e atividades lesivas ao meio ambiente, e dá outras } \\
\text { providências. }\end{array}$ \\
\hline 1999 & Lei n. 9.795 & $\begin{array}{l}\text { Dispõe sobre a educação ambiental, institui a Política Nacional de } \\
\text { Educação Ambiental e dá outras providências. }\end{array}$ \\
\hline 2000 & Lei n. 10.165 & Altera a Lei n. 6.938. \\
\hline 2001 & Resolução CONAMA n. 275 & $\begin{array}{l}\text { Estabelece o código de cores para diferentes resíduos na coleta } \\
\text { seletiva. }\end{array}$ \\
\hline 2002 & Resolução CONAMA n. 307 & $\begin{array}{l}\text { Estabelece diretrizes, critérios e procedimentos para a gestão dos } \\
\text { resíduos da construção civil. }\end{array}$ \\
\hline 2002 & Resolução CONAMA n. 308 & $\begin{array}{l}\text { Licenciamento Ambiental de sistemas de disposição final do } \\
\text { resíduo sólido urbano gerado em cidade de pequeno porte. }\end{array}$ \\
\hline 2003 & Lei n. 10.650 & $\begin{array}{l}\text { Dispõe sobre o acesso público aos dados e informações } \\
\text { existentes nos órgãos e entidades integrantes do Sisnama. }\end{array}$ \\
\hline 2004 & Resolução CONAMA n. 348 & Altera a Resolução CONAMA n. 307. \\
\hline 2008 & Resolução CONAMA n. 404 & $\begin{array}{l}\text { Estabelece critérios e diretrizes para o licenciamento ambiental de } \\
\text { aterro sanitário de pequeno porte de resíduos sólidos urbanos. }\end{array}$ \\
\hline 2010 & Lei n. 12.305 & $\begin{array}{l}\text { Institui a Política Nacional de Resíduos Sólidos; altera a Lei n. } \\
9.605 .\end{array}$ \\
\hline 2010 & Decreto n. 7.404 & Regulamenta a Lei n. 12.305. \\
\hline 2012 & Resolução CONAMA n. 448 & $\begin{array}{l}\text { Altera os arts. } 2^{\circ}, 4^{\circ}, 5^{\circ}, 6^{\circ}, 8^{\circ}, 9^{\circ}, 10 \text { e } 11 \text { da Resolução n. } 307 \text {, } \\
\text { de } 5 \text { de julho de } 2002 \text {, do Conselho Nacional do Meio Ambiente. }\end{array}$ \\
\hline
\end{tabular}

Quadro 1.0 - Legislação sobre resíduos sólidos.

Fonte: Silva e Santos (2014).

Após a instituição da PNRS, os municípios passaram a buscar meios de adequaremse às exigências legais para o manejo dos resíduos sólidos. A implantação da Coleta Seletiva (CS), que não é exigida por lei, foi a ação adotada por muitos municípios em resposta à nova lei. De acordo com a PNRS, os municípios que possuírem plano municipal de gestão dos resíduos sólidos e/ou desenvolverem a CS terão prioridade no repasse de recursos da União, o que pode explicar o aumento no número de municípios que declaram realizar a CS. Na RIDE-DF sete municípios e o DF declararam realizar CS no ano de 2014, 
no entanto, é necessário avaliar a efetividade do serviço de CS desenvolvido nestas cidades.

Esta dissertação é composta por três capítulos que foram desenvolvidos com o intuito de avaliar a gestão dos RSUs na RIDE-DF considerando, especialmente, aspectos da geração, do gerenciamento e da CS dos RSUs.

A maioria dos dados utilizados no estudo pertence à série histórica do Sistema Nacional de Informação sobre Saneamento (SNIS). Os dados são autodeclaratórios, ou seja, são informados pelos próprios municípios. A utilização de dados autodeclaratórios possui algumas limitações. A existência de erros neste tipo de dados é comum e pode ser explicada, em parte, pelo desconhecimento da maneira adequada de preenchimento do questionário do SNIS. Apesar de possíveis erros, no entanto, a base de dados do SNIS reúne o maior número de informações sobre a gestão de RSUs ao longo dos anos.

$\mathrm{O}$ adequado gerenciamento dos RSUs envolve uma série de etapas complexas. A compreensão de fatores que influenciam a geração dos resíduos sólidos é uma dessas etapas, de fundamental importância, porém muitas vezes ignorada nos diagnósticos sobre RSUs. Fatores como o crescimento populacional e o aumento do Produto Interno Bruto (PIB) podem ser correlacionados com o aumento da geração de resíduos sólidos.

No capítulo 1 foram estudados os fatores sociais e econômicos que apresentaram maior correlação com a geração de Resíduos Sólidos Domésticos (RDOs) no Distrito Federal, durante o período de 2003 a 2014. A metodologia utilizada foi a análise estatística por meio de Análise de Componentes Principais (ACP) e Análise de Cluster (AC). O mesmo estudo não pôde ser desenvolvido para os municípios da RIDE-DF devido à falta de dados.

A maior parte dos municípios que compõem a RIDE-DF ainda realiza a disposição de RSUs sem qualquer tratamento em lixões ou aterros controlados, provocando impactos ambientais. Com o objetivo de avaliar a eficiência ambiental do gerenciamento dos RSUs na RIDE-DF, realizou-se o cálculo do Zero Waste Index (ZWI) no capítulo 2. O método, proposto por Zaman (2011), analisa aspectos ambientais como a emissão de gás carbônico, o consumo de água, de energia e de matéria-prima para cada tipo de manejo adotado, seja, por exemplo, a reciclagem ou o aterramento dos resíduos sólidos.

A CS é um instrumento da PNRS e permite que uma quantidade maior de materiais recicláveis seja recuperada, pois evita a contaminação destes materiais por outro tipo de resíduo sólido. Além disso, a CS, quando bem executada, promove a inclusão social dos catadores de materiais recicláveis. No ano de 2014, o Distrito Federal, Cidade Ocidental (GO), Cristalina (GO), Formosa (GO), Luziânia (GO), Santo Antônio do Descoberto (GO), Buritis, Minas Gerais (MG) e Unaí (MG) declararam realizar alguma iniciativa de CS (SNIS, 2016). Estas iniciativas foram avaliadas, no capítulo 3, por meio de dois índices de sustentabilidade da CS propostos por Besen (2011) e Fechine (2014). 
De acordo com Besen (2011, p. 191):

Trabalhar com índices de sustentabilidade possibilita subsidiar políticas públicas voltadas para a questão da coleta seletiva de resíduos sólidos, ao avaliar e comparar o grau de sustentabilidade da coleta seletiva e das organizações de catadores. Contribui também nos debates que se colocam para repensar as políticas e principalmente na revisão da legislação existente ou na elaboração de nova legislação. Promove ainda, um novo nível de avaliação para os investimentos públicos e privados voltados à gestão compartilhada dos resíduos e à coleta seletiva com inclusão de organizações de catadores.

A crescente utilização de índices de sustentabilidade para avaliar sistemas de CS sugere que este método seja o mais adequado, atualmente, para a avaliação da CS. O presente trabalho contribuiu para testar a utilização de diferentes índices de sustentabilidade para um mesmo programa de CS, avaliando se os resultados encontrados foram similares.

A segregação dos resíduos na fonte de geração diminui a taxa de contaminação dos materiais coletados, o que permite que um volume maior de resíduos seja destinado aos tratamentos mais adequados como a reciclagem, a compostagem e a incineração.

A detecção dos sucessos e gargalos dos programas de CS pode auxiliar na elaboração de um modelo mais ajustado à realidade da RIDE-DF, que contemple as exigências de adequação ambiental, autofinanciamento econômico, inclusão social e viabilidade técnica. 


\title{
1 ANÁLISE DA GERAÇÃO DOS RESÍDUOS SÓLIDOS DOMÉSTICOS NO DISTRITO FEDERAL
}

\author{
RESUMO
}

A geração de Resíduos Sólidos Urbanos está relacionada a uma série de fatores socioeconômicos. O Distrito Federal é composto por 31 regiões administrativas e sedia a capital brasileira, Brasília. O Distrito Federal possui uma grande renda, apresentando o maior Produto Interno Bruto per capita do Brasil em 2013. A geração de Resíduos Sólidos Urbanos cresceu 25\% no período de 2003 a 2014. O objetivo foi avaliar a relação de fatores socioeconômicos com a geração de Resíduos Sólidos Domésticos no Distrito Federal entre os anos de 2003 a 2014. Para a análise foram considerados os seguintes fatores: Produto Interno Bruto; Produto Interno Bruto per capita; população total; população urbana; densidade demográfica; Índice de Desenvolvimento Humano Municipal; consumo de energia; consumo de energia per capita e consumo de bens e produtos. $\mathrm{O}$ método utilizado foi a Análise de Componentes Principais e Análise de Cluster. A Análise de Componentes Principais resultou em dois componentes principais, onde o primeiro absorveu 95,029\% da variância inicial. Os maiores escores encontrados foram para o Produto Interno Bruto $(0,993)$, o consumo de energia $(0,992)$ e o consumo de bens e produtos $(0,988)$, mostrando que os fatores relacionados a renda e consumo apresentaram forte relação com a geração dos Resíduos Sólidos Domésticos. As variáveis relacionadas ao crescimento populacional também apresentaram relação significativa com a geração dos resíduos sólidos no Distrito Federal.

Palavras-Chave: Fatores socioeconômicos; Análise de componentes principais, Resíduos sólidos urbanos.

\section{ABSTRACT}

The generation of Urban Solid Waste (USW) is related to a series of socioeconomic factors. The Distrito Federal (DF) comprises 31 administrative regions and hosts the Brazilian capital, Brasilia. The DF has a large income, with the highest GDP per capita of Brazil in 2013. The generation of USW grew $25 \%$ from 2003 to 2014 . The aim was to evaluate the relationship of socioeconomic factors with the generation of Domestic Solid Waste (DSW) in the Distrito Federal between the years 2003 to 2014. For the analysis the following factors were considered: GDP; GDP per capita; total population; urban population; population density; HDI; energy consumption; energy consumption per capita and consumption of goods and products. The method used was the Principal Component Analysis (PCA) and Cluster Analysis (CA). The PCA resulted in two main components, where the first absorbed $95.029 \%$ of the initial variance. The highest scores were found to GDP (0.993), energy consumption (0.992) and consumption of goods and products (0.988), showing that factors related to income and consumption showed a strong relationship with the generation of USW. The variables related to population growth also have significant relationship with the generation of solid waste in DF.

Keywords: Socioeconomic factors. Principal Component Analysis. Urban solid waste.

\section{INTRODUÇÃO}

O aumento da geração de Resíduos Sólidos Urbanos (RSUs) é um fenômeno observado em diversas localidades do mundo. Embora seja um desafio para qualquer cidade, o gerenciamento dos RSUs é especialmente complexo nas regiões menos desenvolvidas e em desenvolvimento. A infraestrutura adequada, para coleta, transporte e 
tratamento dos resíduos sólidos, muitas vezes não acompanha o crescimento urbano e as consequências deste manejo ineficiente vão além dos impactos ambientais.

Aliados ao crescimento urbano, resultante do aumento populacional e da migração rural-urbana, observa-se que o aumento do consumo e da renda familiar também apresentam forte relação com a quantidade de resíduos sólidos gerados.

A identificação dos fatores socioeconômicos que afetam a geração de resíduos sólidos num determinado local é um dos passos fundamentais para a elaboração de um plano de gerenciamento adequado àquela realidade. A realização de análises de composição gravimétrica tem grande importância para compreender a geração de resíduos sólidos por tipo de material. A porcentagem de materiais como papéis, plásticos e eletrônicos tende a aumentar com o crescimento econômico.

No Distrito Federal (DF) observou-se um aumento populacional acima do planejado, bem como um expressivo crescimento da renda. O Produto Interno Bruto (PIB) per capita do DF, em 2013, foi o maior do Brasil. Considerando-se padrões de consumo, Brasília ocupa a terceira posição no ranking de cidades que mais consomem no Brasil, segundo dados do Índice de Potencial de Consumo (IPC) Marketing 2015. A geração de resíduos sólidos urbanos cresceu 25\% no DF durante o período de 2003 a 2014, mostrando que a geração de resíduos sólidos pode ser relacionada a indicadores socioeconômicos.

O objetivo do capítulo foi avaliar o impacto de fatores sociais e econômicos na geração de Resíduos Sólidos Domésticos (RDOs) no DF nos anos 2003 a 2014.

\section{REFERENCIAL TEÓRICO}

A geração de Resíduos Sólidos Urbanos (RSUs) é um fenômeno crescente desencadeado, sobretudo, por fatores ligados ao crescimento populacional e ao desenvolvimento econômico. Jacobi e Besen (2011) apontam que nos países mais desenvolvidos são geradas maiores quantidades de resíduos, entretanto, estes possuem maior capacidade para promover o gerenciamento apropriado destes resíduos por possuírem mais recursos econômicos e recursos tecnológicos. No Brasil, e em outros países em desenvolvimento, observa-se que a infraestrutura e os recursos financeiros empregados no gerenciamento dos resíduos sólidos estão aquém do necessário para o manejo adequado da quantidade crescente de resíduos gerados.

O gerenciamento dos RSUs pode ser otimizado a partir do planejamento da gestão. A primeira etapa na elaboração de um plano de gestão de RSUs é o diagnóstico da situação atual. O levantamento de informações como a quantidade gerada e a composição gravimétrica é essencial para o delineamento de um plano adequado para o local de estudo. 
Os padrões de geração de RSUs dependem de fatores socioeconômicos e podem variar em diferentes áreas de uma mesma cidade de acordo com a renda, a densidade demográfica, a concentração de atividades econômicas, entre outros (GALLARDO et al., 2015). A gestão dos RSUs nos países em desenvolvimento apresenta grandes desafios, pois a infraestrutura para o manejo dos RSUs muitas vezes não acompanha o crescimento populacional e econômico.

Getahun et al. (2012) estudaram o aumento da geração de resíduos sólidos em Jimma, na Etiópia. Aqueles autores constataram que aspectos socioeconômicos como grau de escolaridade e renda familiar resultaram em diferenças no manejo domiciliar dos resíduos. Famílias com renda mais elevada e com maior grau de instrução utilizavam serviços privados de coleta dos resíduos, enquanto famílias com renda mais baixa e menor grau de instrução tendiam a depositar resíduos sólidos em locais inadequados ou queimálos.

A geração de RSUs em Lahore, no Paquistão foi analisada a partir de indicadores socioeconômicos por Kamran, Chaudhry e Batool (2015), concluindo que as áreas economicamente ativas seguiram uma tendência de alta geração de resíduos e representaram $43 \%$ do total de resíduos gerados na cidade.

Segundo Grover e Singh (2014), há um aumento significativo na produção de resíduos, principalmente papel, à medida que a população cresce e se torna mais urbanizada. A composição dos RSUs varia de acordo com os hábitos culturais, o status econômico dos moradores, a estrutura urbana, a densidade populacional, a extensão da atividade comercial e o clima.

$\mathrm{Li}$ et al. (2015) estudaram a relação entre população, renda, urbanização e prosperidade da indústria terciária e a geração de resíduos sólidos na China. Em Lagos, na Nigéria a relação entre fatores socioeconômicos e a geração de RSUs foi estudada por Samuel (2015). Os dados referentes à idade, educação, renda média mensal, tempo de permanência no bairro e tamanho da residência foram analisados a partir de estatística inferencial e regressão múltipla.

Sankoh, Yan e Conteh (2012) analisaram a influência de fatores socioeconômicos na geração e composição dos RSUs em Freetown, Serra Leoa. Os resultados mostraram que a geração de resíduos sólidos e composição foram significativamente afetadas pelo tamanho médio da família, status de emprego e renda mensal.

A composição gravimétrica dos resíduos gerados pode sofrer alterações de acordo com fatores sociais e econômicos. No distrito de Dhanbad, na Índia, Khan, Kumar e Samadder (2016) constataram que a porcentagem de resíduos sólidos orgânicos é alta em todos os grupos de renda. A geração de resíduos de plástico, entretanto, cresceu nos locais de maior renda. 
Kawai e Tasaki (2016) apontam algumas dificuldades para estimar a geração de RSUs em países em desenvolvimento como a falta de equipamentos, a baixa eficiência na coleta dos resíduos, a migração rural-urbana e banco de dados incompletos.

\section{MATERIAL E MÉTODOS}

Para avaliar os fatores que apresentaram maior influência na geração de Resíduos Sólidos Domésticos (RDOs) no Distrito Federal (DF) foram levantados dados do período de 2003 a 2014 referentes a nove variáveis: Produto Interno Bruto (PIB), PIB per capita, Índice de Desenvolvimento Humano Municipal (IDHM), população total, população urbana, densidade demográfica, consumo de energia, consumo de energia per capita e consumo de bens e produtos. 
Tabela 1.1 - Variáveis que influenciam a geração de Resíduos Sólidos Urbanos.

\begin{tabular}{|c|c|c|c|c|c|c|c|c|c|c|c|}
\hline Ano & PIB & $\begin{array}{l}\text { PIB per } \\
\text { capita }\end{array}$ & IDHM & Pop. Total & $\begin{array}{l}\text { Pop. } \\
\text { Urbana }\end{array}$ & $\begin{array}{c}\text { Dens. } \\
\text { Demográfica }\end{array}$ & $\begin{array}{c}\text { RDO } \\
\text { Coletado }\end{array}$ & $\begin{array}{c}\text { RDO } \\
\text { coletado } \\
\text { per capita }\end{array}$ & $\begin{array}{l}\text { Consumo } \\
\text { de energia } \\
\text { (Mwh) }\end{array}$ & $\begin{array}{l}\text { Consumo } \\
\text { energia } \\
\text { per capita }\end{array}$ & $\begin{array}{l}\text { Consumo } \\
\text { de bens e } \\
\text { produtos }\end{array}$ \\
\hline 2003 & 63104900 & 28282 & 0,725 & 2189789 & 2094082 & 378,85 & 561544 & 0,703 & 3587375 & 1,638 & 45,08 \\
\hline 2004 & 70724113 & 30992 & 0,725 & 2282049 & 2182310 & 394,81 & 589843 & 0,708 & 3589693 & 1,573 & 52,60 \\
\hline 2005 & 80526612 & 34515 & 0,725 & 2333108 & 2231138 & 403,65 & 614078 & 0,721 & 3807369 & 1,631 & 62,98 \\
\hline 2006 & 89628553 & 37599 & 0,725 & 2383784 & 2279599 & 412,00 & 644128 & 0,74 & 3991454 & 1,674 & 68,23 \\
\hline 2007 & 99945620 & 40696 & 0,725 & 2455903 & 2348566 & 424,89 & 643947 & 0,718 & 4293525 & 1,748 & 74,91 \\
\hline 2008 & 117572000 & 45997 & 0,725 & 2557158 & 2445396 & 442,41 & 710043 & 0,761 & 4552717 & 1,780 & 79,53 \\
\hline 2009 & 131487000 & 50438 & 0,725 & 2570160 & 2482210 & 444,66 & 741425 & 0,79 & 5001045 & 1,945 & 83,44 \\
\hline 2010 & 149906000 & 58489 & 0,824 & 2606885 & 2492949 & 451,00 & 765830 & 0,805 & 5382635 & 2,064 & 93,01 \\
\hline 2011 & 164482000 & 63020 & 0,824 & 2609998 & 2520685 & 451,55 & 800088 & 0,84 & 5475146 & 2,097 & 100,00 \\
\hline 2012 & 171235534 & 61876 & 0,824 & 2648532 & 2557900 & 458,22 & 822968 & 0,851 & 5666856 & 2,139 & 106,52 \\
\hline 2013 & 175362791 & 62859 & 0,824 & 2789761 & 2694296 & 482,65 & 847207 & 0,832 & 5964400 & 2,137 & 115,61 \\
\hline 2014 & 175538154 & 62921 & 0,824 & 2.852 .372 & 2754765 & 493,49 & 866211 & 0,832 & 6163314 & 2,160 & 120,40 \\
\hline
\end{tabular}

Fonte: Adaptado a partir de dados de ANEEL (s. d.), Distrito Federal (2015), IBGE (2014) e SNIS (2016). 
O método estatístico utilizado no estudo foi a Análise de Componentes Principais (ACP), uma técnica de análise multivariada que indica os componentes que absorvem a maior parte da variância do conjunto de dados, podendo assim resumi-los e representá-los. Para realizar a ACP utilizou-se o programa estatístico IBM SPSS Statistics 23.

Um dos fatores essenciais para a aplicação da ACP é a correlação entre as variáveis de estudo. Para verificar se a ACP poderia ser realizada neste estudo foram utilizados 02 (dois) testes:

1) O Kaiser-Meyer-Olkin (KMO) é um método estatístico que compara as correlações simples com as correlações parciais observadas entre as variáveis. A variação do KMO é de 0 a 1, onde 0 representa uma correlação nula e 1 representa a correlação máxima.

2) O teste de esfericidade de Bartlett, que avalia se a matriz de variáveis iniciais é significativamente diferente. Neste teste, valores de $p$-value inferiores a 0,05 indicam que a ACP pode ser corretamente aplicada.

A confiabilidade dos componentes gerados por meio da ACP deve ser verificada a partir do coeficiente alfa de Cronbach. Valores entre 0,6 e 0,7 indicam um bom grau de confiança dos novos componentes.

\section{RESULTADOS E DISCUSSÃO}

No Distrito Federal (DF), a quantidade de Resíduos Sólidos Urbanos (RSUs) saltou de 1.302.771,9 toneladas em 2003 para 1.634.522,1 toneladas em 2014, representando um aumento de 25\% em 12 anos. Considerando-se apenas os Resíduos Sólidos Domésticos (RDOs) no DF, em 2003 foram coletadas 561.544 toneladas. Já em 2014, o volume de RDO coletado foi $64,8 \%$ maior, chegando a 866.211 toneladas. A geração de RDO per capita (kg/hab/dia) também apresentou um aumento: de 0,703 em 2003 a 0,832 em 2014.

Outro problema enfrentado no DF é a disposição final dos resíduos sólidos sem qualquer tratamento. No ano de 2003, a compostagem e a reciclagem resultaram na recuperação de apenas 4,08\% dos resíduos. Em 2014, a taxa de recuperação de resíduos foi de 7,64\%. Apesar do aumento, estima-se que 1.509.644,6 de toneladas de resíduos sólidos foram depositados em aterro sem qualquer tratamento neste ano. 


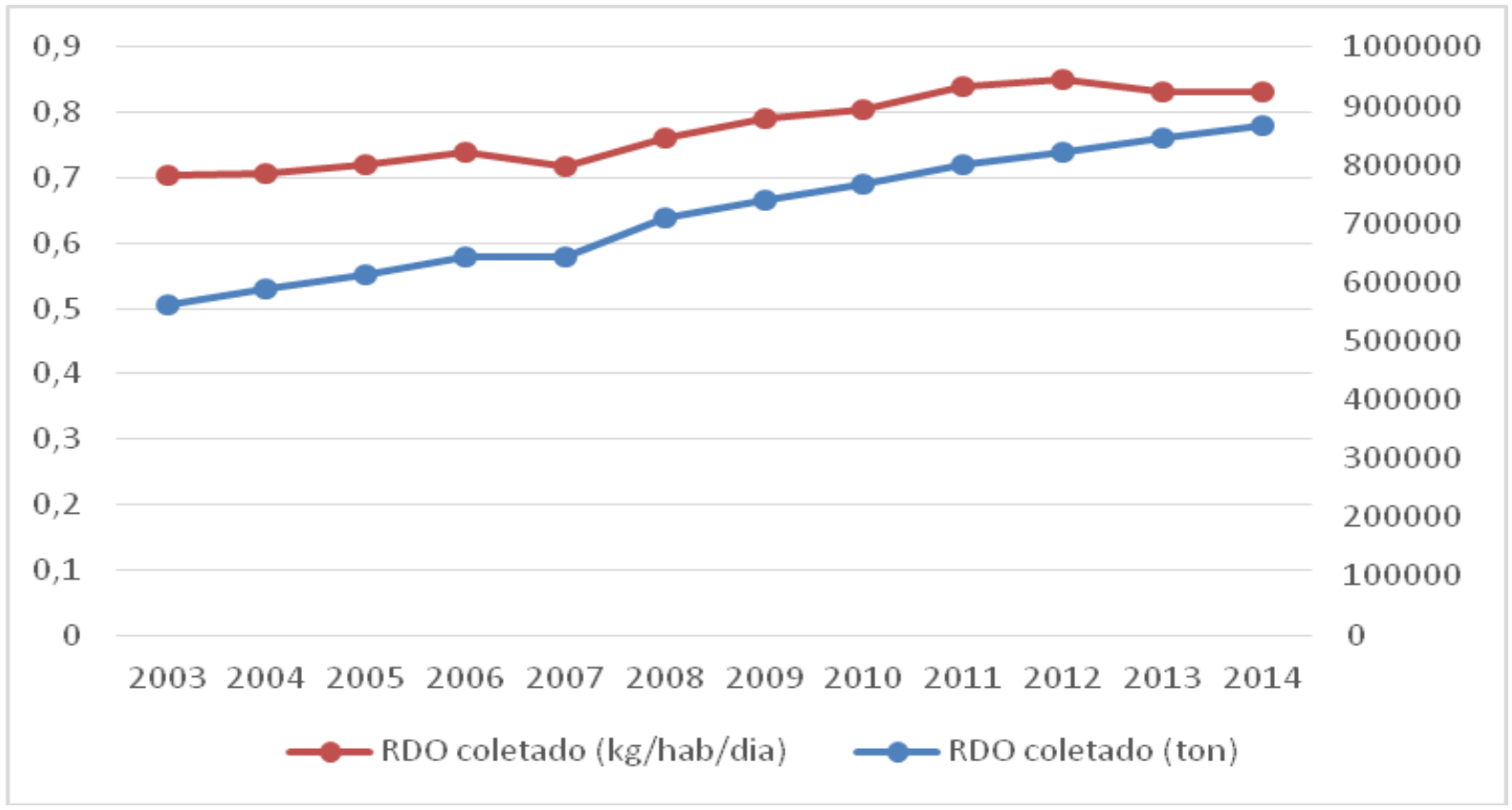

Gráfico 1.1 - Resíduos domiciliares coletados anualmente no Distrito Federal.

Fonte: Adaptado a partir de dados do SNIS (2016).

Ao longo dos 12 anos estudados, a população total e a população urbana do DF apresentaram crescimento. A população total, em 2003 era de 2.189.789 habitantes. Em 2014, a população total estimada para o DF foi 2.852 .372 de habitantes. A densidade demográfica saltou de 378,856 em 2003 para 493,490 em 2014.

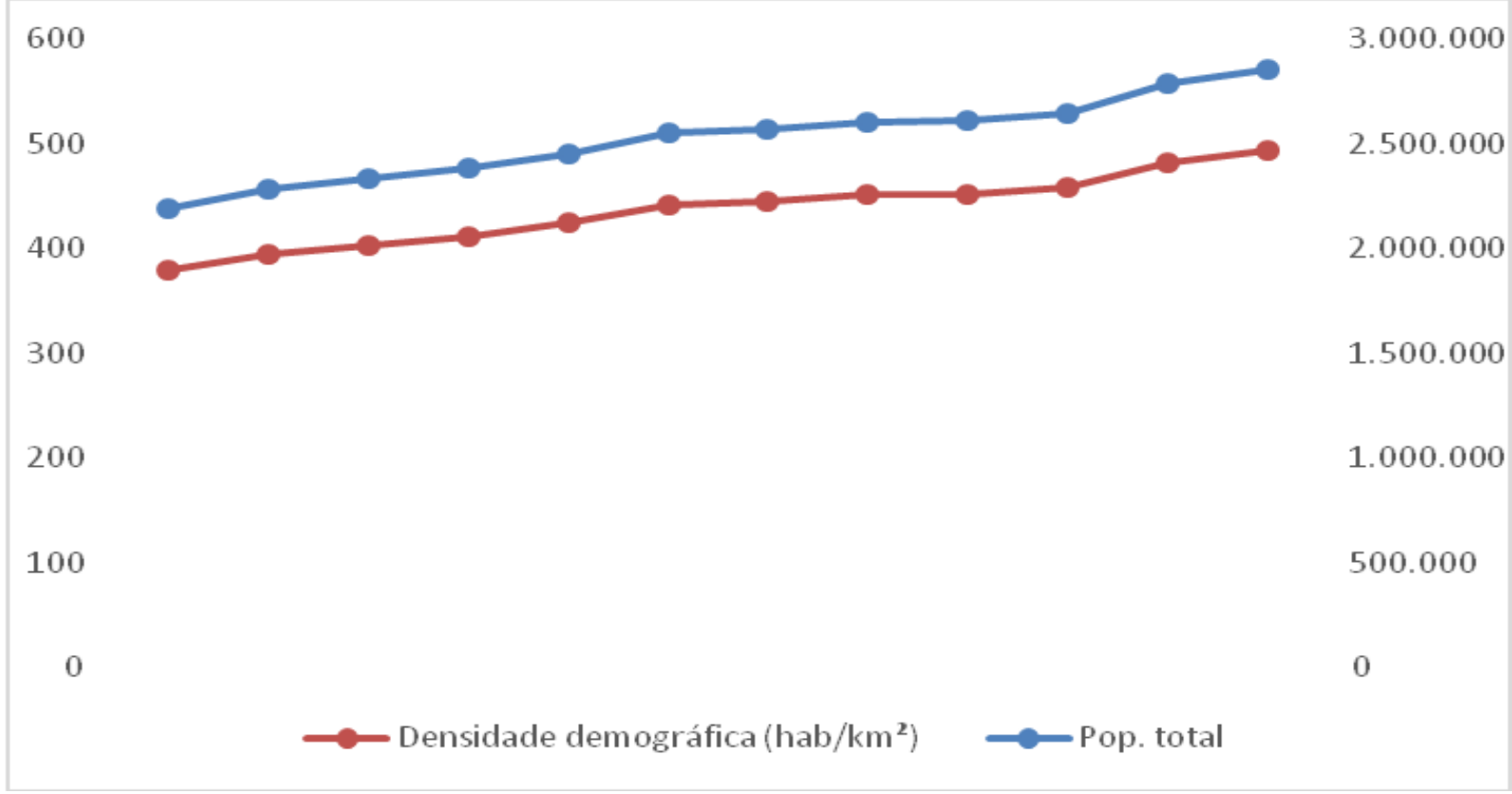

Gráfico 1.2 - Densidade demográfica e população total.

Fonte: Adaptado a partir de dados do IBGE (2014, s. d.). 
A composição gravimétrica dos RSUs é um dado relevante para compreender a geração dos resíduos sólidos numa determinada região, bem como para estabelecer a forma de manejo mais adequada para cada local. Apesar da importância destes dados, não foram encontrados dados anuais de composição gravimétrica dos RSUs no DF. Estes dados foram solicitados ao Serviço de Limpeza Urbana (SLU) do DF, mas não se obteve retorno. Gadelha (2005) apresenta a composição gravimétrica dos RSUs no DF comparada à composição gravimétrica estimada para o Brasil.

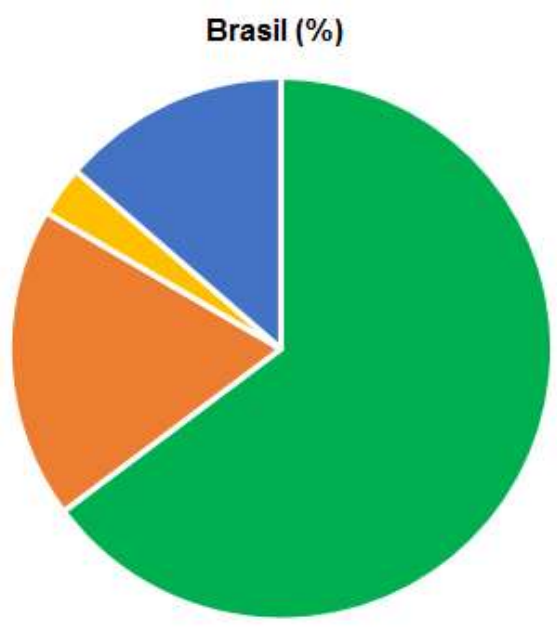

- Matéria orgânica

- Trapo

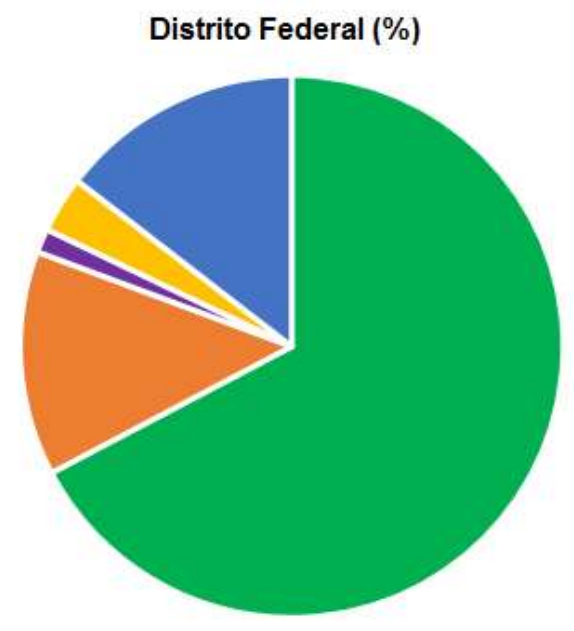

- Papel

- Madeira, couro e borracha

- Vidro, plástico, metal, inertes

Gráfico 1.3 - Composição gravimétrica dos Resíduos Sólidos Urbanos no Brasil e no Distrito Federal. Fonte: Adaptado de Gadelha (2005).

A Análise de Componentes Principais (ACP) das variáveis avaliadas resultou em dois componentes. Os dois componentes absorvem 98,9\% da variância inicial. A adequação da amostragem foi considerada razoável (KMO =0,668). O teste de Bartlett também indica a adequação da amostra ( $p$-value $=0,000)$. 
Tabela 1.2 - Testes de KMO e Barlett.

\begin{tabular}{lcc}
\hline \multicolumn{2}{c}{ Teste de KMO e Bartlett } \\
\hline \multicolumn{2}{c}{ Medida Kaiser-Meyer-Olkin de adequação de amostragem } & 0,668 \\
& Aprox. Qui-quadrado & 351,047 \\
Teste de esfericidade de Bartlett & Gl & 36 \\
& Sig. & 0,000 \\
\hline
\end{tabular}

Fonte: Da autora.

O componente 1 foi responsável por 95,029\% da variância inicial. Dentro deste, o Produto Interno Bruto (PIB) apresentou o maior escore (0,993), seguido do consumo de energia $(0,992)$ e do consumo de bens e produtos $(0,988)$. O coeficiente alfa de Cronbach foi de 0,995 para este componente, o que indica um alto grau de confiabilidade. $O$ componente 2, formado apenas pelo Índice de Desenvolvimento Humano Municipal (IDHM) representa $3,866 \%$ da variância inicial. No entanto, o coeficiente alfa de Cronbach encontrado foi de -1,816, indicando que este componente não possui um bom grau de confiabilidade.

Tabela 1.3 - Escore das variáveis.

\begin{tabular}{lccc}
\hline & Escore & \% de Variância & Alfa de Cronbach \\
\hline Componente 1 & - & $95,029 \%$ & 0,995 \\
PIB & 0,993 & - & - \\
Consumo de energia & 0,992 & - & - \\
Consumo de bens e produtos & 0,988 & - & - \\
PIB per capita & 0,983 & - & - \\
População urbana & 0,979 & - & - \\
Densidade demográfica & 0,974 & - & - \\
População total & 0,974 & - & - \\
Consumo de energia per capita & 0,972 & $3,866 \%$ & $-1,816$ \\
Componente 2 & - & - & - \\
IDHM & 0,865 & - & - \\
\hline
\end{tabular}

Fonte: Da autora.

No componente 1 observou-se que os quatro primeiros escores encontrados são variáveis referentes a fatores econômicos como renda e consumo, o que indica uma forte relação entre a geração de RDOs e o crescimento econômico no DF. Apesar de obter resultados menores, os valores referentes a crescimento populacional também indicam que a geração de resíduos sólidos está relacionada ao aumento da população no período. $A$ variável IDHM apresentou o menor escore dentre as variáveis estudadas. 
Os resultados obtidos para o DF são o inverso dos resultados encontrados por Liu e Wu (2011). Na China, os fatores que mais influenciaram a geração de RSUs, durante o período de 1985 a 2006, foram o crescimento populacional e o aumento da população urbana.

Para cada variável estudada utilizou-se valores referentes ao Distrito Federal como um todo devido à indisponibilidade de dados por Região Administrativa (RA). As 31 RAs possuem valores diferentes de renda, de área, de população e de geração de RDOs, o que poderia levar à uma análise mais precisa do que influencia a geração de RDOs em cada região do DF.

Na Análise de Cluster (AC), utilizando-se o método hierárquico com a distância euclidiana quadrática, obtiveram-se três clusters: Cluster 1 - de 2003 a 2007; Cluster 2 - de 2008 a 2009; Cluster 3 - de 2010 a 2014.

Os resultados obtidos na análise de cluster foram comparados à geração anual de RDOs para avaliar a confiabilidade deste resultado. No intervalo de 2003 a 2007 a geração de RDO ficou entre 561,544 e 643,947 milhões de toneladas. Entre 2008 e 2009 a geração de RDO passou de 710,43 para 741,425 milhões de toneladas. No período de 2010 a 2014, a quantidade de RDO subiu de 765,83 para 866,211 milhões de toneladas. 

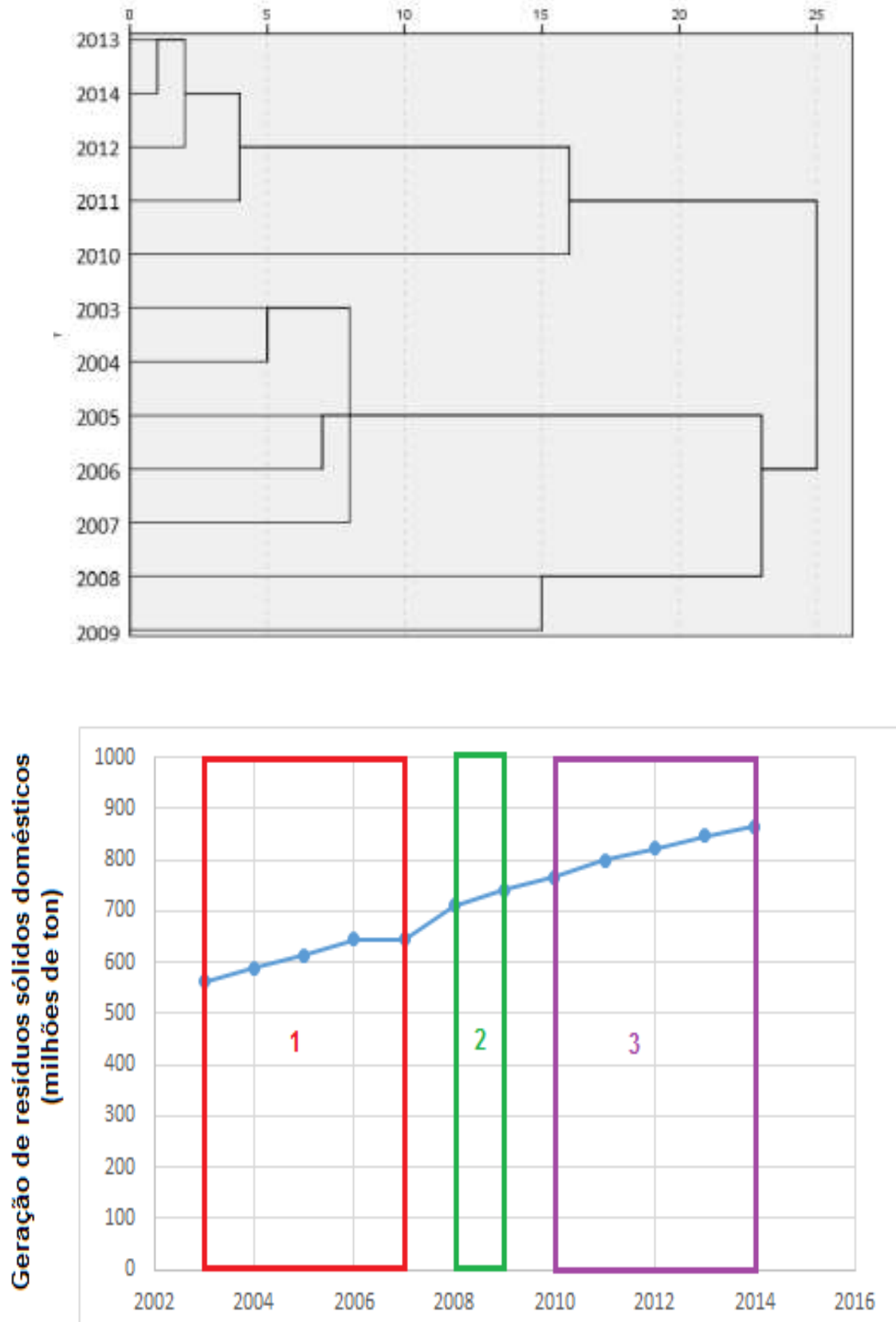

Gráfico 1.4 - Análise de Cluster.

Fonte: Da autora.

A geração de RSUs pode sofrer alterações sazonais, o que implica em mudanças no gerenciamento de acordo com a quantidade gerada. No DF observou-se uma pequena variação na geração mensal de RSUs no ano de 2014 (vide Tabela 1.4, a seguir). Os meses de janeiro e dezembro apresentaram uma geração ligeiramente maior. As 31 RAs são distribuídas em três lotes (vide Figura 1.1, a seguir). 
Tabela 1.4 - Geração mensal de Resíduos Sólidos Urbanos (toneladas) no Distrito Federal, ano 2014.

\begin{tabular}{|c|c|c|c|c|c|c|c|c|c|c|c|c|c|}
\hline \multirow{2}{*}{ Lote } & \multicolumn{12}{|c|}{ Mês } & \multirow{2}{*}{\begin{tabular}{|l} 
Ano \\
2014
\end{tabular}} \\
\hline & Jan & Fev & Mar & Abr & Mai & Jun & Jul & Ago & Set & Out & Nov & Dez & \\
\hline Lote 1 & 41.905 & 42.777 & 35.842 & 35.597 & 36.508 & 32.374 & 34.356 & 33.229 & 35.440 & 35.739 & 36.115 & 41.167 & 441.050 \\
\hline Lote 2 & 22.949 & 19.763 & 20.517 & 20.713 & 20.087 & 18.562 & 20.798 & 19.979 & 21.202 & 21.920 & 21.369 & 24.588 & 252.447 \\
\hline Lote 3 & 13.365 & 11.931 & 12.215 & 12.693 & 11.884 & 11.461 & 11.971 & 11.813 & 12.895 & 13.168 & 12.850 & 14.442 & 150.690 \\
\hline Total & 78.219 & 74.471 & 68.574 & 69.003 & 68.479 & 62.397 & 67.125 & 65.021 & 69.537 & 70.827 & 70.334 & 80.197 & 844.187 \\
\hline
\end{tabular}

Fonte: Distrito Federal (2015).

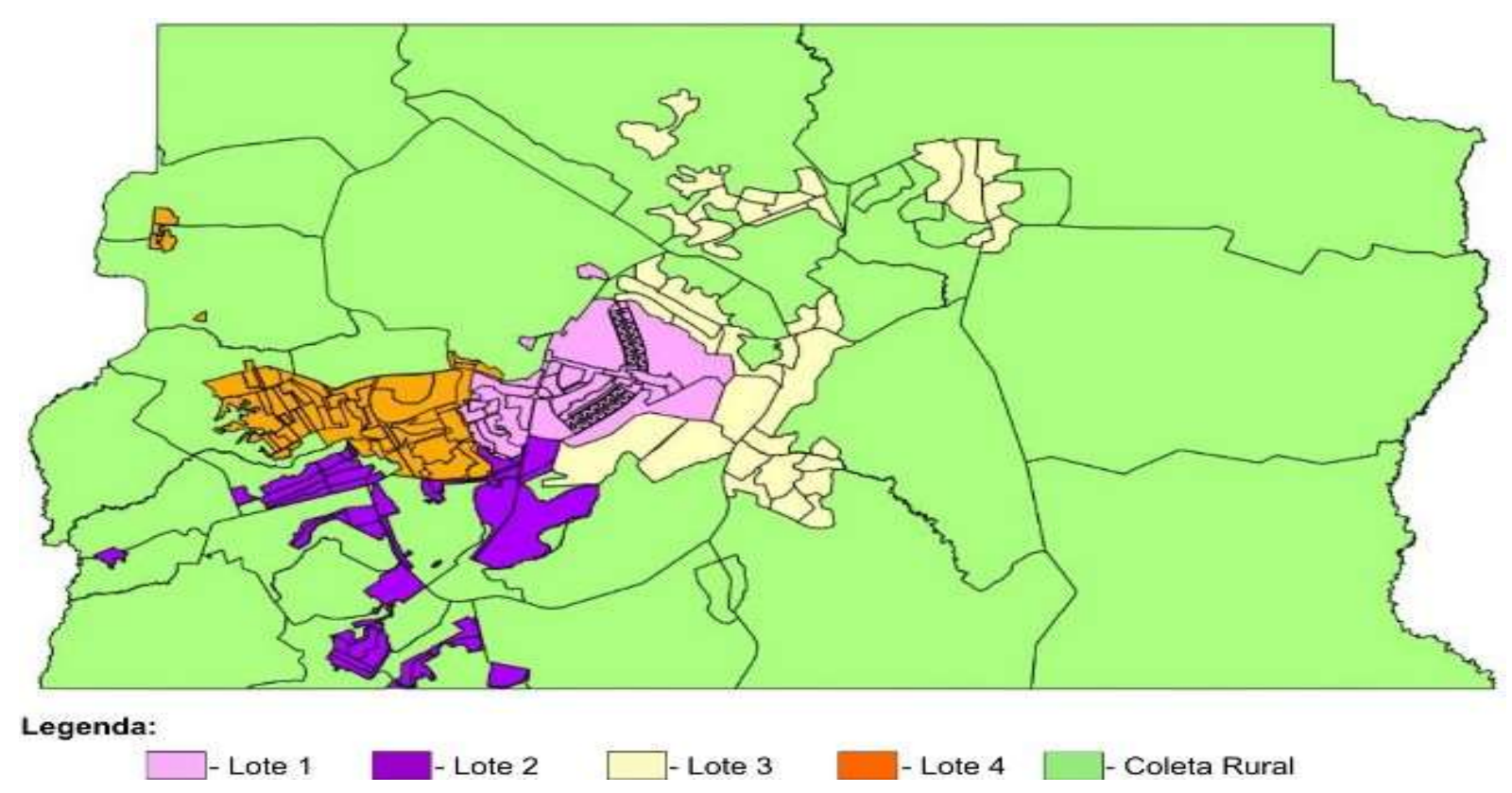

Figura 1.1 - As Regiões Administrativas distribuídas em lotes.

Fonte: Distrito Federal (2015). 


\section{CONCLUSÃO}

A utilização combinada da Análise de Componentes Principais (ACP) e da Análise de Cluster (AC) resulta numa metodologia eficiente para a determinação dos fatores socioeconômicos que influenciam a geração de Resíduos Sólidos Urbanos (RSUs). A compreensão destes fatores é fundamental para o desenvolvimento de prognósticos sobre a geração de RSUs de um determinado local, além de facilitar o desenvolvimento de ações que visem à diminuição da geração destes.

No caso do Distrito Federal (DF), os fatores econômicos apresentaram maior relação com a geração de Resíduos Sólidos Domésticos (RDOs) do que os fatores sociais. O Produto Interno Bruto (PIB), o consumo de energia e o consumo de bens e produtos apresentaram os maiores escores na ACP, indicando maior relação com a geração de RDOs. Estes resultados são reflexos do alto poder econômico da região, que apresenta o maior PIB per capita do Brasil, e do elevado padrão de consumo (o terceiro maior do país). Políticas e ações de Educação Ambiental (EA) voltadas para a redução e a reutilização de resíduos sólidos podem contribuir para diminuir a geração de RSUs no DF.

Os valores utilizados neste estudo, para cada variável, correspondem a valores médios do DF, devido à falta de dados por Região Administrativa (RA). A influência dos fatores socioeconômicos na geração de resíduos sólidos pode, então, sofrer alterações significativas de cidade para cidade, de acordo com o número de habitantes e a renda média, fatores que apresentam grande variação nas cidades que compõem o DF.

Para os próximos anos, nos quais há previsão de retração do PIB, é interessante avaliar se os fatores econômicos manterão forte relação com a geração dos RSUs, esperando-se, assim, que a geração de resíduos sólidos diminua.

\section{REFERÊNCIAS}

\section{AGÊNCIA NACIONAL DE ENERGIA ELÉTRICA - ANEEL. Consumo de energia elétrica} no Brasil. $\quad S$ S. d. $\quad$ Disponível $\quad$ em: <http://relatorios.aneel.gov.br/RelatoriosSAS/Forms/Allltems.aspx>. Acesso em: 1\%/09/2015.

DISTRITO FEDERAL. Vice-Governadoria do Distrito Federal. Secretaria de Infraestrutura e Serviços Públicos. Serviço de Limpeza Urbana. Relatório do Diagnóstico de Resíduos Sólidos do Distrito Federal (2014). Brasília, 2015. Disponível em: <http://www.agenciabrasilia.df.gov.br/images/agencia_brasilia/2015/04ABRIL/Relatorio_diagnostico_residuos_solidos_SLU_2014.pdf>. Acesso em: 1\%/07/2015. 
GADELHA, E. P. Avaliação de inóculos metanogênicos na aceleração do processo de degradação da fração orgânica dos Resíduos Sólidos Urbanos. 2005. Dissertação (Mestrado em Tecnologia Ambiental e Recursos Hídricos) - Departamento de Engenharia Civil e Ambiental, Faculdade de Tecnologia, Universidade de Brasília, Brasília. Disponível em: <http://livros01.livrosgratis.com.br/cp095915.pdf>. Acesso em: 1\%/07/2015.

GALLARDO, A.; CARLOS, M.; PERIS, M.; COLOMER, F. J. Methodology to design a municipal solid waste pre-collection system. A case study. Waste Management, v. 36, p. 111, fev. 2015.

GETAHUN, T.; MENGISTIE, E.; HADDIS, A.; WASIE, F.; ALEMAYEHU, E.; DADI, D.; VAN GERVEN, T.; VAN DER BRUGGEN, B. Municipal solid waste generation in growing urban areas in Africa: current practices and relation to socioeconomic factors in Jimma, Ethiopia. Environmental monitoring and assessment, v. 184, n. 10, p. 6337-6345, out. 2012.

GROVER, P.; SINGH, P. An analytical study oif effect of family income and size on per capita household solid waste generation in developing countries. Review of Arts and Humanities March, v. 3, n. 1, p. 127-143, 2014. Disponível em: <http://aripd.org/journals/rah/Vol_3_No_1_March_2014/11.pdf>. Acesso em: 1\%/09/2015.

INSTITUTO BRASILEIRO DE GEOGRAFIA E ESTATÍSTICA - IBGE. Produto Interno Bruto dos Municípios 2010-2013. 2014. Disponível em: <http://www.ibge.gov.br/home/estatistica/economia/pibmunicipios/2010_2013/default.shtm>. Acesso em: 1\%09/2015.

Séries Históricas e Estatísticas. S. d. Disponível em: <http://seriesestatisticas.ibge.gov.br/lista_tema.aspx?op=0\&no=2>. Acesso em: 1\%/11/2015.

JACOBI, P. R.; BESEN, G. R. Gestão de resíduos sólidos em São Paulo: desafios da sustentabilidade. Estudos Avançados, São Paulo, v. 25, n. 71, p. 135-158, jan./abr. 2011. Disponível em: <http://www.scielo.br/pdf/ea/v25n71/10.pdf>. Acesso em: 1\%/11/2015.

KAMRAN, A.; CHAUDHRY, M. N.; BATOOL, S. A. Effects of socio-economic status and seasonal variation on municipal solid waste composition: a baseline study for future planning and development. Environmental Sciences Europe, v. 27, n. 16, p. 1-8, dez. 2015. Disponível em: <http://link.springer.com/article/10.1186/s12302-015-0050-9>. Acesso em: $1 \% / 11 / 2015$.

KAWAI, K.; TASAKI, T. Revisiting estimates of municipal solid waste generation per capita and their reliability. Journal of Material Cycles and Waste Management, v. 18, n. 1, p. 113, jan. 2016. Disponível em: <http://link.springer.com/article/10.1007/s10163-015-0355-1>. Acesso em: 1\%02/2016.

KHAN, D.; KUMAR, A.; SAMADDER, S. R. Impact of socioeconomic status on municipal solid waste generation rate. Waste Management, n. 49, p. 15-25, mar. 2016. 
LI, L.; GE, X.; ZHANG, J.; WANG, J. Long-term relationship among the generation of municipal solid waste, urbanization, affluence and prosperity of tertiary industry. Metallurgical and Mining Industry, n. 6, p. 206-212, 2015. Disponível em: <http://www.metaljournal.com.ua/assets/Journal/MMI-6/025-Li-Li.pdf>. $\quad$ Acesso em: $1 \% / 02 / 2016$.

LIU, C.; WU, X. W. Factors influencing municipal solid waste generation in China: a multiple statistical analysis study. Waste Management \& Research, v. 29, n. 4, abr. 2011.

SAMUEL, O. O. Socio-economic correlates of household solid waste generation: evidence from Lagos metropolis, Nigeria. Management Research and Practice, v. 7, n. 1, p. 44, 2015.

SANKOH, F. P.; YAN, X.; CONTEH, A. M. H. A situational assessment of socioeconomic factors affecting solid waste generation and composition in Freetown, Sierra Leone. Journal of Environmental Protection, n. 3, p. 563-568, jul. 2012. Disponível em: <http://file.scirp.org/pdf/JEP20120700002_99280824.pdf>. Acesso em: 1\%/02/2016.

SISTEMA NACIONAL DE INFORMAÇÕES SOBRE SANEAMENTO - SNIS. 2016. Disponível em: <http://www.snis.gov.br/>. Acesso: 1\%/04/2014. 


\title{
20 ZERO WASTE INDEX NA REGIÃO INTEGRADA DE DESENVOLVIMENTO DO DISTRITO FEDERAL E ENTORNO A PARTIR DE DADOS DO SISTEMA NACIONAL DE INFORMAÇÃO SOBRE SANEAMENTO: UMA ANÁLISE DO GERECIAMENTO DOS RESÍDUOS SÓLIDOS URBANOS
}

\author{
RESUMO
}

O gerenciamento adequado dos resíduos sólidos na Região Integrada de Desenvolvimento do Distrito Federal e Entorno é um desafio ambiental, econômico e social. Atualmente nenhum dos 22 municípios que a integram e nem o Distrito Federal atendem, simultaneamente, às duas exigências da Política Nacional dos Resíduos Sólidos: o fechamento dos lixões e a disposição ambiental adequada dos resíduos. Após cinco anos da homologação da Lei n. 12.305/2010 é necessário diagnosticar a situação dos resíduos sólidos, bem como analisar se novas ações foram desenvolvidas na região para se adequar à estas exigências. $\mathrm{O}$ objetivo deste capítulo foi analisar o gerenciamento dos resíduos sólidos no Distrito Federal, em Formosa e Luziânia (Goiás) e em Unaí (Minas Gerais) a partir do Zero Waste Index. O índice calcula a eficiência ambiental de acordo com o tipo de tratamento aplicado no manejo dos resíduos sólidos, fornecendo dados como a matéria-prima poupada, água e energia economizadas e a emissão de $\mathrm{CO}_{2}$. Os dados sobre geração, coleta e tratamento utilizados estão disponíveis no Sistema Nacional de Informação sobre Saneamento. Os maiores valores de Zero Waste Index foram encontrados para Luziânia (Goiás), seguidos do Distrito Federal, Formosa (Goiás) e Unaí (Minas Gerais). Estes valores, calculados para a Região Integrada de Desenvolvimento do Distrito Federal, estão muito abaixo dos valores obtidos por Zaman (2013). Um valor baixo de Zero Waste Index indica que o tratamento adotado (aterramento ou disposição em lixões) é ambientalmente ineficaz.

Palavras-Chave: Gestão; Gerenciamento de resíduos sólidos; Zero Waste Index.

\section{ABSTRACT}

Proper management of solid waste in Integrated Region of Development of the Distrito Federal and Surrounding Areas (RIDE-DF) is an environmental, economic and social challenge. Currently none of the 22 municipalities that are part of the RIDE and even the DF follow simultaneously the two requirements of the National Solid Waste Policy (PNRS): closure of dumpsites and proper environmental disposal of waste. After five years of approval of the Federal Law no $12.305 / 2010$ is required to diagnose the situation of solid waste and consider whether new actions were developed in the area to suit these requirements. The aim of this chapter is to analyze the management of solid waste in the Distrito Federal, Formosa (GO), Luziânia (GO) and Unaí (MG) using the Zero Waste Index (ZWI). The index calculates the environmental efficiency according to the type of treatment applied to solid waste management, providing data as the raw material saved, water and energy saved and the $\mathrm{CO}_{2}$ emission. The data about generation, collection and treatment used are available in the database of Sistema Nacional de Informação sobre Saneamento (SNIS). The largest ZWI values were found to Luziânia (GO), followed by the Distrito Federal (DF), Formosa (GO) and Unaí (MG). These values, calculated for RIDE-DF, are much lower than the values obtained by Zaman (2013). A low value of ZWI indicates that the treatment adopted (landfill or disposal in dumpsites) is environmentally ineffective.

Keywords: Management. Urban solid waste. Zero Waste Index. 


\section{INTRODUÇÃO}

O aumento da geração de resíduos está relacionado ao surgimento de tecnologias para a conversão de recursos naturais em matéria-prima para a fabricação de uma série de produtos. Diferente dos ciclos naturais, onde cada processo resulta em recursos continuamente reaproveitáveis, o desenvolvimento de novos materiais foi pensado, por muito tempo, com o intuito de atender apenas às demandas pertinentes à vida útil dos produtos, pouco importando os impactos ocasionados pelo descarte pós-consumo.

Seja por obrigação legal, por agregar boa imagem a uma marca e (ou) por preocupação ambiental, é notória a mudança iniciada na maneira de produzir e de encarar a geração dos resíduos provenientes deste processo. O design de novos produtos e a gestão dos recursos naturais passam a ser pensados desde a escolha do material até a forma de reciclá-lo após o fim de sua vida útil.

Para Sharholy et al. (2007), a produção de resíduos representa o maior símbolo de ineficiência dos sistemas produtivos adotados pela sociedade moderna. O termo "Zero Waste" pode ser traduzido como desperdício zero ou resíduo zero. Esta denominação é utilizada para designar estratégias e práticas voltadas para o desenvolvimento de ciclos produtivos semelhantes aos naturais, onde cada recurso é utilizado e reaproveitado, não havendo produção de resíduos.

Embora seja um conceito de difícil alcance na atual realidade, em especial na realidade dos países menos desenvolvidos, a adoção do zero waste é necessária para a promoção da qualidade ambiental, para a utilização dos recursos naturais de forma mais eficiente e para o aproveitamento econômico de materiais que antes eram descartados.

São ferramentas do Zero Waste, a não geração, a redução, o reaproveitamento e a reciclagem dos materiais. Esgotando-se as alternativas de tratamento, recomenda-se a incineração ou o aterramento dos rejeitos.

As etapas acima também integram a Política Nacional de Resíduos Sólidos (PNRS) e são contempladas no modelo de logística reversa. Neste modelo, produtores, consumidores e poder público se tornam responsáveis pela destinação ambientalmente adequada dos produtos após sua vida útil. No entanto, a atribuição das responsabilidades de cada setor na gestão compartilhada não foi definida legalmente, dificultando que a logística reversa seja implantada para todos os materiais que são produzidos.

A gestão dos resíduos sólidos, um desafio mundial, é ainda mais complexa para nações em desenvolvimento como o Brasil. Atribui-se, principalmente, ao aumento populacional e urbano, ao consumismo e à obsolescência tecnológica o grande aumento na geração de resíduos sólidos. O gerenciamento dos resíduos que é desenvolvido na maioria dos municípios limita-se à: coleta, que ocorre sem a segregação dos resíduos; e à 
disposição final, que geralmente é realizada sem qualquer tratamento em aterros ou lixões.

A Região Integrada de Desenvolvimento do Distrito Federal e Entorno (RIDE-DF) é composta pelo Distrito Federal (DF), por 19 municípios goianos e por três municípios mineiros, todos localizados no entorno do DF. Na RIDE-DF, apenas Formosa (Goiás), Luziânia (Goiás), Unaí (Minas Gerais) e o DF declararam realizar Coleta Seletiva (CS) no ano de 2013 , indicando que a maior parte dos municípios da região realizam um tratamento inadequado dos resíduos sólidos.

O objetivo foi avaliar a eficiência do gerenciamento dos resíduos sólidos no Distrito Federal e em três municípios da RIDE-DF a partir do Zero Waste Index (ZWI) no período de 2003 a 2013.

\section{REFERENCIAL TEÓRICO}

O gerenciamento dos Resíduos Sólidos Urbanos (RSUs) é um conjunto de atividades desenvolvidas com o intuito de dar tratamento adequado aos resíduos sólidos diminuindo, assim, o potencial causador de danos destes resíduos. Braga e Dias (2008) definem o gerenciamento dos resíduos sólidos como a escolha e a aplicação de tecnologias adequadas para o alcance de objetivos no tratamento e disposição final de resíduos sólidos.

O gerenciamento dos resíduos sólidos é um processo complexo, que envolve muitos critérios ambientais e socioeconômicos. A tomada de decisão é realizada em conjunto, e pode ser orientada a partir do levantamento das melhores alternativas para o alcance da solução adequada (SOLTANI et al., 2015).

Para Zanta e Ferreira (2003, p. 9):

As diretrizes das estratégias de gestão e gerenciamento de resíduos sólidos urbanos buscam atender aos objetivos do conceito de prevenção da poluição, evitando-se ou reduzindo a geração de resíduos e poluentes prejudiciais ao meio ambiente e à saúde pública. Desse modo busca-se priorizar, em ordem decrescente de aplicação: a redução na fonte, o reaproveitamento, o tratamento e a disposição final. No entanto cabe mencionar que a hierarquização dessas estratégias é função das condições legais, sociais, econômicas, culturais e tecnológicas existentes no município, bem como das especificidades de cada tipo de resíduo.

Em cidades com baixo recurso financeiro, condição de muitos municípios brasileiros, o gerenciamento dos RSUs é ineficiente. Até mesmo a coleta convencional, atividade mais básica na gestão dos RSUs, é executada de forma deficitária.

O conceito de zero waste, que significa zerar a produção de resíduos, é uma utopia, especialmente nos países em desenvolvimento. O que é proposto por este conceito, na verdade, é que os mecanismos de manejo dos resíduos sólidos sejam aprimorados, com o intuito de diminuir a geração, de otimizar os tratamentos e de reduzir os impactos ambientais 
causados pelos RSUs.

Com base neste conceito, Zaman e Lehmann (2013) desenvolveram o Zero Waste Index (ZWI). Este índice consiste numa metodologia que estima os impactos ambientais de cada sistema de tratamento dos RSUs. Por ele são calculados o consumo de água, de energia, de matéria-prima e a emissão de gás carbônico de cada forma de tratamento aplicada. Tratamentos mais eficientes, como a reciclagem, resultam na economia de recursos e apresentam melhores resultados no ZWI.

\section{MATERIAIS E MÉTODOS}

Local de estudo

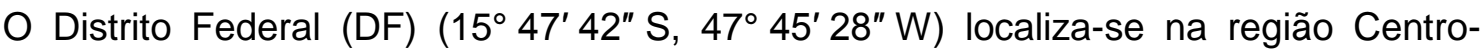
oeste e é uma unidade federativa do Brasil, composto por regiões administrativas. O Serviço de Limpeza Urbana (SLU) é uma autarquia do governo responsável pelo manejo dos resíduos sólidos no DF, prestando serviços como coleta, transporte e destinação final dos RSUs.

No DF, $98 \%$ dos domicílios são atendidos com o serviço de coleta de resíduos. Para o ano de 2014, os gastos com os serviços de manejo dos resíduos chegaram a $\mathrm{R} \$$ 154,00/hab/ano, totalizando os custos em $\mathrm{R} \$ 443.000 .000,00$. A produção per capita de Resíduos Sólidos Domésticos (RDOs) no DF foi de $0,81 \mathrm{~kg} / \mathrm{hab} / \mathrm{dia}$, o que corresponde a uma geração média diária de 2.500 toneladas. Além disso, uma média de 6.000 toneladas de entulho são geradas diariamente (SLU, 2015). A disposição da maior parte dos resíduos é efetuada no Aterro do Jóquei, também conhecido como Lixão da Estrutural.

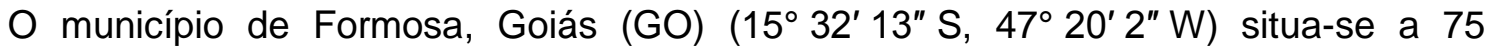
quilômetros de Brasília e a $282 \mathrm{Km}$ de Goiânia. A Secretaria Municipal de Meio Ambiente (SEMMA) é o órgão responsável pelo gerenciamento dos resíduos sólidos em Formosa.

Segundo dados do Sistema Nacional de Informações sobre Saneamento (SNIS) (2016), cerca de $91 \%$ da população total do município é atendida pelo serviço de coleta desenvolvido pela Secretaria. Em relação à população urbana, a taxa de cobertura da coleta chega a $100 \%$. O custo médio da coleta, no ano de 2013 , foi de $\mathrm{R} \$ 166,67$ por tonelada. Os resíduos sólidos são depositados em aterro sanitário.

O município de Luziânia (GO) (16 $15^{\prime} 10^{\prime \prime} \mathrm{S}, 4^{\circ} 57^{\prime} 0^{\prime \prime}$ W) fica a 200 km de Goiânia e aproximadamente $60 \mathrm{~km}$ de Brasília. A Secretaria Municipal de Desenvolvimento Urbano (SMDU) é órgão municipal responsável pelo manejo dos resíduos sólidos da cidade. Os resíduos sólidos são depositados num aterro controlado ou num lixão. 
A taxa de cobertura da coleta convencional dos Resíduos Sólidos Urbanos (RSUs) é de $85,82 \%$ para a população total do município e de $92 \%$ para a população urbana. O custo estimado para a coleta convencional foi de $\mathrm{R} \$ 107,91$ no ano de 2013.

O município de Unaí, Minas Gerais (MG) (16² 21' 50" S, 46 $54^{\prime} 15^{\prime \prime}$ W) localiza-se a aproximadamente $170 \mathrm{~km}$ de Brasília e a $590 \mathrm{~km}$ da capital mineira, Belo Horizonte. O órgão que realiza o gerenciamento dos resíduos sólidos em Unaí é a Secretaria Municipal de Obras, Infraestrutura, Trânsito e Serviços Urbanos (EMOIT). Os resíduos sólidos são encaminhados para um lixão da cidade.

Nesta cidade a taxa de cobertura da coleta convencional foi de $80,36 \%$ considerando a população municipal total. Para a população urbana, a taxa de cobertura chegou a $100 \% \mathrm{em}$ 2013. O valor da coleta convencional, estimado para o mesmo ano, foi de $\mathrm{R} \$ 117,16$.

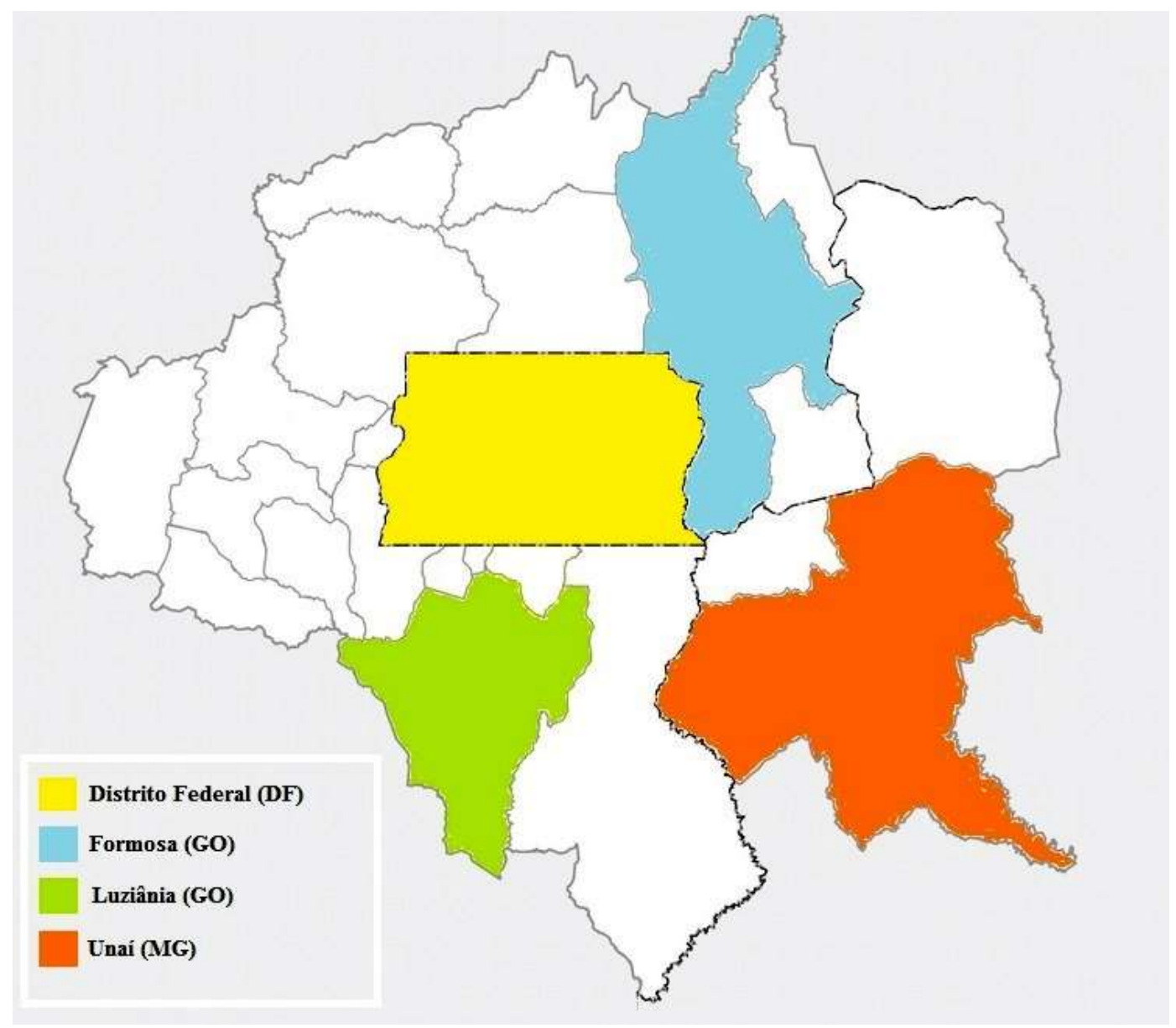

Figura 2.1 - A Região Integrada de Desenvolvimento do Distrito Federal e Entorno e os locais de estudo.

Fonte: Adaptado de Cordeiro e França (2012). 
Tabela 2.1 - Dados das quatro áreas de estudo.

\begin{tabular}{|c|c|c|c|c|c|c|}
\hline & População & Área $\left(\mathbf{k m}^{2}\right)$ & $\begin{array}{c}\text { Dens. } \\
\text { Demográfica } \\
\left(\mathrm{hab} / \mathrm{km}^{2}\right)\end{array}$ & PIB & $\begin{array}{l}\text { PIB per } \\
\text { capita }\end{array}$ & IDH-M \\
\hline $\begin{array}{l}\text { Distrito } \\
\text { Federal (DF) }\end{array}$ & 2.914 .830 & 5.780 & 444,66 & $171 \mathrm{bi}$ & 4.653 & 0,824 \\
\hline $\begin{array}{l}\text { Formosa } \\
\text { (GO) }\end{array}$ & 100.085 & $5.811,788$ & 17,22 & $911.427,778$ & $9.106,63$ & 0,744 \\
\hline $\begin{array}{l}\text { Luziânia } \\
\text { (GO) }\end{array}$ & 174.531 & $3.961,122$ & 44,06 & $2.077 .842,338$ & $11.904,27$ & 0,701 \\
\hline Unaí (MG) & 77.565 & $8.447,107$ & 9,18 & $1.398 .983,028$ & $18.030,46$ & 0,736 \\
\hline
\end{tabular}

Fonte: Adaptado de IBGE $(2014 ; 2010)$.

Zero Waste Index

O Zero Waste Index (ZWI) é uma ferramenta desenvolvida por A. U. Zaman para estimar a eficiência no manejo dos resíduos sólidos de um determinado local. Diferente do cálculo básico de porcentagem de resíduos tratados por resíduos gerados, o ZWI estima a quantidade de água, energia e matéria-prima que são poupados quando os resíduos sólidos recebem tratamento adequado como a reciclagem ou a compostagem. No caso de aterramento dos resíduos sem qualquer tratamento, o ZWI fornece dados sobre a emissão de $\mathrm{CO}_{2}$ ocasionado por tal prática.

Para o cálculo do zero waste index utilizaram-se os dados referentes à gestão de resíduos sólidos no DF disponíveis na série histórica do SNIS. Os dados utilizados foram do período de 2003 a 2013 e referem-se à quantidade de resíduos gerada e a forma de tratamento adotada.

A equação para calcular o ZWI é a seguinte:

Zero waste index $\quad \underline{\Sigma}$ Quantidade de resíduo manejado * coeficiente $\mathrm{p} /$ tipo de sistema

Quantidade total de resíduos gerados

Equação 2.1 - Cálculo do Zero Waste Index.

Fonte: Zaman (2014).

Os coeficientes adotados por Zaman foram calculados em diferentes estudos sobre manejo de resíduos sólidos no mundo. Os valores são calculados de acordo com o tipo de resíduo e o mecanismo de tratamento adotado. Estes valores podem variar para localidades diferentes, entretanto, utilizaram-se os coeficientes a seguir para o cálculo do ZWI pela inexistência de dados específicos para o DF. 
Tabela 2.2 - Valores de substituição para o Zero Waste Index.

\begin{tabular}{ccccccc}
\hline $\begin{array}{c}\text { Sistema de } \\
\text { Gestão }\end{array}$ & $\begin{array}{c}\text { Categoria } \\
\text { de resíduos }\end{array}$ & $\begin{array}{c}\text { Resíduos } \\
\text { totais (ton) }\end{array}$ & $\begin{array}{c}\text { Matéria- } \\
\text { prima } \\
\text { economizada }\end{array}$ & $\begin{array}{c}\text { Energia } \\
\text { economizada } \\
\text { (GJ) }\end{array}$ & $\begin{array}{c}\text { CO2 não } \\
\text { emitido } \\
\text { (ton) }\end{array}$ & $\begin{array}{c}\text { Água } \\
\text { economizada } \\
\text { (mil litros) }\end{array}$ \\
\hline Reciclagem & Papel & - & $0,84-1,00$ & $6,33-10,76$ & $0,60-3,20$ & 2,91 \\
Reciclagem & Vidro & - & $0,90-1,00$ & $6,07-6,85$ & $0,18-0,62$ & 2,3 \\
Reciclagem & Metal & - & $0,79-0,96$ & $36,09-191,42$ & $1,40-17,8$ & $5,97-181,77$ \\
Reciclagem & Plástico & - & $0,90-0,97$ & $38,81-64,08$ & $0,95-1,88$ & $-11,37$ \\
Reciclagem & Misto & - & $0,25-0,45$ & $5,00-15,00$ & 1,15 & $2,0-10,00$ \\
Compostagem & Orgânico & - & $0,60-, 65$ & $0,18-0,47$ & $0,2500,75$ & 0,44 \\
Aterro & Misto & - & 0 & $0,00-0,84$ & $(-) 0,42-1,2$ & 0 \\
\hline
\end{tabular}

Fonte: Zaman (2014).

Sistema Nacional de Informação sobre Saneamento

Os dados utilizados estão disponíveis na série histórica do SNIS na área de resíduos sólidos. As informações que compõem a série histórica são fornecidas pelas próprias cidades por meio de questionário. Para o cálculo do ZWI foram usados os seguintes indicadores:

- CO050: População urbana atendida no município, abrangendo o distrito-sede e localidades (habitantes);

- CO119: Quantidade total de RDO e RSU coletada por todos os agentes (tonelada/ano);

- CS001: Existe Coleta Seletiva (CS) no município? (sim/não);

- CS009: Quantidade total de materiais recicláveis recuperados (toneladas/ano);

- CS010: Quantidade de Papel e papelão recicláveis recuperados (toneladas/ano);

- CS011: Quantidade de Plásticos recicláveis recuperados (toneladas/ano);

- CS012: Quantidade de Metais recicláveis recuperados (toneladas/ano);

- CS013: Quantidade de Vidros recicláveis recuperados (toneladas/ano);

- CS014: Quantidade de Outros materiais recicláveis recuperados (toneladas/ano);

- N016: Taxa de cobertura do serviço de coleta de RDO em relação à população urbana (\%);

- IN021: Massa coletada (RDO + RSU) per capita em relação à população urbana (kg/hab/dia);

- IN028: Massa de resíduos domiciliares e públicos (RDO + RSU) coletada per capita em relação à população total atendida pelo serviço de coleta $(\mathrm{kg} / \mathrm{habitante} / \mathrm{dia})$. 


\section{RESULTADOS E DISCUSSÃO}

O cálculo do Zero Waste Index (ZWI) foi realizado para as quatro cidades estudadas com os dados anuais disponíveis no Sistema Nacional de Informações sobre Saneamento (SNIS). Apenas o Distrito Federal (DF) possui informações cadastradas para todos os anos (2003 a 2013). Para o município de Formosa, Goiás (GO) utilizou-se dados referentes ao ano de 2013, único ano que houve informação dos dados necessários para o cálculo. O ZWI pôde ser calculado para o município de Luziânia (GO) nos anos 2007, 2009, 2011, 2012 e 2013. O município de Unaí, Minas Gerais (MG) forneceu os dados para o SNIS apenas no ano 2009. O DF apresenta, então, o maior número de dados disponível resultando num diagnóstico mais preciso da gestão dos Resíduos Sólidos Urbanos (RSUs). Os valores de ZWI calculados encontram-se em anexo (vide Apêndices "A", "B", "C" e "D").

Os valores de ZWI calculados para a Região Integrada de Desenvolvimento do Distrito Federal e Entorno (RIDE-DF) foram muito baixos quando comparados aos valores encontrados por Zaman e Lehmann (2013) para as cidades de Adelaide, Estocolmo e São Francisco. O município de Unaí (MG) não forneceu dados ao SNIS no ano de 2013, não sendo possível calcular o ZWI para esta cidade neste ano. Dentre as cidades da RIDE-DF, Luziânia (GO) apresentou o melhor valor de ZWI para o ano de 2013, à frente do DF.

Tabela 2.3 - O Zero Waste Index para o ano de 2013.

\begin{tabular}{cc}
\hline Cidade & ZWI \\
\hline Adelaide (Austrália) & 0,23 \\
Estocolmo (Suécia) & 0,17 \\
São Francisco (EUA) & 0,51 \\
Distrito Federal (DF) & 0,0047 \\
Formosa (GO) & 0,0013 \\
Luziânia (GO) & 0,0391 \\
\hline
\end{tabular}

Fonte: Da autora.

O Zero Waste Index para o Distrito Federal

No DF, o ZWI variou de 0,0020 a 0,0056, atingindo os maiores valores nos anos de 2003 e 2004. Já os piores índices correspondem aos anos 2008, 2009 e 2010 como observado na Tabela 2.4 , a seguir. 
Tabela 2.4 - O Zero Waste Index para o Distrito Federal (2003 a 2013).

\begin{tabular}{ccccccccccccc}
\hline \multicolumn{11}{c}{ Ano } \\
\hline & 2003 & 2004 & 2005 & 2006 & 2007 & 2008 & 2009 & $\mathbf{2 0 1 0}$ & $\mathbf{2 0 1 1}$ & $\mathbf{2 0 1 2}$ & $\mathbf{2 0 1 3}$ \\
\hline ZWI & 0,0056 & 0,0055 & 0,0050 & 0,0040 & 0,0049 & 0,0029 & 0,0021 & 0,0020 & 0,0034 & 0,0050 & 0,0047 \\
\hline
\end{tabular}

Fonte: Da autora.

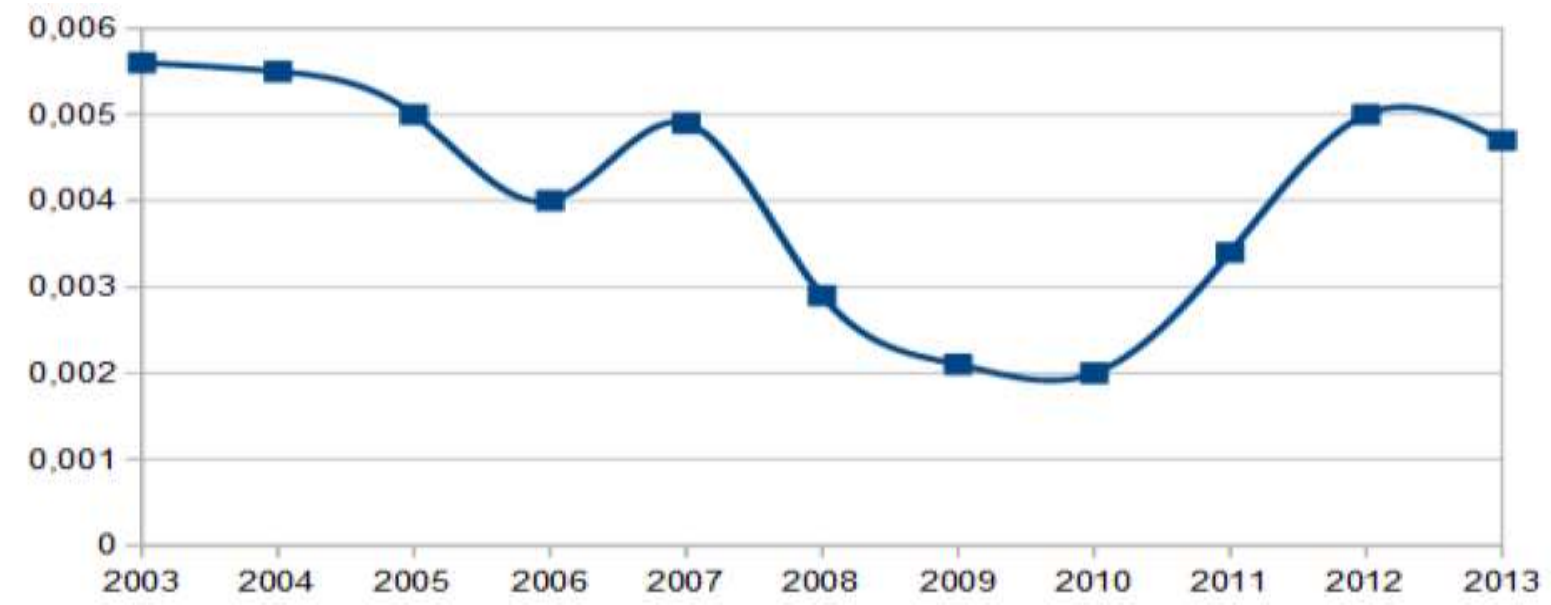

Gráfico 2.1 - O Zero Waste Index no Distrito Federal.

Fonte: Da autora.

Durante o período (2003 a 2013), a reciclagem no DF recuperou 85.740 toneladas de resíduos, sendo plástico e papel os materiais mais reciclados. Este valor é inferior a 1\% de todo o resíduo gerado no mesmo período, indicando que a gestão dos resíduos sólidos no DF foi ineficiente nestes anos.

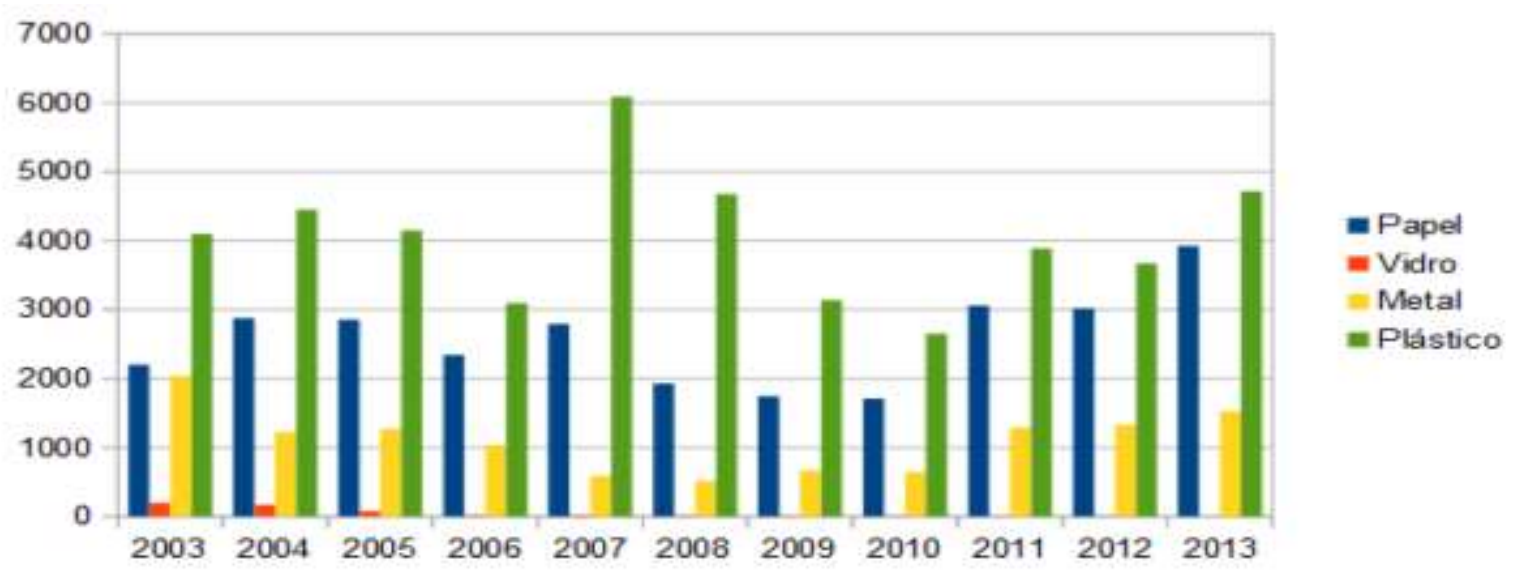

Gráfico 2.2 - A reciclagem no Distrito Federal (2003-2013).

Fonte: Da autora. 
Matéria prima economizada

Durante o período estudado a quantidade total de matéria-prima poupada pela reciclagem dos resíduos sólidos foi de $74.123,39$ toneladas. O Gráfico 2.3, a seguir, indica a quantidade de matéria-prima que foi economizada anualmente no DF devido à reciclagem dos resíduos sólidos.

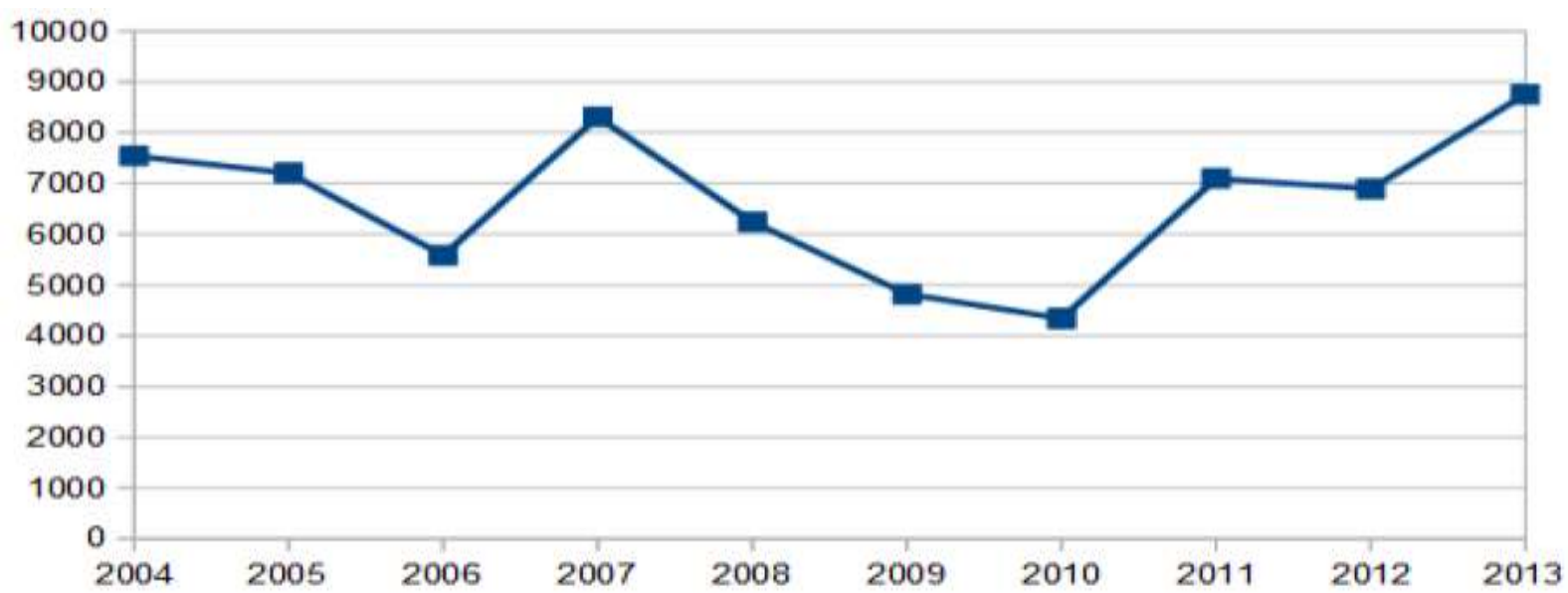

Gráfico 2.3 - Matéria prima (tonelada) poupada anualmente pela reciclagem nos resíduos sólidos.

Fonte: Da autora.

Energia economizada

A reciclagem dos materiais resultou na economia total de 3.919.030,17 Giga Joules (GJ) de energia, o que corresponde a, aproximadamente, 1088 Giga-Watt-hora (GWh) economizados ao longo de 11 anos no DF.

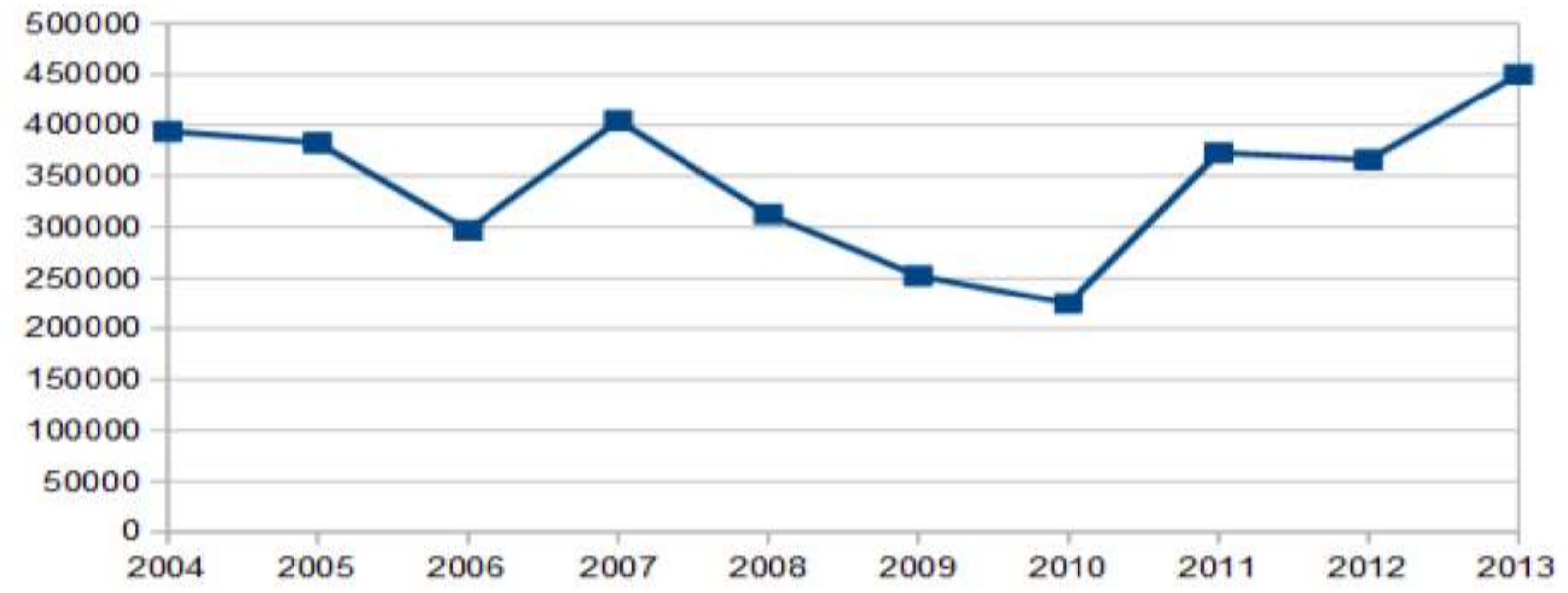

Gráfico 2.4 - Energia economizada em Giga Joules.

Fonte: Da autora. 
O manejo dos resíduos sólidos adotado pode gerar impactos positivos ou negativos quanto a emissão de gás carbônico. Enquanto a reciclagem e a compostagem dos materiais possuem efeitos positivos ao evitar a produção de $\mathrm{CO}_{2}$, o aterramento dos resíduos sólidos sem qualquer tratamento é responsável pela geração de grandes quantidades deste gás. Como a taxa de reciclagem no DF é muito baixa, a redução de gás carbônico total pela reciclagem foi de $224.780,8$ toneladas. Já a taxa de emissão de $\mathrm{CO}_{2}$ ocasionada pelo aterramento foi de $7.861 .738,4$ toneladas.

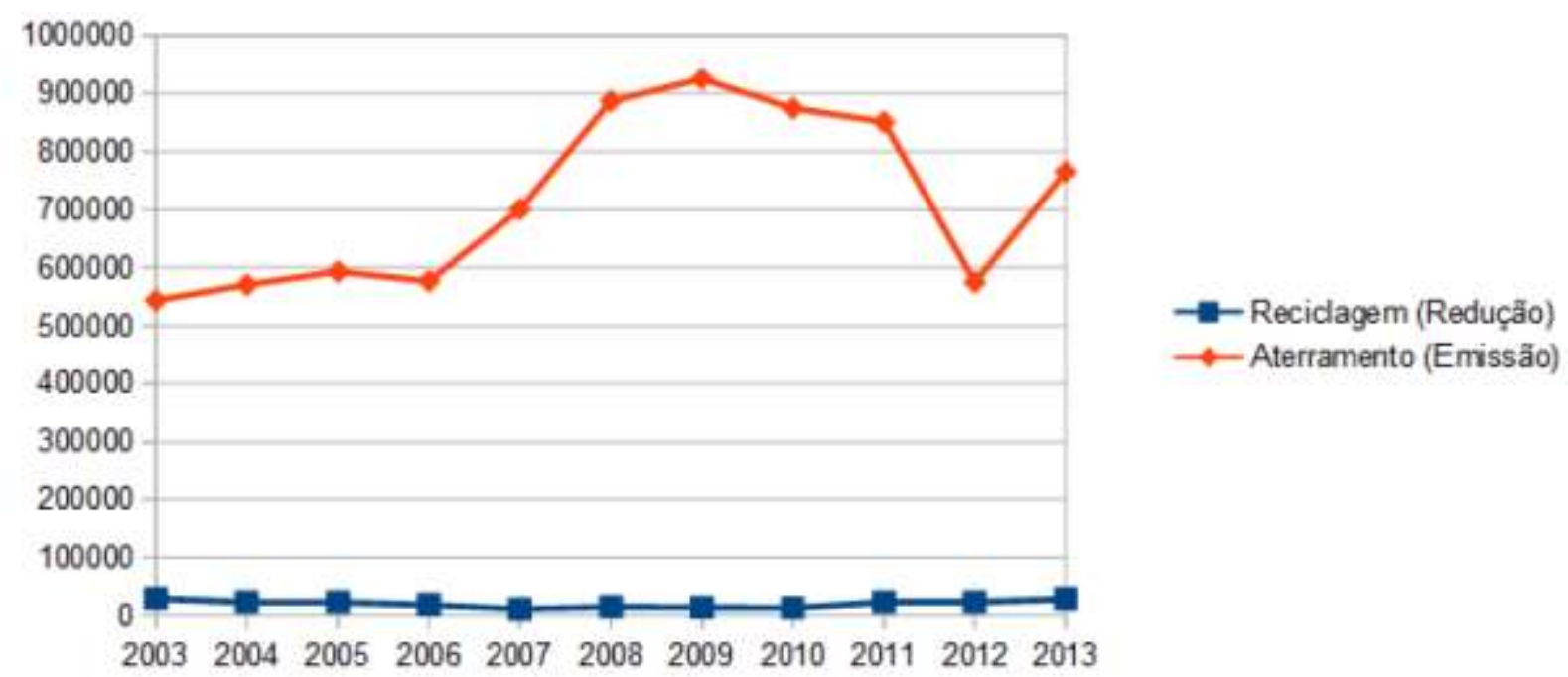

Gráfico 2.5 - Redução e emissão de $\mathrm{CO}_{2}$ (toneladas) pelo manejo dos resíduos sólidos no Distrito Federal. Fonte: Da autora.

Água economizada

A reciclagem de papel, vidro e metal resultou na economia de 1.180.896,78 litros de água durante o período, no entanto, para a reciclagem do plástico gastou-se aproximadamente 509.008,03 litros. Então, a economia de água foi de $671.888,75$ litros. 


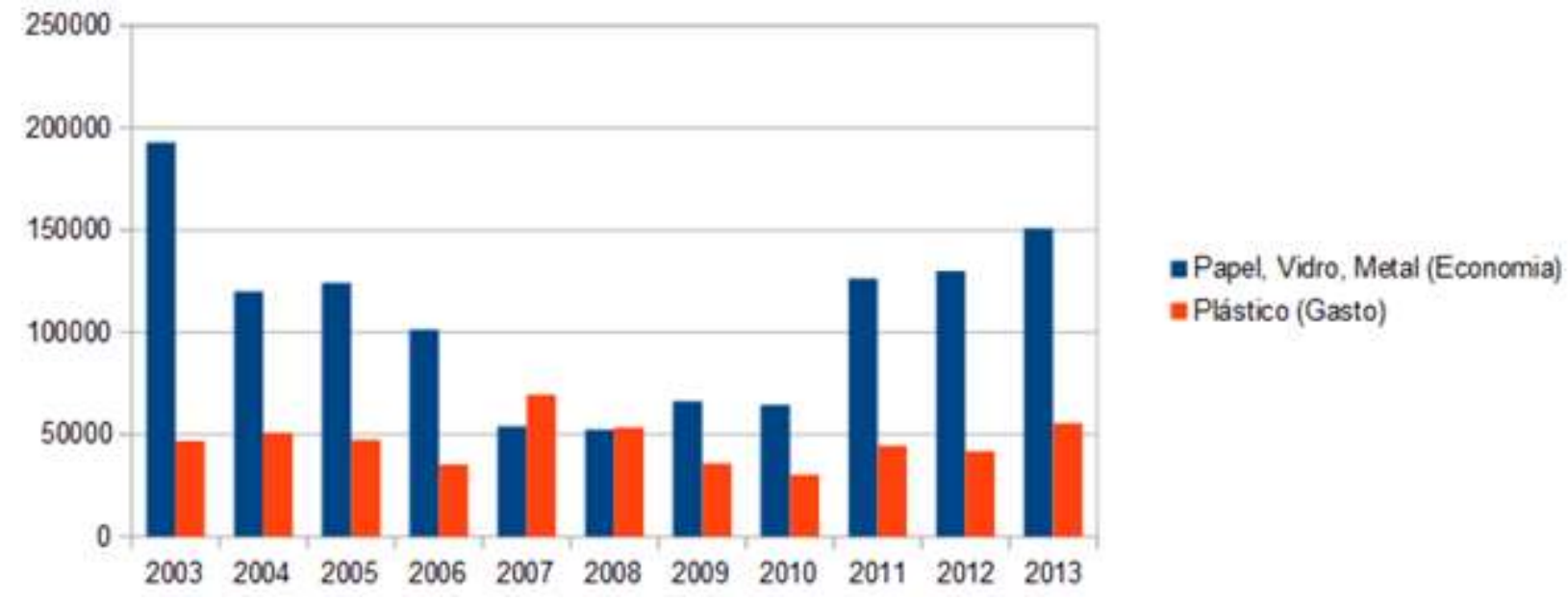

Gráfico 2.6 - Economia ou demanda de água (litros).

Fonte: Da autora.

Para o aterramento dos resíduos sólidos, a economia de matéria-prima e de água são nulos. No entanto deve-se ressaltar que o aterro de resíduos pode ser responsável pela contaminação dos solos, lençóis freáticos e cursos d'água o que resultaria, indiretamente, em gasto de água, especialmente pelo alto poder de contaminação do chorume e dos metais pesados.

\section{O Zero Waste Index para Formosa, Goiás}

Em Formosa (GO) foi possível calcular o ZWI apenas para 2013, pois este foi o único ano em que o município forneceu dados ao SNIS. O ZWI encontrado foi de 0,0013, sendo o menor da RIDE-DF. Do total de 33.070 toneladas de RSUs gerados, apenas 54 toneladas $(0,1 \%)$ foram recicladas. A reciclagem resultou no desvio de 46 toneladas de papel e oito toneladas de plástico do aterro. Não houve reciclagem de vidro e metal na cidade. 


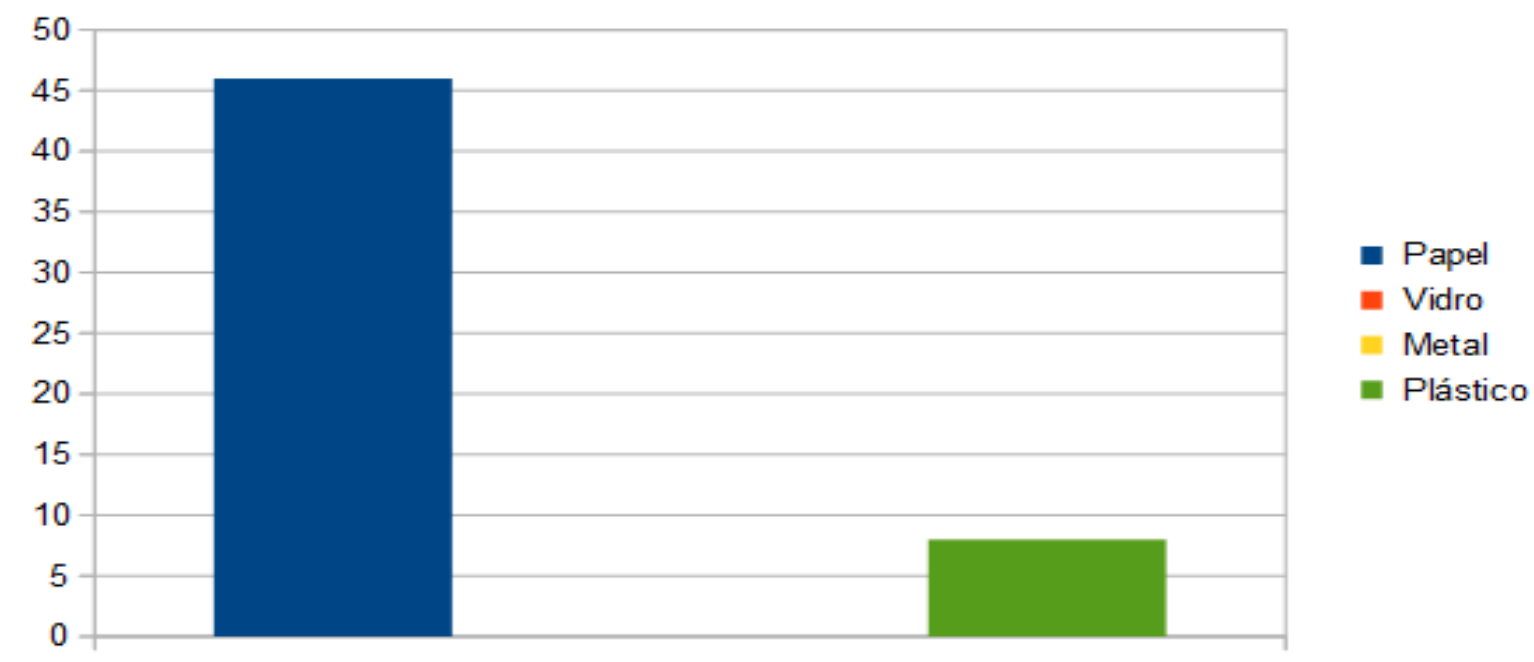

Gráfico 2.7 - A reciclagem no Município de Formosa, Goiás, em 2013.

Fonte: Da autora.

A quantidade de matéria-prima poupada foi de 45,84 toneladas. A energia economizada pela reciclagem foi de $804,04 \mathrm{GJ}$, o que equivale a 0,22 GWh. A emissão de gás carbônico teve balanço negativo: a reciclagem contribuiu para a não emissão de 98,6 toneladas de gás carbônico; o aterro dos resíduos resultou na emissão de 13.866,72 toneladas de $\mathrm{CO}_{2}$. A reciclagem de 46 toneladas de papel resultou na economia de 133.860 litros de água. Já a reciclagem de oito toneladas de plástico demandou 90.960 litros de água.

O Zero Waste Index para Luziânia, Goiás

Luziânia (GO) forneceu dados para o SNIS nos anos 2007, 2009, 2011, 2012 e 2013. Os valores de ZWI calculados para o município foram os maiores da RIDE-DF, apresentando o melhor resultado no ano de 2007.

Tabela 2.5 - O Zero Waste Index em Luziânia, Goiás.

\begin{tabular}{lccccc}
\hline & \multicolumn{5}{c}{ Ano } \\
\hline & $\mathbf{2 0 0 7}$ & $\mathbf{2 0 0 9}$ & $\mathbf{2 0 1 1}$ & $\mathbf{2 0 1 2}$ & $\mathbf{2 0 1 3}$ \\
\hline ZWI & 0,0399 & 0,1016 & 0,0280 & 0,0397 & 0,0391 \\
\hline
\end{tabular}

Fonte: Da autora.

A Coleta Seletiva (CS) resultou na reciclagem de 17.776,7 toneladas de resíduos sólidos durante o período, destacando-se a reciclagem de papel e plástico. 


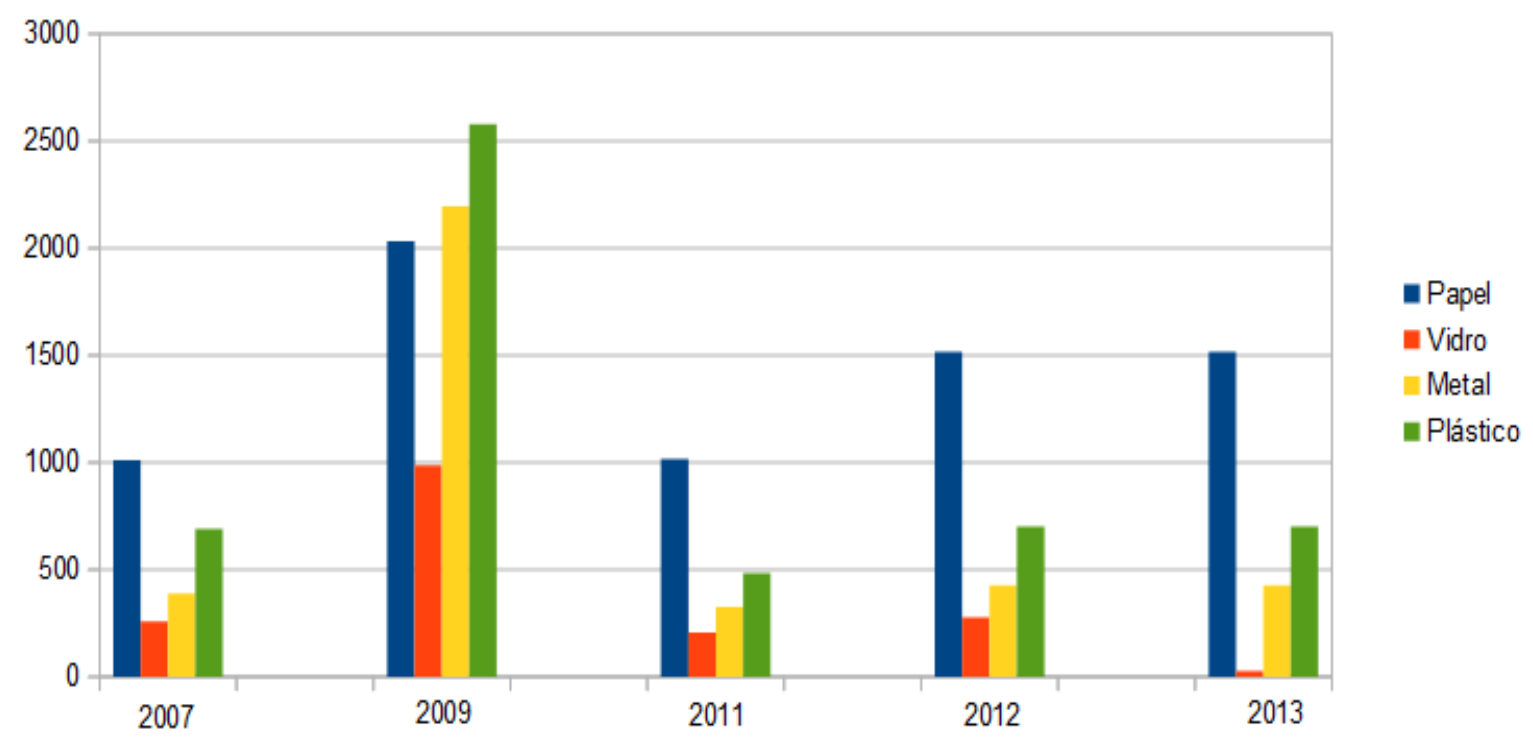

Gráfico 2.8 - Quantidade de Resíduos Sólidos Urbanos reciclados em Luziânia, Goiás.

Fonte: Da autora.

Matéria prima economizada

A partir da reciclagem de papel, vidro, metal e plástico no município foi possível poupar 15.158,976 toneladas de matéria-prima.

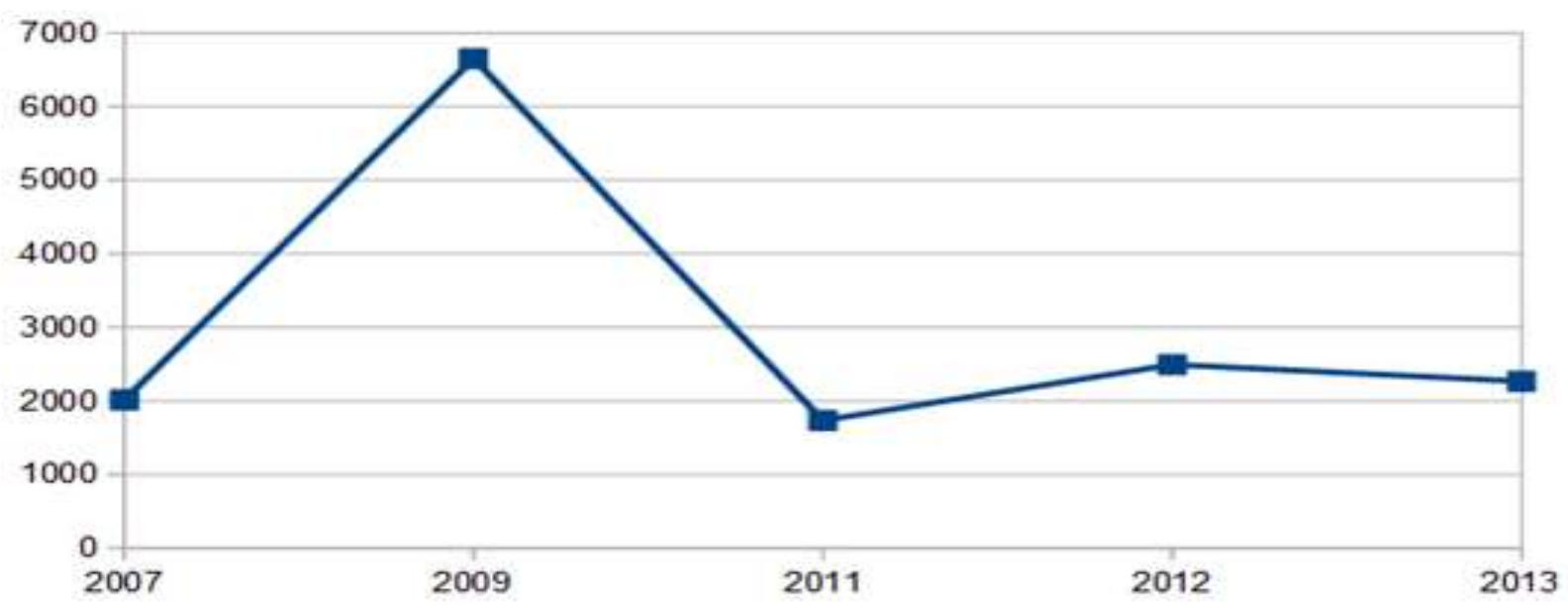

Gráfico 2.9 - Matéria prima economizada.

Fonte: Da autora.

A reciclagem também possibilitou uma economia expressiva de energia. Nos seis anos estudados economizou-se 765.670,194 GJ de energia, o que equivale a 212,686 GWh. 


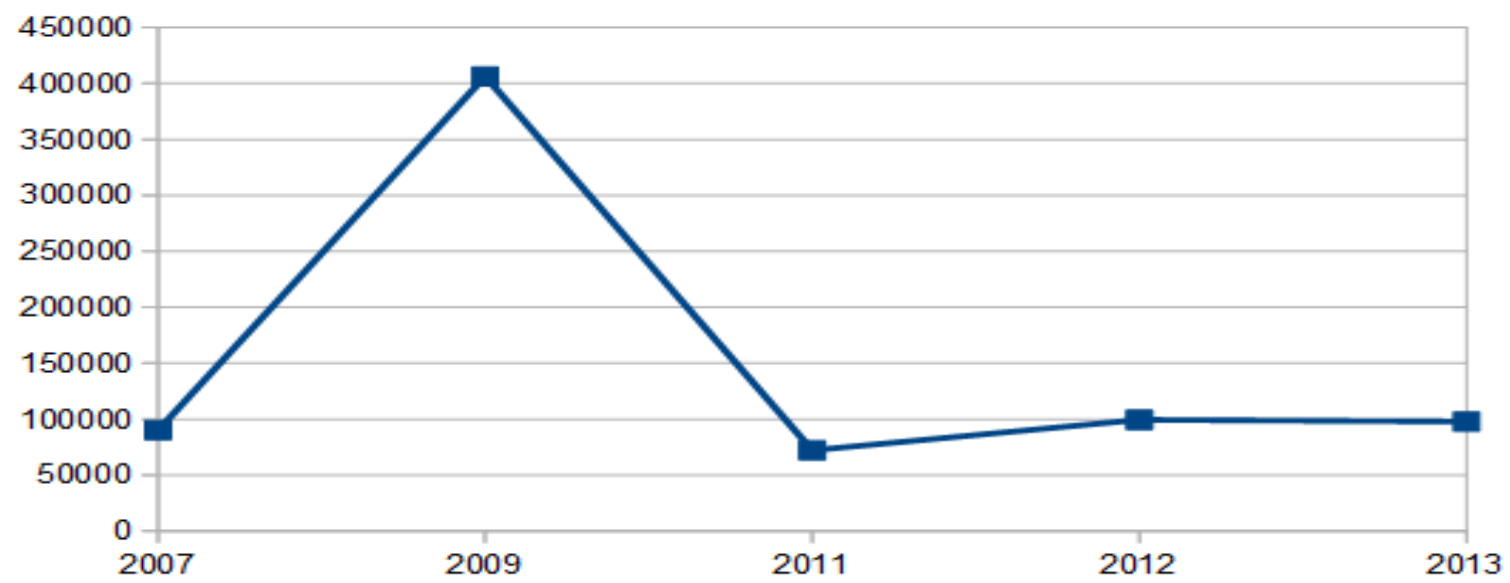

Gráfico 2.10 - Energia economizada.

Fonte: Da autora.

Emissão de $\mathrm{CO}_{2}$

$\mathrm{O}$ balanço nas emissões de $\mathrm{CO}_{2}$ é realizado de acordo com o tipo de tratamento adotado no manejo dos resíduos sólidos. A reciclagem evitou a emissão de 57.564,69 toneladas de $\mathrm{CO}_{2}$. Já o aterramento dos resíduos sólidos, sem qualquer tratamento, resultou na emissão de $365.204,406$ toneladas de $\mathrm{CO}_{2}$.

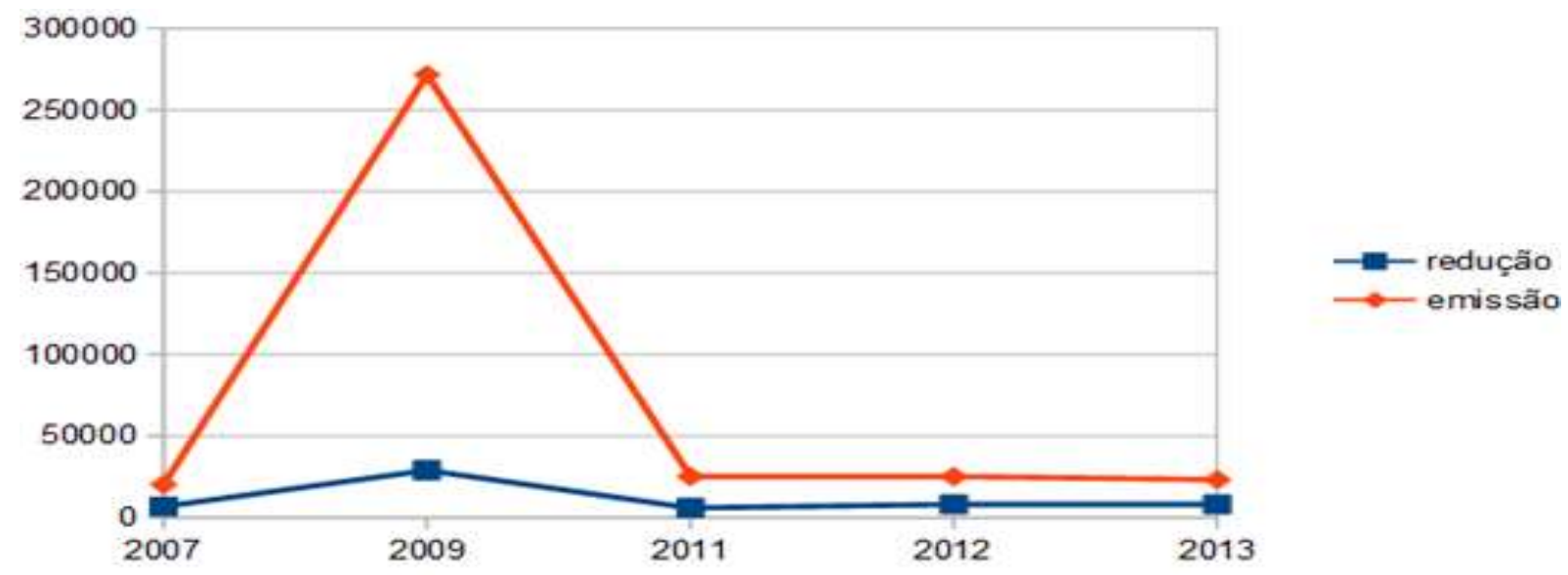

Gráfico 2.11 - Emissão de $\mathrm{CO}_{2}$.

Fonte: Da autora.

Água economizada

A reciclagem de papel, metal e vidro possibilita a economia de água. Já o processo de reciclagem de plástico demanda uma grande quantidade de água. O Gráfico 2.12, a seguir, mostra a proporção de economia e gasto de água, indicando que a reciclagem teve um 
efeito positivo na economia hídrica.

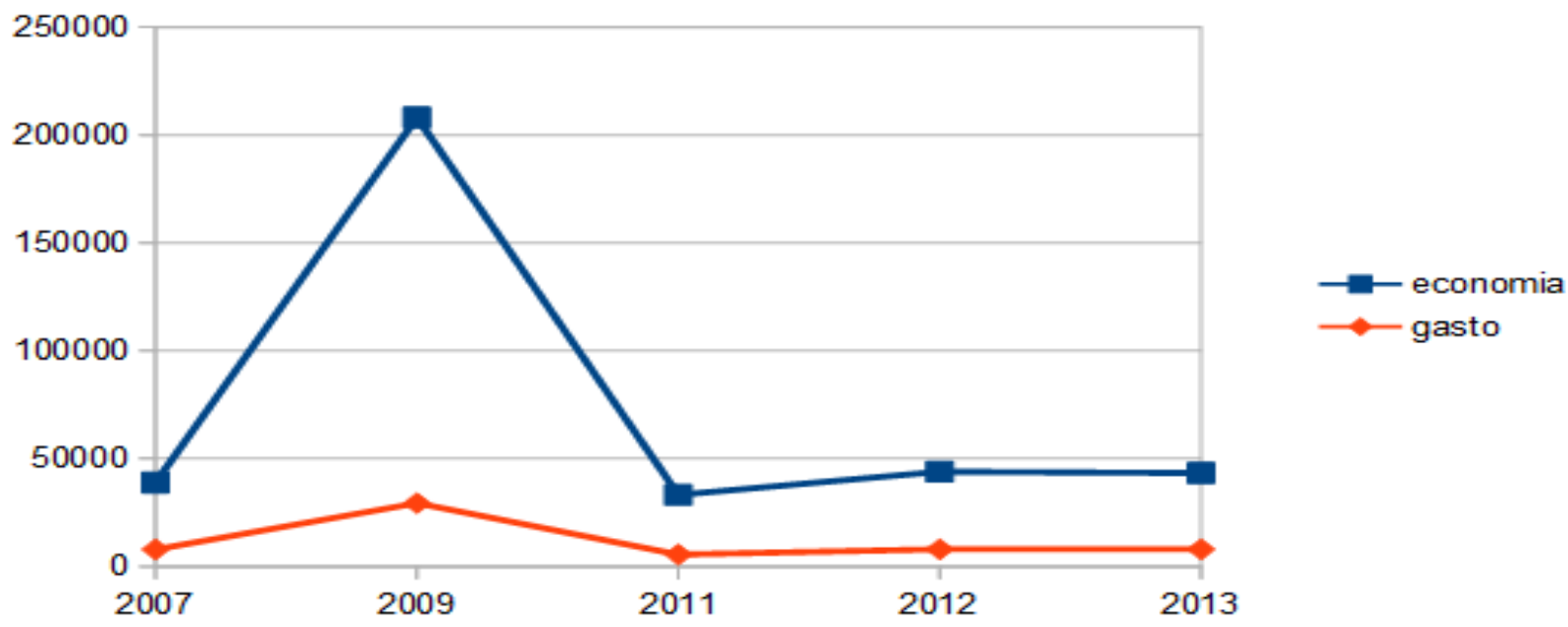

Gráfico 2.12 - Utilização de água (economia e gasto).

Fonte: Da autora.

O Zero Waste Index para Unaí, Minas Gerais

Em Unaí, o ZWI pôde ser calculado apenas para o ano de 2009. O valor encontrado foi de 0,01182. Neste ano foram recicladas 262 toneladas de resíduos sólidos.

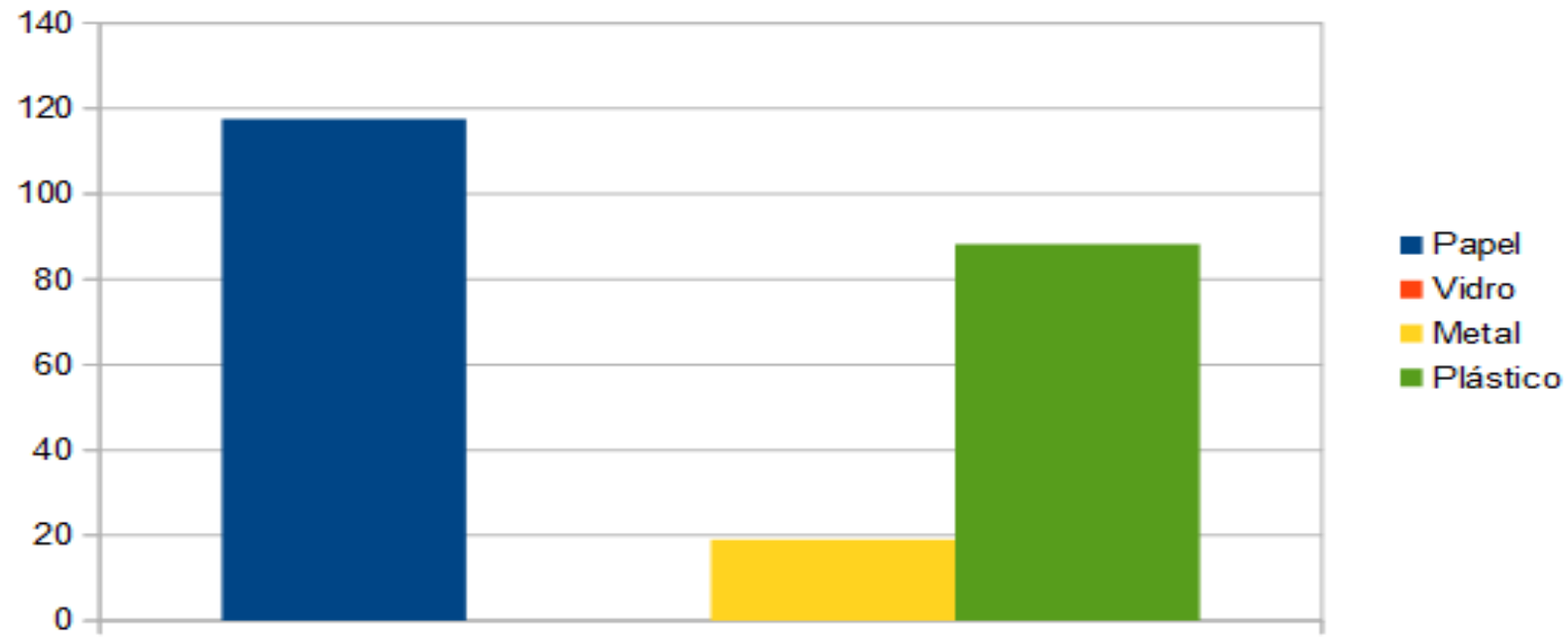

Gráfico 2.13 - Resíduos sólidos reciclados em Unaí, Minas Gerais (2009).

Fonte: Da autora.

A reciclagem no ano de 2009 permitiu a economia de 8.964 GJ de energia, que corresponde 0,002 GWh. A reciclagem evitou a emissão de 633,6 toneladas de $\mathrm{CO}_{2}$, entretanto, os resíduos que foram depositados em aterro geraram 7.869,96 toneladas de 
gás carbônico. A quantidade de papel, vidro e metal reciclada foi responsável pela economia de 2.591,4 kl de água. Já a reciclagem de plástico demandou 1.114,26 kl de água.

\section{CONCLUSÃO}

Do total de Resíduos Sólidos Urbanos (RSUs) gerado no Distrito Federal (DF) e nos três municípios estudados, apenas uma fração muito pequena recebe tratamento adequado. A maior parte dos resíduos é depositada em aterros controlados ou lixões sem qualquer tratamento. Além dos impactos calculados a partir do Zero Waste Index (ZWI), é importante ressaltar que a disposição inadequada pode levar à contaminação do solo, do lençol freático e de cursos d'água, bem como ocasionar a proliferação de pragas e doenças.

Os dados sobre resíduos sólidos que compõem a série histórica do Sistema Nacional de Informações sobre Saneamento (SNIS) puderam ser usados no cálculo do ZWI. A série histórica deve incluir, no questionário enviado aos municípios, perguntas sobre a compostagem de resíduos orgânicos e sobre o valor gasto com a Coleta Seletiva (CS). Entre os locais estudados somente o DF forneceu dados ao sistema desde 2003, permitindo que uma análise mais concisa fosse realizada. Apesar da coleta de dados sobre resíduos sólidos ter sido iniciada em 2003, ainda se observa a descontinuidade no envio de informações e a baixa participação por parte dos municípios.

O ZWI mostrou-se uma ferramenta eficiente para avaliar o gerenciamento dos resíduos sólidos na Região Integrada de Desenvolvimento do Distrito Federal e Entorno (RIDE-DF). Como vantagem destaca-se a facilidade de comparação que o método permite. A partir deste índice é possível comparar diferentes modelos de gestão que são desenvolvidos em diversos locais, em escala regional ou global.

Além disso, o ZWI aprofunda os conhecimentos ambientais pertinentes à gestão dos RSUs. Diferente de outros métodos, que indicam apenas a quantidade de resíduos recuperados, o ZWI mostra que cada tipo de tratamento acarreta em impactos positivos ou negativos na emissão de gás carbônico e na utilização de matéria prima, de água e de energia.

A desvantagem consiste em se tratar de um método que avalia exclusivamente a esfera ambiental, não sendo aconselhado como única metodologia de avaliação da gestão dos resíduos sólidos. Aspectos econômicos, sociais, sanitários e técnico-operacionais possuem igual importância num modelo de gestão de RSUs. Deste modo, aconselha-se a utilização de outros métodos que, somados ao ZWI, permitam um diagnóstico mais preciso do gerenciamento dos RSUs na área estudada. 


\section{REFERÊNCIAS}

BRAGA, N. C.; DIAS, N. C. Gestão de resíduos sólidos urbanos. Curitiba, 2008. Disponível em: <http://www.administradores.com.br/_resources/files/_modules/academics/academics_1079 _201002281825303644.pdf>. Acesso em: Acesso em: 1\%/09/2015.

CORDEIRO, L. D.; FRANÇA, M. O. M. A dinâmica migratória na área metropolitana de Brasília - AMB entre 1991 e 2010. In: Anais do XVIII Encontro Nacional de Estudos Populacionais, ABEP, Águas de Lindóia, SP, de 19 a 23 de novembro de 2012. Disponível em: <http://www.abep.nepo.unicamp.br/xviii/anais/files/POSTER[407]ABEP2012.pdf>. Acesso em: 1\%09/2015.

SHARHOLY, M.; AHMAD, K.; VAISHYA, R. C.; GUPTA, R. D. Municipal solid waste characteristics and management in Allahabad, India. Journal of Waste Management, n. 27, p. 490-496, 2007. Disponível em: <http://www.seas.columbia.edu/earth/wtert/sofos/Sharholy_MSW\%20Characteristics\%20and \%20Management\%20in\%20Allahabad,\%20India.pdf>. Acesso em: 1\%/09/2015.

SISTEMA NACIONAL DE INFORMAÇÕES SOBRE SANEAMENTO - SNIS. 2016. Disponível em: <http://www.snis.gov.br/>. Acesso em: 1\%/04/2014.

SOLTANI, A.; HEWAGE, K.; REZA, B.; SADIG, R. Multiple stakeholders in multi-criteria decision-making in the context of Municipal Solid Waste Management: a review. Waste Management, v. 35, p. 318-328, jan. 2015.

ZAMAN, A. U.; LEHMANN, S. The zero waste index: a performance measurement tool for waste management systems in a 'zero waste city'. Journal of Cleaner Production, v. 50, p. 123-132, jul. 2013.

ZANTA, V. M.; FERREIRA, C. F. A. Gerenciamento integrado de Resíduos Sólidos Urbanos. In: BORGES, A. C. (Coord.). Resíduos sólidos urbanos: aterro sustentável para municípios de pequeno porte. 1. ed. São Carlos, SP: Rima Artes e Textos, 2003. v. 1. 


\section{APÊNDICES}

Apêndice "A" - O Zero Waste Index no Distrito Federal

\begin{tabular}{|c|c|c|c|c|c|c|c|c|}
\hline \multirow[b]{2}{*}{ Ano } & \multicolumn{7}{|c|}{ Itens } & \multirow[b]{2}{*}{ ZWI } \\
\hline & $\begin{array}{l}\text { Sistema de } \\
\text { Gestão }\end{array}$ & $\begin{array}{l}\text { Categoria de } \\
\text { resíduos }\end{array}$ & $\begin{array}{l}\text { Resíduos totais } \\
\text { (ton) }\end{array}$ & $\begin{array}{c}\text { Matéria-prima } \\
\text { economizada } \\
\text { (ton) }\end{array}$ & $\begin{array}{c}\text { Energia } \\
\text { economizada } \\
\text { (GJ) }\end{array}$ & $\begin{array}{c}\mathrm{CO}_{2} \text { não } \\
\text { emitido (ton) }\end{array}$ & $\begin{array}{c}\text { Água } \\
\text { economizada } \\
\text { (mil litros) }\end{array}$ & \\
\hline \multirow{6}{*}{2003} & Reciclagem & Papel & 2205 & 1852,2 & 18830,7 & 4189,5 & 6416,55 & \multirow{6}{*}{0,0056} \\
\hline & Reciclagem & Vidro & 200 & 180 & 1292 & 80 & 460 & \\
\hline & Reciclagem & Metal & 2043 & 1613,97 & 232493,4 & 19612,8 & 185913 & \\
\hline & Reciclagem & Plástico & 4101 & 3690,9 & 210791,4 & 5741,4 & $-46628,37$ & \\
\hline & \multirow[t]{2}{*}{ Aterro } & \multirow[t]{2}{*}{ Misto } & 1294222,9 & 0 & 0 & $-543573,62$ & 0 & \\
\hline & & & 1302771,9 & 7337,07 & 463407,5 & $-513949,92$ & 146161,18 & \\
\hline \multirow{6}{*}{2004} & Reciclagem & Papel & 2874 & 2414,16 & 24543,96 & 5460,6 & 8363,34 & \multirow{6}{*}{0,0055} \\
\hline & Reciclagem & Vidro & 171 & 153,9 & 1104,66 & 68,4 & 393,3 & \\
\hline & Reciclagem & Metal & 1222 & 965,38 & 139063,6 & 11731,2 & 111202 & \\
\hline & Reciclagem & Plástico & 4453 & 4007,7 & 228884,2 & 6234,2 & $-50630,61$ & \\
\hline & Aterro & Misto & 1358251 & 0 & 0 & $-570465,42$ & 0 & \\
\hline & & & 1366971 & 7541,14 & 393596,42 & $-546971,02$ & 69328,03 & \\
\hline \multirow{6}{*}{2005} & Reciclagem & Papel & 2857 & 2399,88 & 24398,78 & 5428,3 & 8313,87 & \multirow{6}{*}{0,0050} \\
\hline & Reciclagem & Vidro & 77 & 69,3 & 497,42 & 30,8 & 177,1 & \\
\hline & Reciclagem & Metal & 1270 & 1003,3 & 144526 & 12192 & 115570 & \\
\hline & Reciclagem & Plástico & 4146 & 3731,4 & 213104,4 & 5804,4 & $-47140,02$ & \\
\hline & Aterro & Misto & 1412204,6 & 0 & 0 & $-593125,93$ & 0 & \\
\hline & & & 1420554,6 & 7203,88 & 383526,6 & $-569670,43$ & 76920,95 & \\
\hline
\end{tabular}




\begin{tabular}{|c|c|c|c|c|c|c|c|c|}
\hline \multirow[b]{2}{*}{ Ano } & \multicolumn{7}{|c|}{ Itens } & \multirow[b]{2}{*}{ ZWI } \\
\hline & $\begin{array}{l}\text { Sistema de } \\
\text { Gestão }\end{array}$ & $\begin{array}{l}\text { Categoria de } \\
\text { resíduos }\end{array}$ & $\begin{array}{c}\text { Resíduos totais } \\
\text { (ton) }\end{array}$ & $\begin{array}{c}\text { Matéria-prima } \\
\text { economizada } \\
\text { (ton) }\end{array}$ & $\begin{array}{c}\text { Energia } \\
\text { economizada } \\
\text { (GJ) }\end{array}$ & $\begin{array}{c}\mathrm{CO}_{2} \text { não } \\
\text { emitido (ton) }\end{array}$ & $\begin{array}{c}\text { Água } \\
\text { economizada } \\
\text { (mil litros) }\end{array}$ & \\
\hline \multirow{6}{*}{2006} & Reciclagem & Papel & 2340 & 1965,6 & 19983,6 & 4446 & 6809,4 & \multirow{6}{*}{0,0040} \\
\hline & Reciclagem & Vidro & 23 & 20,7 & 148,58 & 9,2 & 52,9 & \\
\hline & Reciclagem & Metal & 1036 & 818,44 & 117896,8 & 9945,6 & 94276 & \\
\hline & Reciclagem & Plástico & 3091 & 2781,9 & 158877,4 & 4327,4 & $-35144,67$ & \\
\hline & \multirow[t]{2}{*}{ Aterro } & \multirow[t]{2}{*}{ Misto } & 1372719 & 0 & 0 & $-576541,98$ & 0 & \\
\hline & & & 1379209 & 5586,64 & 296906,38 & $-557813,78$ & 65993,63 & \\
\hline \multirow{6}{*}{2007} & Reciclagem & Papel & 2790 & 2343,6 & 23826,6 & 5301 & 8118,9 & \multirow{6}{*}{0,0049} \\
\hline & Reciclagem & Vidro & 21 & 18,9 & 135,66 & 8,4 & 48,3 & \\
\hline & Reciclagem & Metal & 592 & 467,68 & 67369 & 5683,2 & 53872 & \\
\hline & Reciclagem & Plástico & 6087 & 5478,3 & 312871,8 & 8521,8 & $-69209,19$ & \\
\hline & Aterro & Misto & 1667878,5 & 0 & 0 & -70050897 & 0 & \\
\hline & & & 1677368,5 & 8308,48 & 404203,06 & -70031382 & $-15288,89$ & \\
\hline \multirow{6}{*}{2008} & Reciclagem & Papel & 1924 & 1616,16 & 13802,01 & 3655,6 & 5598,84 & \multirow{6}{*}{0,0029} \\
\hline & Reciclagem & Vidro & 12 & 10,8 & 77,52 & 4,8 & 27,6 & \\
\hline & Reciclagem & Metal & 511 & 403,69 & 58151,8 & 4905,6 & 46501 & \\
\hline & Reciclagem & Plástico & 4679 & 4211,1 & 240500,6 & 6550,6 & $-53200,23$ & \\
\hline & Aterro & Misto & 2111254,2 & 0 & 0 & -886726764 & 0 & \\
\hline & & & 21188380,2 & 6241,75 & 312531,93 & -886711647 & $-1072,79$ & \\
\hline
\end{tabular}




\begin{tabular}{|c|c|c|c|c|c|c|c|c|}
\hline \multirow[b]{2}{*}{ Ano } & \multicolumn{7}{|c|}{ Itens } & \multirow[b]{2}{*}{ ZWI } \\
\hline & $\begin{array}{l}\text { Sistema de } \\
\text { Gestão }\end{array}$ & $\begin{array}{l}\text { Categoria de } \\
\text { resíduos }\end{array}$ & $\begin{array}{c}\text { Resíduos totais } \\
\text { (ton) }\end{array}$ & $\begin{array}{c}\text { Matéria-prima } \\
\text { economizada } \\
\text { (ton) }\end{array}$ & $\begin{array}{c}\text { Energia } \\
\text { economizada } \\
\text { (GJ) }\end{array}$ & $\begin{array}{c}\mathrm{CO}_{2} \text { não } \\
\text { emitido (ton) }\end{array}$ & $\begin{array}{c}\text { Água } \\
\text { economizada } \\
\text { (mil litros) }\end{array}$ & \\
\hline \multirow{6}{*}{2009} & Reciclagem & Papel & 1744 & 1464,96 & 14893,76 & 3313,6 & 5075,04 & \multirow{6}{*}{0,0021} \\
\hline & Reciclagem & Vidro & 7 & 6,3 & 45,22 & 2,8 & 16,1 & \\
\hline & Reciclagem & Metal & 670 & 529,3 & 76246 & 6432 & 60970 & \\
\hline & Reciclagem & Plástico & 3135 & 2821,5 & 161139 & 4389 & $-35644,95$ & \\
\hline & Aterro & Misto & 2202808,7 & 0 & 0 & $-925179,65$ & 0 & \\
\hline & & & 2208364,7 & 4822,06 & 252323,98 & $-911042,25$ & 30416,19 & \\
\hline \multirow{6}{*}{2010} & Reciclagem & Papel & 1710 & 1436,4 & 14603,4 & 3249 & 4976,1 & \multirow{6}{*}{0,0020} \\
\hline & Reciclagem & Vidro & 6 & 5,4 & 38,76 & 2,4 & 13,8 & \\
\hline & Reciclagem & Metal & 651 & 514,29 & 74083,8 & 6249,6 & 59241 & \\
\hline & Reciclagem & Plástico & 2648 & 2383,2 & 136107,2 & 3707,2 & $-30107,76$ & \\
\hline & Aterro & Misto & 2081860 & 0 & 0 & $-874381,2$ & 0 & \\
\hline & & & 2086875 & 4339,29 & 224833,16 & -861173 & 34123,14 & \\
\hline \multirow{6}{*}{2011} & Reciclagem & Papel & 3060 & 2570,4 & 26132,4 & 5814 & 8904,6 & \multirow{6}{*}{0,0034} \\
\hline & Reciclagem & Vidro & 7 & 6,3 & 45,22 & 2,8 & 16,1 & \\
\hline & Reciclagem & Metal & 1288 & 1017,52 & 146574,4 & 12364,8 & 117208 & \\
\hline & Reciclagem & Plástico & 3890 & 3501 & 199946 & 5446 & $-44229,3$ & \\
\hline & Aterro & Misto & 2025741,3 & 0 & 0 & $-850811,35$ & 0 & \\
\hline & & & 2033986,3 & 7095,22 & 372698,02 & $-827183,75$ & 81899,4 & \\
\hline
\end{tabular}




\begin{tabular}{|c|c|c|c|c|c|c|c|c|}
\hline \multirow[b]{2}{*}{ Ano } & \multicolumn{7}{|c|}{ Itens } & \multirow[b]{2}{*}{ ZWI } \\
\hline & $\begin{array}{l}\text { Sistema de } \\
\text { Gestão }\end{array}$ & $\begin{array}{l}\text { Categoria de } \\
\text { resíduos }\end{array}$ & $\begin{array}{l}\text { Resíduos totais } \\
\text { (ton) }\end{array}$ & $\begin{array}{c}\text { Matéria-prima } \\
\text { economizada } \\
\text { (ton) }\end{array}$ & $\begin{array}{c}\text { Energia } \\
\text { economizada } \\
\text { (GJ) }\end{array}$ & $\begin{array}{l}\mathrm{CO}_{2} \text { não } \\
\text { emitido (ton) }\end{array}$ & $\begin{array}{c}\text { Água } \\
\text { economizada } \\
\text { (mil litros) }\end{array}$ & \\
\hline \multirow{6}{*}{2012} & Reciclagem & Papel & 3017 & 2534,28 & 25765,18 & 5732,3 & 8779,47 & \multirow{6}{*}{0,0050} \\
\hline & Reciclagem & Vidro & 6 & 5,4 & 38,76 & 2,4 & 13,8 & \\
\hline & Reciclagem & Metal & 1331 & 1051,49 & 151467,8 & 12777,6 & 121121 & \\
\hline & Reciclagem & Plástico & 3668 & 3301,2 & 188535,2 & 5135,2 & $-41705,16$ & \\
\hline & \multirow[t]{2}{*}{ Aterro } & \multirow[t]{2}{*}{ Misto } & 1369117 & 0 & 0 & $-575029,14$ & 0 & \\
\hline & & & 1377139 & 6892,37 & 365806,94 & $-551381,64$ & 88209,11 & \\
\hline \multirow{6}{*}{2013} & Reciclagem & Papel & 3927 & 3298,68 & 33536,58 & 7461,3 & 11427,57 & \multirow{6}{*}{0,0047} \\
\hline & Reciclagem & Vidro & 0 & 0 & 0 & 0 & 0 & \\
\hline & Reciclagem & Metal & 1529 & 1207,91 & 174000,2 & 14678,4 & 139139 & \\
\hline & Reciclagem & Plástico & 4721 & 4248,9 & 242659,4 & 6609,4 & $-553677,77$ & \\
\hline & \multirow[t]{2}{*}{ Aterro } & \multirow[t]{2}{*}{ Misto } & 1822367,7 & 0 & 0 & $-765394,43$ & 0 & \\
\hline & & & 1832544,7 & 8755,49 & 450196,18 & $-736645,33$ & $-403111,2$ & \\
\hline
\end{tabular}


Apêndice "B" - O Zero Waste Index em Formosa, Goiás

\begin{tabular}{|c|c|c|c|c|c|c|c|c|}
\hline \multirow[b]{2}{*}{ Ano } & \multicolumn{7}{|c|}{ Itens } & \multirow[b]{2}{*}{ ZWI } \\
\hline & $\begin{array}{l}\text { Sistema de } \\
\text { Gestão }\end{array}$ & $\begin{array}{l}\text { Categoria de } \\
\text { resíduos }\end{array}$ & $\begin{array}{l}\text { Resíduos totais } \\
\text { (ton) }\end{array}$ & $\begin{array}{c}\text { Matéria-prima } \\
\text { economizada } \\
\text { (ton) }\end{array}$ & $\begin{array}{c}\text { Energia } \\
\text { economizada } \\
\text { (GJ) }\end{array}$ & $\begin{array}{c}\mathrm{CO}_{2} \text { não } \\
\text { emitido (ton) }\end{array}$ & $\begin{array}{c}\text { Água } \\
\text { economizada } \\
\text { (mil litros) }\end{array}$ & \\
\hline \multirow{6}{*}{2013} & Reciclagem & Papel & 46 & 38,64 & 392,84 & 87,4 & 133,86 & \multirow{6}{*}{0,0013} \\
\hline & Reciclagem & Vidro & 0 & 0 & 0 & 0 & 0 & \\
\hline & Reciclagem & Metal & 0 & 0 & 0 & 0 & 0 & \\
\hline & Reciclagem & Plástico & 8 & 7,2 & 411,2 & 11,2 & $-90,96$ & \\
\hline & Aterro & Misto & 33016 & 0 & 0 & $-13866,72$ & 0 & \\
\hline & & & 33070 & 45,84 & 804,04 & $-13768,12$ & 42,9 & \\
\hline
\end{tabular}


Apêndice "C" - O Zero Waste Index em Luziânia, Goiás

\begin{tabular}{|c|c|c|c|c|c|c|c|c|}
\hline \multirow[b]{2}{*}{ Ano } & \multicolumn{7}{|c|}{ Itens } & \multirow[b]{2}{*}{ ZWI } \\
\hline & $\begin{array}{l}\text { Sistema de } \\
\text { Gestão }\end{array}$ & $\begin{array}{l}\text { Categoria de } \\
\text { resíduos }\end{array}$ & $\begin{array}{c}\text { Resíduos totais } \\
\text { (ton) }\end{array}$ & $\begin{array}{l}\text { Matéria-prima } \\
\text { economizada } \\
\text { (ton) }\end{array}$ & $\begin{array}{c}\text { Energia } \\
\text { economizada } \\
\text { (GJ) }\end{array}$ & $\begin{array}{l}\mathrm{CO}_{2} \text { não } \\
\text { emitido (ton) }\end{array}$ & $\begin{array}{c}\text { Água } \\
\text { economizada } \\
\text { (mil litros) }\end{array}$ & \\
\hline \multirow{6}{*}{2007} & Reciclagem & Papel & 1011,1 & 849,324 & 8634,794 & 1921,09 & 2942,301 & \multirow{6}{*}{0,0399} \\
\hline & Reciclagem & Vidro & 259 & 233,1 & 1673,14 & 103,6 & 595,7 & \\
\hline & Reciclagem & Metal & 388,8 & 307,152 & 44245,44 & 3732,48 & 35380,8 & \\
\hline & Reciclagem & Plástico & 691,8 & 622,62 & 35558,52 & 968,52 & $-7865,766$ & \\
\hline & Aterro & Misto & 48022,3 & 0 & 0 & $-20169,366$ & 0 & \\
\hline & & & 50373 & 2012,196 & 90111,894 & $-13443,676$ & 31053,035 & \\
\hline \multirow{6}{*}{2009} & Reciclagem & Papel & 2033 & 1707,72 & 17361,82 & 3862,7 & 5916,03 & \multirow{6}{*}{0,1016} \\
\hline & Reciclagem & Vidro & 986 & 887,4 & 6369,56 & 394,4 & 2267,8 & \\
\hline & Reciclagem & Metal & 2197 & 1735,63 & 250018,6 & 21091,2 & 199927 & \\
\hline & Reciclagem & Plástico & 2579 & 2321,1 & 132560,6 & 3610,6 & $-29323,23$ & \\
\hline & Aterro & Misto & 646649 & 0 & 0 & $-271592,58$ & 0 & \\
\hline & & & 654444 & 6651,85 & 406310,58 & $-242633,68$ & 178787,6 & \\
\hline \multirow{6}{*}{2011} & Reciclagem & Papel & 1017 & 854,28 & 8685,18 & 1932,3 & 2959,47 & \multirow{6}{*}{0,0280} \\
\hline & Reciclagem & Vidro & 208 & 187,2 & 1343,68 & 83,2 & 478,4 & \\
\hline & Reciclagem & Metal & 327 & 258,33 & 37212,6 & 3139,2 & 29757 & \\
\hline & Reciclagem & Plástico & 484 & 435,6 & 24877,6 & 677,6 & $-5503,08$ & \\
\hline & Aterro & Misto & 59894 & 0 & 0 & $-25155,48$ & 0 & \\
\hline & & & 61930 & 1735,41 & 72119,06 & $-19323,18$ & 27691,79 & \\
\hline
\end{tabular}




\begin{tabular}{|c|c|c|c|c|c|c|c|c|}
\hline \multirow[b]{2}{*}{ Ano } & \multicolumn{7}{|c|}{ Itens } & \multirow[b]{2}{*}{ ZWI } \\
\hline & $\begin{array}{l}\text { Sistema de } \\
\text { Gestão }\end{array}$ & $\begin{array}{l}\text { Categoria de } \\
\text { resíduos }\end{array}$ & $\begin{array}{c}\text { Resíduos totais } \\
\text { (ton) }\end{array}$ & $\begin{array}{c}\text { Matéria-prima } \\
\text { economizada } \\
\text { (ton) }\end{array}$ & $\begin{array}{c}\text { Energia } \\
\text { economizada } \\
\text { (GJ) }\end{array}$ & $\begin{array}{c}\mathrm{CO}_{2} \text { não } \\
\text { emitido (ton) }\end{array}$ & $\begin{array}{c}\text { Água } \\
\text { economizada } \\
\text { (mil litros) }\end{array}$ & \\
\hline \multirow{6}{*}{2012} & Reciclagem & Papel & 1517 & 1274,28 & 12955,18 & 2882,3 & 4414,47 & \multirow{6}{*}{0,0397} \\
\hline & Reciclagem & Vidro & 278 & 250,2 & 1795,88 & 111,2 & 639,4 & \\
\hline & Reciclagem & Metal & 427 & 337,33 & 48592,6 & 4099,2 & 38857 & \\
\hline & Reciclagem & Plástico & 701 & 630,9 & 36031,4 & 981,4 & $-7970,37$ & \\
\hline & Aterro & Misto & 59767 & 0 & 0 & $-25102,14$ & 0 & \\
\hline & & & 62690 & 2492,71 & 99375,06 & $-17028,04$ & 35940,5 & \\
\hline \multirow{6}{*}{2013} & Reciclagem & Papel & 1517 & 1274,28 & 12955,18 & 2882,3 & 4414,47 & \multirow{6}{*}{0,0391} \\
\hline & Reciclagem & Vidro & 27 & 24,3 & 174,42 & 10,8 & 62,1 & \\
\hline & Reciclagem & Metal & 427 & 337,33 & 48592,6 & 4099,2 & 38857 & \\
\hline & Reciclagem & Plástico & 701 & 630,9 & 36031,4 & 981,4 & $-7970,37$ & \\
\hline & Aterro & Misto & 55202 & 0 & 0 & $-23184,84$ & 0 & \\
\hline & & & 57874 & 2266,81 & 97753,6 & $-15211,14$ & 35363,2 & \\
\hline
\end{tabular}


Apêndice "D" - O Zero Waste Index em Unaí, Minas Gerais

\begin{tabular}{|c|c|c|c|c|c|c|c|c|}
\hline \multirow[b]{2}{*}{ Ano } & \multicolumn{7}{|c|}{ Itens } & \multirow[b]{2}{*}{ ZWI } \\
\hline & $\begin{array}{l}\text { Sistema de } \\
\text { Gestão }\end{array}$ & $\begin{array}{l}\text { Categoria de } \\
\text { resíduos }\end{array}$ & $\begin{array}{c}\text { Resíduos totais } \\
\text { (ton) }\end{array}$ & $\begin{array}{l}\text { Matéria-prima } \\
\text { economizada } \\
\text { (ton) }\end{array}$ & $\begin{array}{c}\text { Energia } \\
\text { economizada } \\
\text { (GJ) }\end{array}$ & $\begin{array}{c}\mathrm{CO}_{2} \text { não } \\
\text { emitido (ton) }\end{array}$ & $\begin{array}{c}\text { Água } \\
\text { economizada } \\
\text { (mil litros) }\end{array}$ & \\
\hline \multirow{6}{*}{2009} & Reciclagem & Papel & 140 & 117,6 & 1195,6 & 266 & 407,4 & \multirow{6}{*}{0,0118} \\
\hline & Reciclagem & Vidro & 0 & 0 & 0 & 0 & 0 & \\
\hline & Reciclagem & Metal & 24 & 18,96 & 2731,2 & 230,4 & 2184 & \\
\hline & Reciclagem & Plástico & 98 & 88,2 & 5037,2 & 137,2 & $-1114,26$ & \\
\hline & Aterro & Misto & 18738 & 0 & 0 & $-7869,96$ & 0 & \\
\hline & & & 19000 & 224,76 & 8964 & $-7236,36$ & 1477,14 & \\
\hline
\end{tabular}




\title{
3 AVALIAÇÃO DA COLETA SELETIVA NA REGIÃO INTEGRADA DE DESENVOLVIMENTO DO DISTRITO FEDERAL E ENTORNO A PARTIR DE DOIS ÍNDICES DE SUSTENTABILIDADE
}

\author{
RESUMO
}

A Região Integrada de Desenvolvimento do Distrito Federal e Entorno é composta pelo Distrito Federal, por 19 municípios goianos e por três municípios mineiros. Em 2014, o Distrito Federal e seis municípios declararam que executavam iniciativa de Coleta Seletiva. O objetivo deste capítulo foi avaliar a efetividade dos programas de Coleta Seletiva desenvolvidos na referida Região, no ano de 2014. As análises foram realizadas por meio de dados secundários da série histórica de Resíduos Sólidos Urbanos do Sistema Nacional de Informação sobre Saneamento. A metodologia utilizada foi a aplicação de dois índices de sustentabilidade específicos para a Coleta Seletiva, desenvolvidos por Besen (2011) e Fechine (2014). Os índices são compostos por indicadores que avaliam a sustentabilidade da Coleta Seletiva considerando aspectos ambientais, sociais e econômicos. Os dois índices foram utilizados, de forma comparativa, com o intuito de verificar se índices diferentes resultariam em avaliações distintas para o mesmo conjunto de dados. Os resultados indicaram que todos os programas de Coleta Seletiva analisados apresentaram baixa ou muito baixa sustentabilidade. Os resultados obtidos pelos dois índices diferiram para a maioria das localidades estudadas.

Palavras-Chave: Região Integrada de Desenvolvimento do Distrito Federal e Entorno; Resíduos Sólidos Urbanos; Coletiva seletiva.

\section{ABSTRACT}

The Integrated Region of Development of the Distrito Federal and Surrounding Areas (RIDEDF) is composed of the DF, by 19 municipalities of Goiás and 3 municipalities of Minas Gerais. In 2014, the Federal District and 6 municipalities have declared that performed some initiative of selective waste collection. The aim of this chapter is to evaluate the effectiveness of selective waste collection programs developed in the RIDE-DF, in 2014. Analyses were performed by secondary data of the historical series of municipal solid waste from the Sistema Nacional de Informação sobre Saneamento (SNIS). The methodology used was the application of two specific sustainability indexes for selective waste collection, developed by Besen (2011) and Fechine (2014). The indices are composed of indicators that assess the sustainability of the selective collection considering environmental, social and economic. Two indices were used, in a comparative manner, in order to verify if different indexes result in different ratings for the same set of data. The results indicated that all of selective waste collection programs analyzed exhibited low or very low sustainability. The results obtained by the two indexes differed from most locations studied.

Keywords: RIDE-DF. Urban Solid Waste. Selective collection.

INTRODUÇÃO

A Coleta Seletiva (CS) de Resíduos Sólidos Urbanos (RSUs) resulta em mais vantagens econômicas, sociais e ambientais do que a coleta convencional. Apesar do serviço de CS ser geralmente mais caro do que o serviço de coleta convencional, a vantagem econômica é verificada quando os resíduos sólidos recicláveis, oriundos da CS, 
são desviados de aterros, retornando ao ciclo produtivo, gerando recursos financeiros para as associações de catadores e evitando impactos ambientais que demandam muito investimento de recursos para a sua mitigação.

Apesar de todas as vantagens que a CS apresenta em relação à coleta convencional, há uma série de dificuldades para a implantação e a consolidação de um programa de CS. Ribeiro e Besen (2007, p. 2) definem as principais dificuldades encontradas:

Os programas em parceria com catadores organizados enfrentam dificuldades de ordem técnica (falta de capacitação), organizacional (organização do trabalho e baixa implementação da prática cooperativista) e econômica (competição pelo material reciclável, ausência de remuneração pelos serviços prestados pelos catadores) e carecem tanto de inserção institucional com base em instrumentos legais que garantam sua continuidade quanto de indicadores que possibilitem seu monitoramento e aprimoramento na perspectiva da sustentabilidade socioambiental e econômica.

Conke (2015) cita como principais barreiras para a consolidação de um programa de CS a falta de infraestrutura, o desconhecimento sobre o potencial de reciclagem de cada tipo de material, a desigualdade na relação custo-benefício dos aspectos ambientais da cadeia produtiva de reciclagem, o modelo equivocado de financiamento da CS e a necessidade de uma legislação que torne o mercado de produtos reciclados mais competitivos.

A prática da CS não é obrigatória por lei. Contudo, o serviço de CS facilita o cumprimento das exigências constantes na Política Nacional de Resíduos Sólidos, que determinou o fechamento dos lixões e o fim da disposição final de resíduos sólidos sem qualquer tratamento. A segregação dos resíduos na fonte geradora é, então, passo fundamental para o manejo adequado dos RSUs.

O planejamento e a execução da CS envolvem aspectos sociais (inclusão de catadores; participação da população), aspectos econômicos (custo do serviço; renda dos catadores) e aspectos ambientais (quantidade de resíduos gerados; quantidade de resíduos reciclados). Sendo assim, o sucesso de um programa de CS depende da participação efetiva da sociedade, de processos economicamente viáveis e do manejo dos resíduos ambientalmente adequado.

A implantação de programas de CS tem aumentado no Brasil. Em 2014, cerca de 64,8\% dos municípios brasileiros possuía alguma iniciativa de CS (ABRELPE, 2014). Este aumento é reflexo, principalmente, da publicação da PNRS e da busca por meios de adequar-se às demandas desta lei. Em 2009, antes da instituição da PNRS, a taxa de iniciativas de CS era de $56,6 \%$ do total de municípios. Na Região Integrada de Desenvolvimento do Distrito Federal e Entorno (RIDE-DF), o número de municípios com iniciativas de CS passou de 3, em 2009, para 8 em 2014 (SNIS, 2009 e 2014). 
O aumento das iniciativas de CS pode ser explicado por fatores econômicos, sobretudo pela baixa disponibilidade de recursos financeiros nos municípios. Dentre as ações propostas pela PNRS como o fechamento dos lixões e o tratamento adequado dos resíduos sólidos, a CS é, sem dúvidas a opção menos onerosa. Além disso, os municípios que executam a CS têm prioridade no repasse dos recursos da União em relação aqueles que não promovem este serviço.

O aumento do percentual de municípios com iniciativa de CS não implica, obrigatoriamente, numa melhoria significativa na gestão dos RSUs. A execução da CS sem qualquer planejamento pode levar a um baixo retorno, ou seja, o investimento de recursos financeiros sem o alcance das metas almejadas, como o aumento da taxa de reciclagem e o desvio de resíduos sólidos de aterros.

O objetivo deste capítulo foi avaliar, a partir de dois indicadores de sustentabilidade, os programas de CS desenvolvidos no Distrito Federal e nos seis municípios integrantes da RIDE-DF, que declararam realizar a CS no ano de 2014.

A CS de RSUs consiste na coleta de materiais separados por tipo e composição na fonte geradora. A separação dos materiais permite que uma quantidade maior de resíduos sejam reciclados, pois evita a contaminação dos materiais recicláveis e facilita o processo de triagem. Para Buque e Ribeiro (2015), a CS vai além da reciclagem e da conservação do meio ambiente, pois envolve áreas como infraestrutura, planejamento urbano, saúde pública e educação social.

Eigenheer e Ferreira (2015, p. 677) descrevem a CS:

Entendida como recolhimento diferenciado de materiais separados já nas fontes geradoras, visando facilitar o seu reaproveitamento bem como assegurar a qualidade deles, a coleta seletiva de resíduos sólidos urbanos é conhecida e praticada desde o início do século $X X$, quando foram implantadas as primeiras experiências organizadas na Europa e nos Estados Unidos.

O número de iniciativas de CS aumentou depois da instituição da PNRS. Entretanto, para que os benefícios ambientais e socioeconômicos da CS sejam atingidos, é necessário que os programas implantados apresentem uma boa gestão.

\section{REFERENCIAL TEÓRICO}

Índices de sustentabilidade

Os índices de sustentabilidade propostos por Besen (2011) e Fechine (2014) foram desenvolvidos a partir do método Delphi, onde especialistas da área de resíduos sólidos foram consultados para auxiliar na elaboração dos indicadores. A validação dos índices foi 
realizada a partir da aplicação destes na avaliação de sistemas de Coleta Seletiva (CS). Ambas as autoras consideram que os índices de sustentabilidade foram eficientes para a análise dos programas de CS estudados.

Embora diversos índices de sustentabilidade para a CS tenham sido desenvolvidos, não há, até o momento, estudos que utilizem dois ou mais índices com o intuito de comparálos. Então, é necessário verificar se diferentes índices resultam em diagnósticos similares para o mesmo sistema de CS.

Geração de Resíduos Sólidos Urbanos

A geração de RSUs nos locais de estudo, para o ano de 2014, foi avaliada a partir do total de Resíduos Sólidos Urbanos (RSUs) coletados. Observa-se que o município de Buritis (MG) apresentou uma grande geração per capita $(2 \mathrm{~kg} / \mathrm{hab} / \mathrm{dia})$ ficando à frente do Distrito Federal (vide Tabela 3.1, a seguir).

Tabela 3.1 - Resíduo Sólido Urbano coletado nas áreas de estudo.

\begin{tabular}{lccc}
\hline \multicolumn{1}{c}{ Cidade } & RSU coletado (ton) & $\begin{array}{c}\text { População Total } \\
\text { atendida }\end{array}$ & $\begin{array}{c}\text { Massa coletada per } \\
\text { capita (kg/hab/dia) }\end{array}$ \\
\hline Distrito Federal (DF) & $1.634 .522,10$ & 2.795 .324 & 1,63 \\
Cidade Ocidental (GO) & $10.540,00$ & 49.110 & 0,59 \\
Cristalina (GO) & $25.320,00$ & 43.085 & 1,61 \\
Formosa (GO) & $50.156,10$ & 105.000 & 1,35 \\
Luziânia (GO) & $62.690,00$ & 161.496 & 0,96 \\
Santo Antônio do & $14.400,00$ & & 0,64 \\
Descoberto (GO) & $12.463,00$ & 61.974 & 2 \\
Buritis (MG) & 17.114 & 2 \\
\hline
\end{tabular}

Fonte: Adaptado a partir de dados do SNIS (2014).

Disposição final

A disposição final dos resíduos sólidos na Região Integrada de Desenvolvimento do Distrito Federal e Entorno (RIDE-DF), segundo dados do SNIS, é apresentada no Quadro 3.1, a seguir. Os dados são declarados pelos próprios municípios, podendo haver erro na informação fornecida. Observou-se que o Distrito Federal e sete municípios da RIDE-DF ainda depositam os RSUs gerados em lixões, sem qualquer tratamento prévio. 


\begin{tabular}{|c|c|}
\hline Estado/Cidade & Disposição Final \\
\hline Distrito Federal & Lixão \\
\hline \multicolumn{2}{|l|}{ Goiás (GO) } \\
\hline Abadiânia & Aterro controlado \\
\hline Águas Lindas & Aterro sanitário \\
\hline Alexânia & Aterro controlado \\
\hline Cabeceiras & Lixão \\
\hline Cidade Ocidental & Aterro sanitário \\
\hline Cocalzinho de Goiás & Lixão \\
\hline Cristalina & Lixão \\
\hline Formosa & Aterro sanitário \\
\hline Luziânia & Lixão \\
\hline Padre Bernardo & Aterro sanitário \\
\hline Pirenópolis & Aterro controlado \\
\hline Planaltina & Aterro sanitário \\
\hline Santo Antônio do Descoberto & Lixão \\
\hline Valparaíso & Lixão \\
\hline Vila Boa & Lixão \\
\hline \multicolumn{2}{|l|}{ Minas Gerais (MG) } \\
\hline Buritis & Aterro controlado \\
\hline Cabeceira Grande & Aterro controlado \\
\hline Unaí & Aterro controlado \\
\hline
\end{tabular}

Quadro 3.1 - Disposição final de Resíduos Sólidos Urbanos na Região Integrada de Desenvolvimento do Distrito Federal e Entorno.

Fonte: Adaptado a partir de dados do SNIS (2014).

Coleta convencional

A coleta convencional é a ação mais básica dentre as etapas do gerenciamento dos RSUs. Esta etapa é fundamental para evitar problemas como o surgimento de lixões, a queima e o aterramento de resíduos, bem como a proliferação de pragas e doenças. Apesar de ser uma atividade básica, muitos municípios brasileiros enfrentam dificuldades para implantar a coleta convencional ou para ampliar a área de abrangência da coleta dentro do município.

Na RIDE-DF, observou-se que a abrangência da coleta convencional no município de Padre Bernardo (GO) diminuiu. Em 2011 toda a população urbana era atendida pela coleta, o que correspondia a 38,9\% da população total do município. Em 2014 apenas 21,24\% da população foi atendida. A quantidade coletada de RSUs caiu pela metade neste intervalo, o que pode indicar problemas no gerenciamento dos RSUs no município (vide Tabela 3.2, a 
seguir).

Tabela 3.2 - A coleta convencional no município de Padre Bernardo, Goiás.

\begin{tabular}{|c|c|c|c|c|c|c|c|c|}
\hline \multirow[t]{2}{*}{ Cidade } & \multicolumn{2}{|c|}{ População total } & \multicolumn{2}{|c|}{$\begin{array}{l}\text { População urbana } \\
\text { (\%) }\end{array}$} & \multicolumn{2}{|c|}{$\begin{array}{l}\text { População atendida } \\
\text { pela coleta } \\
\text { convencional (\%) }\end{array}$} & \multicolumn{2}{|c|}{ RSU coletado } \\
\hline & 2011 & 2014 & 2011 & 2014 & 2011 & 2014 & 2011 & 2014 \\
\hline $\begin{array}{l}\text { Padre } \\
\text { Bernardo } \\
\text { (GO) }\end{array}$ & 28.144 & 30.599 & 38,97 & 38,9784 & 38,97 & 21,24 & $9.864,00$ & $4.745,00$ \\
\hline
\end{tabular}

Fonte: Adaptado a partir de dados do SNIS (2016).

\section{MATERIAIS E MÉTODOS}

Local de estudo: localidades que realizam a Coleta Seletiva

Na Região Integrada de Desenvolvimento do Distrito Federal e Entorno (RIDE-DF), o Distrito Federal e sete municípios declararam realizar a Coleta Seletiva (CS) de Resíduos Sólidos Urbanos (RSUs) no ano de 2014. Apesar de declarar que há coleta seletiva na cidade, o município de Unaí, Minas Gerais (MG) não forneceu dados referentes à quantidade de resíduos reciclados sendo, assim, excluído do estudo sobre a CS. 


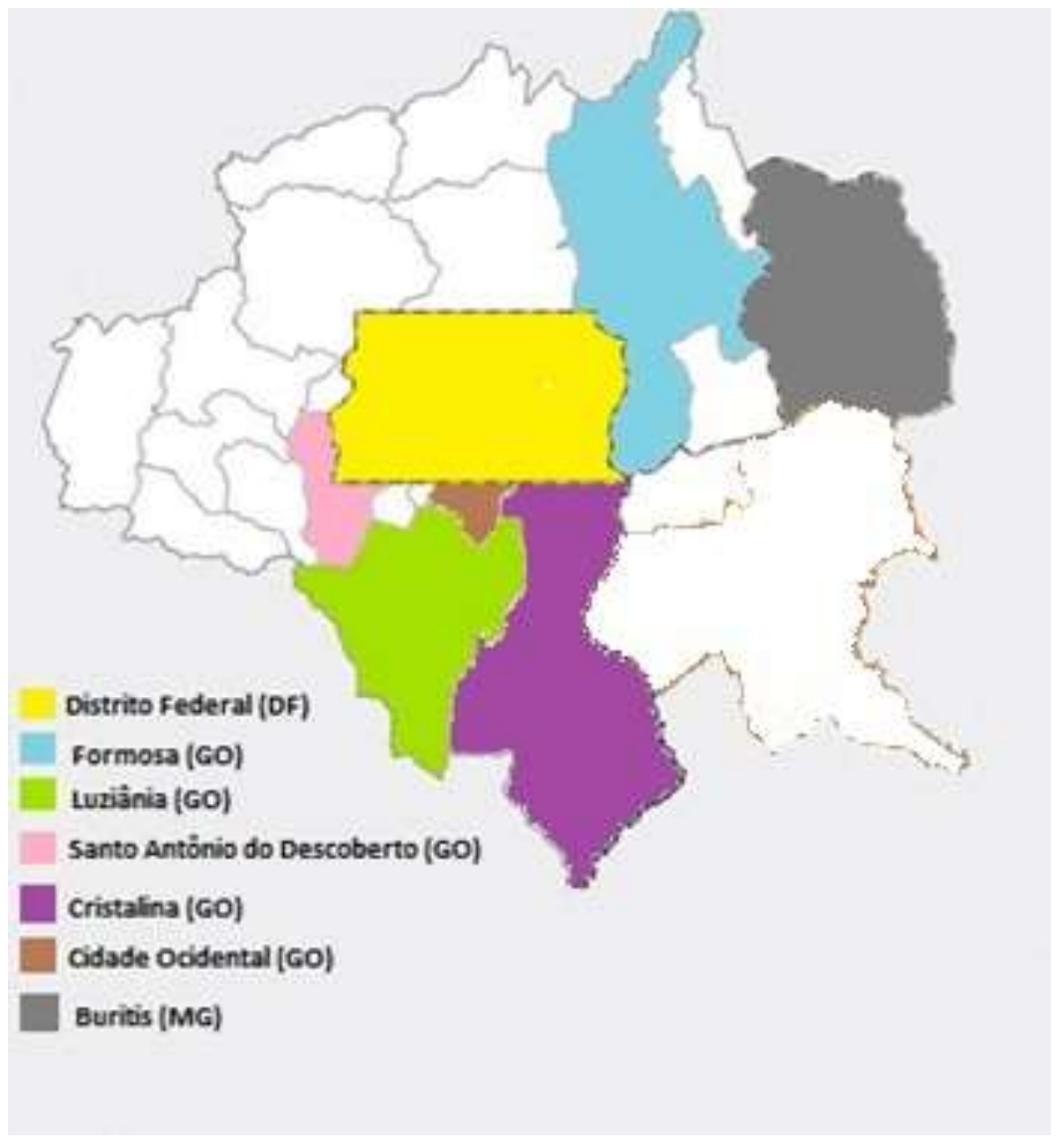

Figura 3.1 - Localidades da Região Integrada de Desenvolvimento do Distrito Federal e Entorno que declararam realizar Coleta Seletiva (2014).

Fonte: Adaptado de Cordeiro e França (2012) e SNIS (2014).

Índices de sustentabilidade da Coleta Seletiva

A CS foi avaliada a partir de dois índices de sustentabilidade com o intuito de verificar se indicadores diferentes apresentariam resultados similares ou distintos quando aplicados para o mesmo local. Os índices utilizados foram desenvolvidos por Besen (2011) e Fechine (2014). Os dados utilizados fazem parte da série histórica do SNIS e são referentes à CS realizada no ano de 2014.

O índice de sustentabilidade elaborado por Besen (2011) é composto por duas matrizes. A matriz de sustentabilidade para a CS, que foi utilizada, aborda 14 indicadores. 


\begin{tabular}{|c|c|c|c|c|c|c|}
\hline \multirow{2}{*}{ Ordem } & \multirow{2}{*}{ Item } & \multicolumn{3}{|c|}{ Tendência à sustentabilidade } & \multirow{2}{*}{ Peso } & \multirow{2}{*}{ Valor } \\
\hline & & Alta $(1,0)$ & Média $(0,5)$ & Baixa $(0,0)$ & & \\
\hline 1 & $\begin{array}{l}\text { Adesão da } \\
\text { população }\end{array}$ & $\geq 80 \%$ & $40,1-79,9 \%$ & $\leq 40 \%$ & 0,91 & \\
\hline 2 & $\begin{array}{l}\text { Atendimento da } \\
\text { população }\end{array}$ & $80-100 \%$ & $40,1-79,9 \%$ & $\leq 40 \%$ & 0,90 & \\
\hline 3 & $\begin{array}{l}\text { Taxa de recuperação } \\
\text { de recicláveis - } \\
\text { TRMR }\end{array}$ & $\geq 20 \%$ & $10,1-19,9 \%$ & $\leq 10 \%$ & 0,89 & \\
\hline 4 & Taxa de rejeito & $\leq 10 \%$ & $10,1-29,9 \%$ & $>30 \%$ & 0,87 & \\
\hline 5 & $\begin{array}{l}\text { Condições de } \\
\text { trabalho }\end{array}$ & $80-100 \%$ & $50,1-79,9 \%$ & $\leq 50 \%$ & 0,84 & \\
\hline 6 & $\begin{array}{l}\text { Instrumentos legais } \\
\text { na relação com org. } \\
\text { de catadores }\end{array}$ & $\begin{array}{l}\text { Contrato ou convênio } \\
\text { remunerado }\end{array}$ & $\begin{array}{c}\text { Convênio } \\
\text { sem } \\
\text { remuneração }\end{array}$ & $\begin{array}{l}\text { Não há } \\
\text { contrato ou } \\
\text { convênio } \\
\end{array}$ & 0,83 & \\
\hline 7 & $\begin{array}{l}\text { Custo do } \\
\text { serviço/quantidade } \\
\text { seletiva }\end{array}$ & $\leq \mathrm{R} \$ 175,00 / \mathrm{t}$ & $\begin{array}{l}\mathrm{R} \$ 170,01- \\
\mathrm{R} \$ 350,00\end{array}$ & $\geq \mathrm{R} \$ 350,00$ & 0,82 & \\
\hline 8 & $\begin{array}{l}\text { Custo da coleta } \\
\text { seletiva/regular + } \\
\text { destinação final }\end{array}$ & $\leq 50 \%$ & $501-199,9 \%$ & $\geq 200 \%$ & 0,81 & \\
\hline 9 & Autofinanciamento & $80-100 \%$ & $50,1-79,9 \%$ & $\leq 50 \%$ & 0,80 & \\
\hline 10 & Educação/divulgação & Permanente/Quinzenal/Mensal & $\begin{array}{c}\text { Bimestral e } \\
\text { Trimestral }\end{array}$ & Anual/pontual & 0,79 & \\
\hline 11 & $\begin{array}{l}\text { Custo da } \\
\text { coleta/manejo de } \\
\text { resíduos sólidos }\end{array}$ & $\leq 50 \%$ & $50,1-74,9 \%$ & $\geq 75 \%$ & 0,78 & \\
\hline 12 & $\begin{array}{l}\text { Inclusão de } \\
\text { catadores avulsos }\end{array}$ & $80-100 \%$ & $50,1-79,9 \%$ & $\leq 50 \%$ & 0,74 & \\
\hline 13 & $\begin{array}{l}\text { Gestão } \\
\text { compartilhada }\end{array}$ & Existe e funciona & $\begin{array}{l}\text { Existe, mas } \\
\text { não funciona }\end{array}$ & Não existe & 0,73 & \\
\hline 14 & Parcerias & $80-100 \%$ & $50,1-79,9 \%$ & $\leq 50 \%$ & 0,72 & \\
\hline
\end{tabular}

Quadro 3.2 - Matriz de indicadores de sustentabilidade para a Coleta Seletiva.

Fonte: Besen (2011).

As notas para cada indicador são definidas de acordo com a seguinte fórmula:

Valor Final $=$ Peso $\times$ Valor da tendência à sustentabilidade

Onde: Alta $=1 ;$ Média $=0,5 ;$ Baixa $=0$.

Equação 3.1 - Cálculo das notas para cada indicador.

Fonte: Da autora.

O resultado final obtido é avaliado segundo a Figura 3.2, a seguir. 


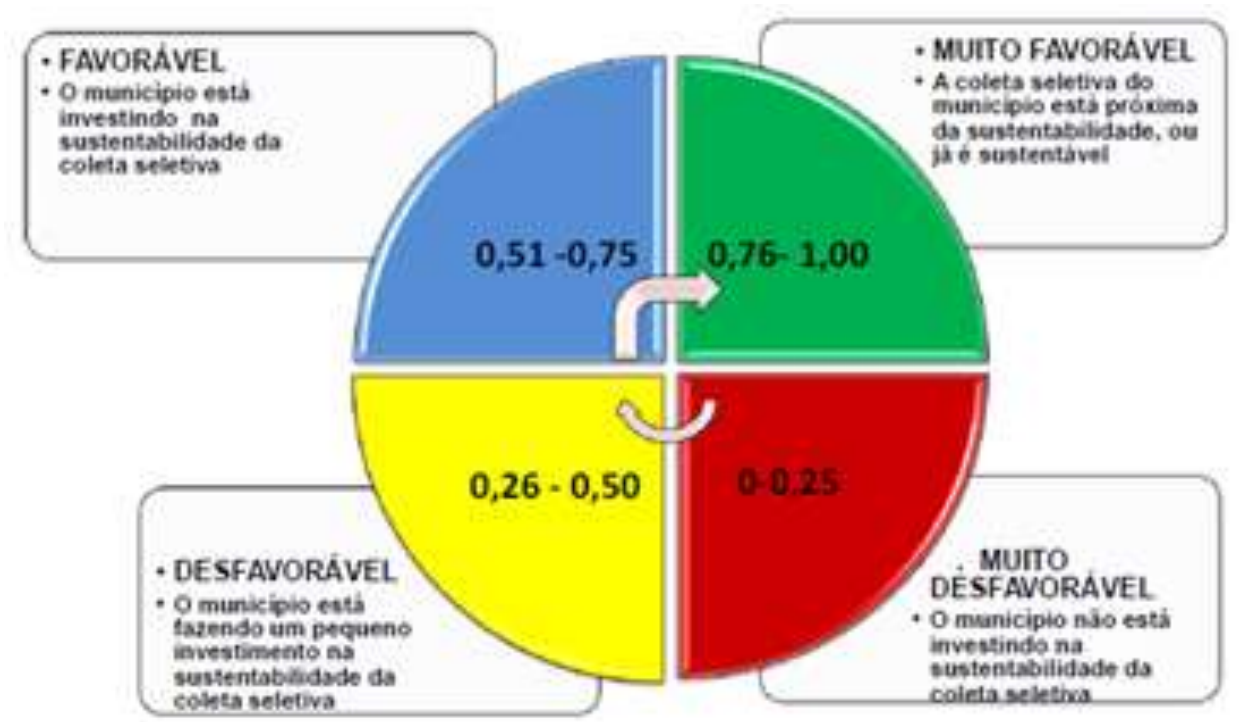

Figura 3.2 - Avaliação da tendência à sustentabilidade (radar da sustentabilidade) da Coleta Seletiva. Fonte: Besen (2011).

O índice elaborado por Fechine (2014) é composto por quatro matrizes, totalizando 22 indicadores. Cada matriz é utilizada para avaliar uma dimensão da CS: Institucional/Operacional; Econômica; Ambiental; Sociocultural. 


\begin{tabular}{|c|c|c|c|c|}
\hline Ordem & Indicadores & Forma de apuração & $\begin{array}{c}\text { Tendência à } \\
\text { Sustentabilidade }\end{array}$ & Nota \\
\hline \multirow[t]{3}{*}{1} & \multirow[t]{3}{*}{ Gestão compartilhada. } & \multirow{3}{*}{$\begin{array}{l}\text { Existência de } \\
\text { instrumentos/instâncias de } \\
\text { participação efetiva da } \\
\text { sociedade. }\end{array}$} & T1 - existe e funciona. & 5 \\
\hline & & & $\begin{array}{l}\text { T2 - existe, mas não funciona } \\
\text { ou funciona de forma } \\
\text { inadequada. }\end{array}$ & 2 \\
\hline & & & T3 - não existe. & 1 \\
\hline \multirow[t]{3}{*}{2} & \multirow[t]{3}{*}{ Marco legal no município. } & \multirow{3}{*}{$\begin{array}{l}\text { Possui Plano Municipal de } \\
\text { Gestão Integrada de } \\
\text { Resíduos Sólidos que } \\
\text { contemple a coleta seletiva? }\end{array}$} & $\begin{array}{l}\text { T1 - sim, com projetos e } \\
\text { ações propostos sendo } \\
\text { implementados. }\end{array}$ & 5 \\
\hline & & & $\begin{array}{l}\text { T2 - sim, elaborado, mas não } \\
\text { implementado ou em } \\
\text { processo de elaboração. }\end{array}$ & 2 \\
\hline & & & T3 - não possui. & 1 \\
\hline \multirow[t]{3}{*}{3} & \multirow{3}{*}{$\begin{array}{l}\text { Instrumentos legais na } \\
\text { relação com as org. de } \\
\text { catadores. }\end{array}$} & \multirow[t]{3}{*}{$\begin{array}{l}\text { Atendimento aos requisitos } \\
\text { legais de contratação. }\end{array}$} & $\begin{array}{l}\text { T1 - contrato ou convênio } \\
\text { com remuneração. }\end{array}$ & 5 \\
\hline & & & $\begin{array}{l}\text { T2 - convênio sem } \\
\text { remuneração. }\end{array}$ & 3 \\
\hline & & & T3 - inexistência de ambos. & 1 \\
\hline \multirow[t]{3}{*}{4} & \multirow{3}{*}{$\begin{array}{l}\text { Percentual de pessoas } \\
\text { atendidas pela coleta } \\
\text { seletiva. }\end{array}$} & \multirow{3}{*}{$\begin{array}{l}\text { ( } \mathrm{n}^{\circ} \text { de habitantes urbanos } \\
\text { atendidos pela coleta } \\
\text { seletiva)/(no total de } \\
\text { habitantes urbanos do } \\
\text { município) } \times 100 \text {. }\end{array}$} & T1 - 80 a $100 \%$. & 5 \\
\hline & & & T2 - 40,1 a $79,9 \%$. & 3 \\
\hline & & & T3 $-\leq 40 \%$ & 1 \\
\hline \multirow[t]{3}{*}{5} & \multirow{3}{*}{$\begin{array}{l}\text { Área de abrangência do } \\
\text { serviço de coleta seletiva. }\end{array}$} & \multirow{3}{*}{$\begin{array}{l}\text { Qual a abrangência da } \\
\text { coleta seletiva no município. }\end{array}$} & T1 - todo o município. & 5 \\
\hline & & & T2 - em toda a área urbana. & 4 \\
\hline & & & T3 - em parte da área urbana. & 1 \\
\hline \multirow[t]{3}{*}{6} & \multirow{3}{*}{$\begin{array}{l}\text { Parcerias entre as } \\
\text { organizações. }\end{array}$} & \multirow{3}{*}{$\begin{array}{l}\text { Tipo de parceria entre as } \\
\text { organizações. }\end{array}$} & T1 - apoio continuado. & 5 \\
\hline & & & $\begin{array}{l}\text { T2 - orientador com prazo } \\
\text { determinado. }\end{array}$ & 3 \\
\hline & & & T3 - assistencialista. & 1 \\
\hline
\end{tabular}

Quadro 3.3 - Matriz para a Dimensão Institucional/Operacional.

Fonte: Fechine (2014). 


\begin{tabular}{|c|c|c|c|c|}
\hline Ordem & Indicadores & Forma de apuração & $\begin{array}{c}\text { Tendência à } \\
\text { Sustentabilidade }\end{array}$ & Nota \\
\hline \multirow[t]{3}{*}{7} & \multirow{3}{*}{$\begin{array}{l}\text { Custo total do programa } \\
\text { em relação à quantidade } \\
\text { coletada seletivamente - } \\
\mathrm{R} \$ / \mathrm{t} \text {. }\end{array}$} & \multirow{3}{*}{$\begin{array}{l}\text { (custo total com coleta } \\
\text { seletiva incluindo } \\
\text { triagem)/(quantidade } \\
\text { coletada pela coletada } \\
\text { seletivamente. }\end{array}$} & $\mathrm{T} 1-\leq \mathrm{R} \$ 250,00 / \mathrm{t}$ & 5 \\
\hline & & & $\begin{array}{l}\text { T2 - Entre } R \$ 250,00 \text { a } R \$ \\
500,00\end{array}$ & 3 \\
\hline & & & $\mathrm{T} 3-\geq \mathrm{R} \$ 500,00$ & 1 \\
\hline \multirow[t]{4}{*}{8} & \multirow{4}{*}{$\begin{array}{l}\text { Percentual de } \\
\text { autofinanciamento da } \\
\text { coleta seletiva - \%. }\end{array}$} & \multirow{4}{*}{$\begin{array}{l}\text { (custo total da coleta seletiva } \\
\text { incluindo } \\
\text { triagem)/(arrecadação da } \\
\text { taxa de lixo ou recurso do } \\
\text { IPTU e preço público } \\
\text { cobrado de grandes } \\
\text { geradores)x100. }\end{array}$} & T1 - 75 a $100 \%$ & 5 \\
\hline & & & T2 - 50,1 a $74,9 \%$ & 4 \\
\hline & & & T3 - 25 a $49,9 \%$ & 3 \\
\hline & & & $\mathrm{T} 4-<25 \%$ & 1 \\
\hline \multirow[t]{3}{*}{9} & \multirow{3}{*}{$\begin{array}{l}\text { Custo da coleta seletiva } \\
\text { em relação à coleta regular } \\
\text { e disposição final } \\
\text { adequada - \%. }\end{array}$} & \multirow{3}{*}{$\begin{array}{l}\text { (custo total com coleta } \\
\text { seletiva)/(custo da coleta } \\
\text { regular e disposição final } \\
\text { adequada)x100. }\end{array}$} & $\mathrm{T} 1-\leq 50 \%$ & 5 \\
\hline & & & T2 - 50,1 a $199,9 \%$ & 3 \\
\hline & & & T3 - $\geq 200 \%$ & 1 \\
\hline \multirow[t]{4}{*}{10} & \multirow{4}{*}{$\begin{array}{l}\text { Custo da coleta seletiva } \\
\text { em relação aos custos com } \\
\text { limpeza urbana e manejo } \\
\text { de resíduos sólidos - \%. }\end{array}$} & \multirow{4}{*}{$\begin{array}{l}\text { (custo total com coleta } \\
\text { seletiva)/(custo com limpeza } \\
\text { urbana e manejo de } \\
\text { resíduos sólidos)x } 100 \text {. }\end{array}$} & $\mathrm{T} 1-\leq 25 \%$ & 5 \\
\hline & & & T2 - 25,1 a $50 \%$ & 4 \\
\hline & & & T3 - 50,1 a $74,9 \%$ & 2 \\
\hline & & & $\mathrm{T} 4-\geq 75 \%$ & 1 \\
\hline \multirow[t]{3}{*}{11} & \multirow{3}{*}{$\begin{array}{l}\text { Aplicação dos recursos } \\
\text { financeiros provenientes da } \\
\text { coleta seletiva. }\end{array}$} & \multirow{3}{*}{$\begin{array}{l}\text { Forma de aplicação dos } \\
\text { recursos financeiros } \\
\text { provenientes da coleta } \\
\text { seletiva. }\end{array}$} & $\begin{array}{l}\text { T1 - na própria manutenção } \\
\text { da coleta seletiva }\end{array}$ & 5 \\
\hline & & & $\begin{array}{l}\text { T2 - atividades socioculturais } \\
\text { e assistenciais }\end{array}$ & 4 \\
\hline & & & $\begin{array}{l}\text { T3 - outra destinação (saúde, } \\
\text { educação e prevenção de } \\
\text { acidentes) }\end{array}$ & 1 \\
\hline
\end{tabular}

Quadro 3.4 - Matriz para a Dimensão Econômica.

Fonte: Fechine (2014). 


\begin{tabular}{|c|c|c|c|c|}
\hline Ordem & Indicadores & Forma de apuração & $\begin{array}{c}\text { Tendência à } \\
\text { Sustentabilidade }\end{array}$ & Nota \\
\hline \multirow[t]{3}{*}{12} & \multirow{3}{*}{$\begin{array}{l}\text { Massa per capita anual } \\
\text { recuperada - kg/hab. }\end{array}$} & \multirow{3}{*}{$\begin{array}{l}\text { (massa total de materiais } \\
\text { recicláveis } \\
\text { recuperados)/(população } \\
\text { urbana). }\end{array}$} & $\mathrm{T} 1->15 \mathrm{~kg} / \mathrm{hab} . \mathrm{ano}$ & 5 \\
\hline & & & T2 - 7 a 15 kg/hab.ano & 3 \\
\hline & & & T3 - < 7 kg/hab.ano & 1 \\
\hline \multirow[t]{3}{*}{13} & \multirow{3}{*}{$\begin{array}{l}\text { Massa per capita coletada } \\
\text { seletivamente - } \\
\text { kg/hab.ano. }\end{array}$} & \multirow{3}{*}{$\begin{array}{l}\text { (quantidade total recolhida } \\
\text { pela coleta } \\
\text { seletiva)/(população urbana). }\end{array}$} & $\mathrm{T} 1$ - > $21 \mathrm{~kg} / \mathrm{hab} . \mathrm{ano}$ & 5 \\
\hline & & & T2 - 10 a 21 kg/hab.ano & 3 \\
\hline & & & T3 $-<10$ kg/hab.ano & 1 \\
\hline \multirow[t]{3}{*}{14} & \multirow[t]{3}{*}{ Taxa de rejeitos - \%. } & \multirow{3}{*}{$\begin{array}{l}\text { (massa coletada } \\
\text { seletivamente - massa } \\
\text { recuperada)/(quantidade da } \\
\text { coleta seletiva)x100. }\end{array}$} & $\mathrm{T} 1-\leq 10 \%$ & 5 \\
\hline & & & T2 - 10,1 a $19,90 \%$ & 3 \\
\hline & & & T3 - $\geq 20 \%$ & 1 \\
\hline \multirow[t]{4}{*}{15} & \multirow{4}{*}{$\begin{array}{l}\text { Taxa de material recolhido } \\
\text { nos } \\
\text { PEVs em relação à massa } \\
\text { coletada seletivamente - } \\
\% \text {. }\end{array}$} & \multirow{4}{*}{$\begin{array}{l}\text { (massa recolhida nos } \\
\mathrm{PEVs} /(\text { quantidade coleta } \\
\text { seletivamente) } \times 100 .\end{array}$} & $\mathrm{T} 1->40 \%$ & 5 \\
\hline & & & T2 - 20 a $40 \%$ & 3 \\
\hline & & & T3 $-<20 \%$ & 2 \\
\hline & & & $\begin{array}{l}\text { T4 - não possui PEV ou } \\
\text { desativados }\end{array}$ & 1 \\
\hline \multirow[t]{3}{*}{16} & \multirow{3}{*}{$\begin{array}{l}\text { Taxa de recuperação de } \\
\text { materiais recicláveis em } \\
\text { relação à quantidade total } \\
\text { (RDO+RPU) coletada - \%. }\end{array}$} & \multirow{3}{*}{$\begin{array}{l}\text { (massa coletada } \\
\text { seletivamente-massa de } \\
\text { rejeitos)/(massa coletada } \\
\text { seletivamente + massa de } \\
\text { coleta regular) } \times 100 .\end{array}$} & $\mathrm{T} 1->11 \%$ & 5 \\
\hline & & & $\mathrm{T} 2-5,1$ a $10 \%$ & 3 \\
\hline & & & T3 - até $5 \%$ & 1 \\
\hline
\end{tabular}

Quadro 3.5 - Matriz para a Dimensão Ambiental.

Fonte: Fechine (2014). 


\begin{tabular}{|c|c|c|c|c|}
\hline Ordem & Indicadores & Forma de apuração & $\begin{array}{c}\text { Tendência à } \\
\text { Sustentabilidade }\end{array}$ & Nota \\
\hline \multirow[t]{3}{*}{17} & \multirow[t]{3}{*}{ Adesão da população - \%. } & \multirow{3}{*}{$\begin{array}{l}(\mathrm{n} \text { o de residências que } \\
\text { participa do programa)/(no } \\
\text { de residências atendidas } \\
\text { pelo programa) } \times 100\end{array}$} & $\mathrm{~T} 1->80 \%$ & 5 \\
\hline & & & T2 - 40,1 a $79,9 \%$ & 4 \\
\hline & & & $\mathrm{T} 3-\leq 40 \%$ & 1 \\
\hline \multirow[t]{3}{*}{18} & \multirow[t]{3}{*}{$\begin{array}{l}\text { Programas de educação e } \\
\text { divulgação. }\end{array}$} & \multirow[t]{3}{*}{$\begin{array}{l}\text { Frequência das atividades } \\
\text { desenvolvidas. }\end{array}$} & $\begin{array}{l}\text { T1 - permanente, quinzenal, } \\
\text { mensal }\end{array}$ & 5 \\
\hline & & & T2 - bi ou trimestral & 3 \\
\hline & & & T3 - anual ou esporádica & 1 \\
\hline \multirow[t]{3}{*}{19} & \multirow{3}{*}{$\begin{array}{l}\text { Inclusão de catadores } \\
\text { avulsos - \%. }\end{array}$} & \multirow{3}{*}{$\begin{array}{l}\text { ( } \mathrm{n}^{\circ} \text { de catadores avulsos } \\
\text { incluídos no programa de } \\
\text { coleta seletiva)/( } \mathrm{n}^{\circ} \text { total de } \\
\text { catadores avulsos } \\
\text { existentes) } \times 100 \text {. }\end{array}$} & T1 - 80 a $100 \%$ & 5 \\
\hline & & & T2 - 50,1 a $79,9 \%$ & 4 \\
\hline & & & $\mathrm{T} 3-\leq 50 \%$ & 2 \\
\hline \multirow[t]{3}{*}{20} & \multirow[t]{3}{*}{$\begin{array}{l}\text { Renda média mensal nas } \\
\text { cooperativas - } R \$ \text {. }\end{array}$} & \multirow{3}{*}{$\begin{array}{l}\text { Valor médio pago aos } \\
\text { catadores organizados em } \\
\text { cooperativas. }\end{array}$} & $\begin{array}{l}\text { T1 - Acima de } 1 \text { salário } \\
\text { mínimo (SM }\end{array}$ & 5 \\
\hline & & & T2 - Entre 0,5 e $1 \mathrm{SM}$ & 3 \\
\hline & & & $\mathrm{T} 3-<0,5 \mathrm{SM}$ & 1 \\
\hline \multirow[t]{3}{*}{21} & \multirow{3}{*}{$\begin{array}{l}\text { Participação de catadores } \\
\text { nas ações de coleta } \\
\text { seletiva. }\end{array}$} & \multirow{3}{*}{$\begin{array}{l}\text { Forma de participação dos } \\
\text { catadores nas ações de } \\
\text { coleta seletiva. }\end{array}$} & $\begin{array}{l}\text { T1 - organizados em } \\
\text { cooperativas ou associações }\end{array}$ & 5 \\
\hline & & & T2 - isolada (individual) & 3 \\
\hline & & & $\begin{array}{l}\text { T3 - outra (grupos de } \\
\text { tamanhos diversos, mas sem } \\
\text { associação) }\end{array}$ & 1 \\
\hline \multirow[t]{3}{*}{22} & \multirow{3}{*}{$\begin{array}{l}\text { Existência de cooperativas } \\
\text { ou associações no } \\
\text { município - coop./hab. }\end{array}$} & \multirow{3}{*}{$\begin{array}{l}\mathrm{n} 0 \text { de cooperativas ou } \\
\text { associações de } \\
\text { catadores } / 106 \text {. }\end{array}$} & $\mathrm{T} 1->35$ & 5 \\
\hline & & & T2 - entre 15 e 34 & 3 \\
\hline & & & T3 $-<15$ & 1 \\
\hline
\end{tabular}

Quadro 3.6 - Matriz para a Dimensão Sociocultural.

Fonte: Fechine (2014).

\begin{tabular}{|c|c|}
\hline Intervalo & Grau de Sustentabilidade (GS) \\
\hline 0 a 2,5 & Insustentável \\
\hline 2,6 a 5,0 & Baixa sustentabilidade \\
\hline 5,1 a 7,5 & Média sustentabilidade \\
\hline 7,6 a 10 & Alta sustentabilidade \\
\hline
\end{tabular}

Quadro 3.7 - Grau de sustentabilidade da coleta seletiva.

Fonte: Fechine (2014).

\section{RESULTADOS E DISCUSSÃO}

Observou-se que os municípios de Cristalina, Goiás (GO), Santo Antônio do Descoberto (GO) e Buritis, Minas Gerais (MG) possuem iniciativas de Coleta Seletiva (CS), sem a existência de programas consolidados de CS. As peculiaridades dos programas 
existentes nas outras localidades, objeto de estudo, são abordadas a seguir.

Distrito Federal

Embora o Distrito Federal (DF) declare ao SNIS a realização da CS desde 2002, observou-se que esta declaração se refere a uma pequena parcela dos Resíduos Sólidos Urbanos (RSUs) que foram reciclados, sem haver, no entanto, um programa estruturado de CS durante todo o intervalo (2002 a 2014).

Em 2014 um novo sistema de CS foi implantado no DF. A CS é realizada porta-a-porta por duas empresas contratadas pelo Serviço de Limpeza Urbana (SLU): a Quebec e a Valor Ambiental. O caminhão da CS possui rota definida de acordo com os lotes. A frequência da coleta porta-a-porta varia de 1 a 3 dias na semana.

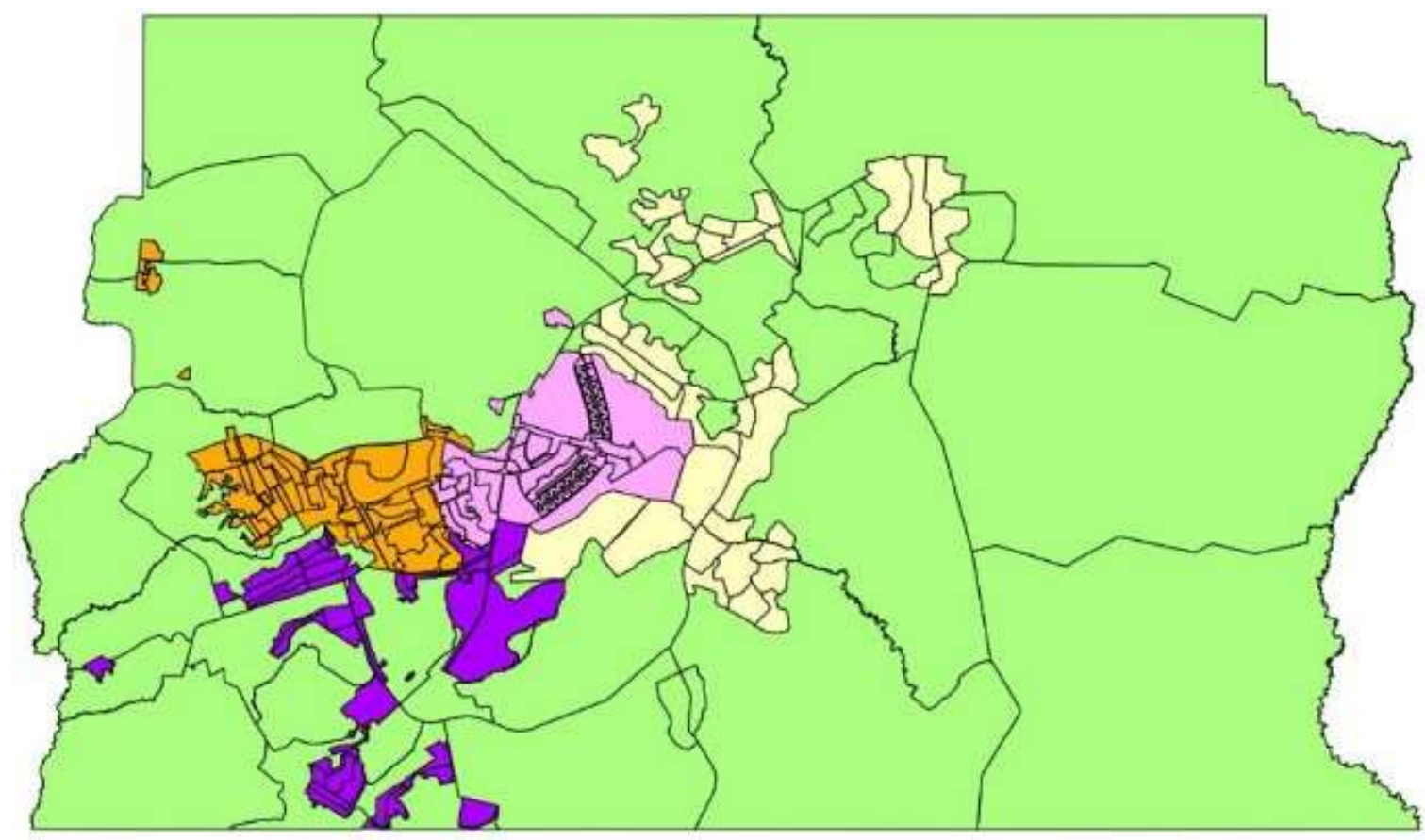

Legenda:

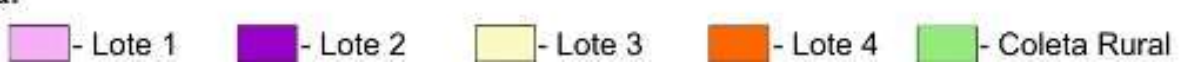

Figura 3.3 - Rota da Coleta Seletiva no Distrito Federal.

Fonte: Distrito Federal (2015).

Os lotes compreendem as 31 Regiões Administrativas (RAs) do DF. Além dos lotes, o SLU expandiu a coleta seletiva para a área rural. No entanto, no final de 2015, a CS foi suspensa em nove RAs do DF (Candangolândia, Gama, Núcleo Bandeirante, Park Way (a partir da Quadra 6), Recanto das Emas, Riacho Fundo I e II, Samambaia e Santa Maria). A suspensão do serviço foi justificada pelo SLU como um processo de análise da operação 
para aprimorar a CS nestas áreas.

Segundo o SLU (DISTRITO FEDERAL, 2015), havia 34 entidades de catadores de materiais reciclados no DF (Quadro 12). O referido órgão aponta que a maioria das organizações listadas não segue diretrizes de associativismo e cooperativismo. O DF conta com quatro centros de triagem dos resíduos sólidos para a reciclagem de materiais e para a compostagem dos resíduos orgânicos. 


\begin{tabular}{|c|c|c|c|c|c|c|c|}
\hline Ordem & Instituição & Endereço & \multicolumn{2}{|c|}{ Contato } & Equipamento & Terreno & $\begin{array}{l}\text { Número de } \\
\text { Catadores }\end{array}$ \\
\hline \multicolumn{8}{|c|}{ Brasília } \\
\hline 1 & APCORB & $\begin{array}{l}\text { Usina do } \\
\text { SLU/NUIREL SUL } \\
\text { - L4 SUL }\end{array}$ & Alessandra & $8508-2071$ & $\begin{array}{l}3 \text { prensas, } 1 \\
\text { esteira vide CDT }\end{array}$ & $\begin{array}{l}\text { Usina Asa Sul e } \\
\text { Galpão só cobertura e } \\
\text { piso SLU de } 1.350 \mathrm{~m}^{2}\end{array}$ & 98 \\
\hline 2 & RECICLA BRASÍLIA & $\begin{array}{l}\text { SGON Q. } 05 \text { Lote } \\
23 \text { DL NORTE }\end{array}$ & Roque & $8562-8447$ & $\begin{array}{l}1 \text { prensa, } 1 \\
\text { caminhão vide } \\
\text { CDT }\end{array}$ & Galpão SLU 700m² & 35 \\
\hline 3 & ACAPAS & $\begin{array}{l}\text { SGON Q. } 05 \text { Lote } \\
23 \text { DL NORTE }\end{array}$ & Luzia & $9964-9567$ & 1 caminhão & Galpão SLU 700m² & 25 \\
\hline 4 & ACOPLANO & $\begin{array}{l}\text { SCIA Q. } 13 \text { Cj. } 3 \\
\text { Lote } 9 \text { Cidade do } \\
\text { Automóvel }\end{array}$ & Socorro & $8434-8831$ & sem equipamentos & $\begin{array}{l}\text { Galpão fechado } \\
\text { SEDEST Cid. do } \\
\text { Automóvel }\end{array}$ & 8 \\
\hline 5 & AGEPLAN & $\begin{array}{l}\text { UnB próximo às } \\
\text { tendas }\end{array}$ & Francisco & $8170-5587$ & vide CDT & $\begin{array}{l}\text { área sedida pela UnB } \\
\text { de } 400 \mathrm{~m}^{2}\end{array}$ & 35 \\
\hline 6 & CRV & $\begin{array}{l}\text { Q. } 02 \text { Cnj. D } \\
\text { Varjão }\end{array}$ & Ana Carla & $9280-5328$ & sem equipamentos & $\begin{array}{l}\text { Galpão fechado RA } \\
\text { Varjão } 510 \mathrm{~m}^{2}\end{array}$ & 25 \\
\hline 7 & COOPERE & $\begin{array}{l}\text { Estrutural - Aterrro } \\
\text { do Jóquei }\end{array}$ & Adriana & $9636-3498$ & $\begin{array}{l}\text { sem equipamentos } \\
\text { vide CDT }\end{array}$ & Aterro do Jóquei & 300 \\
\hline 8 & AMBIENTE & $\begin{array}{l}\text { Estrutural - Aterrro } \\
\text { do Jóquei }\end{array}$ & Ana Cláudia & $8627-0863$ & $\begin{array}{l}3 \text { prensas e } 1 \\
\text { esteira vide CDT }\end{array}$ & Aterro do Jóquei & 600 \\
\hline 9 & PLASFERRO & $\begin{array}{l}\text { Estrutural - Aterrro } \\
\text { do Jóquei }\end{array}$ & Moisés & $3464-6785$ & $\begin{array}{l}1 \text { prensa e } 1 \\
\text { caminhão vide } \\
\text { CDT }\end{array}$ & Aterro do Jóquei & 25 \\
\hline 10 & COORACE & $\begin{array}{l}\text { Estrutural - Aterrro } \\
\text { do Jóquei }\end{array}$ & Lúcia & $8142-0067$ & $\begin{array}{l}2 \text { prensas e } 1 \\
\text { caminhão vide } \\
\text { CDT }\end{array}$ & Aterro do Jóquei & 300 \\
\hline 11 & CONSTRUIR & $\begin{array}{l}\text { Estrutural - Aterrro } \\
\text { do Jóquei }\end{array}$ & Conceição & $9397-7173$ & vide CDT & Aterro do Jóquei & 200 \\
\hline 12 & COOPERNOES & $\begin{array}{l}\text { Estrutural - Aterrro } \\
\text { do Jóquei }\end{array}$ & Alex & $8154-4768$ & $\begin{array}{l}1 \text { prensa e } 1 \\
\text { caminhão vide } \\
\text { CDT }\end{array}$ & Aterro do Jóquei & 20 \\
\hline
\end{tabular}

Quadro 3.8 - Organizações de catadores de materiais recicláveis no Distrito Federal (continua). 


\begin{tabular}{|c|c|c|c|c|c|c|c|}
\hline Ordem & Instituição & Endereço & \multicolumn{2}{|c|}{ Contato } & Equipamento & Terreno & $\begin{array}{l}\text { Número de } \\
\text { Catadores }\end{array}$ \\
\hline \multicolumn{8}{|c|}{ Brasília } \\
\hline 13 & COOPATIVA & $\begin{array}{l}\text { S.I.A Trecho } 17 \text { via } \\
\text { I } 4 \text { It } 1660 / 1700\end{array}$ & Edson & $9248-6050$ & vide CDT & $\begin{array}{l}\text { Galpão só cobertura } \\
\text { GDF } 1.500 \mathrm{~m}^{2}\end{array}$ & 30 \\
\hline 14 & COORTRAP & $\begin{array}{l}\text { SCIA Q. } 09 \text { Cj. } 01 \\
\text { Lote } 02 \text { Cid. do } \\
\text { Automóvel }\end{array}$ & José Carlos & $9331-7561$ & $\begin{array}{l}1 \text { prensa, } 1 \\
\text { caminhão, } \\
\text { mesas vide CDT }\end{array}$ & $\begin{array}{l}\text { Galpão fechado próprio } \\
1.500 \mathrm{~m}^{2}\end{array}$ & 25 \\
\hline 15 & RENASCER & $\begin{array}{l}\text { Cid. Automóvel e } \\
\text { Torre Digital }\end{array}$ & Bernardino & $8566-3657$ & sem equipamentos & sem área & 20 \\
\hline 16 & ARCAN & $\begin{array}{l}\text { QR AO Cj. VC AE- } \\
\text { atrás C. Bomb. } \\
\text { Candang. }\end{array}$ & Moisés & $3301-8681$ & 1 prensa & $\begin{array}{l}\text { área irregular } \\
\text { Candangolândia }\end{array}$ & 12 \\
\hline 17 & SONHO DE LIBERDADE* & Estrutural & Fernando & $9693-6465$ & $\begin{array}{l}\text { triturador, } 1 \\
\text { caminhão }\end{array}$ & $\begin{array}{l}\text { área irregular Estrutural } \\
\text { estrutura em } \\
\text { madeira }\end{array}$ & 100 \\
\hline 18 & COOPERCOCO** & $\begin{array}{l}\text { SCLN } 214 \text { Blc. A } \\
\text { loja } 32 / 34 \text { Asa } \\
\text { Norte }\end{array}$ & José Roberto & $8440-8052$ & $\begin{array}{l}\text { processadores } \\
\text { comprados; falta } \\
\text { instalar }\end{array}$ & $\begin{array}{l}\text { área de } 20.000 \mathrm{~m}^{2} \\
\text { Riacho } \mathrm{F} 1 \mathrm{p} / \\
\text { construção }\end{array}$ & sem registro \\
\hline \multicolumn{8}{|c|}{ Sobradinho } \\
\hline 19 & PLANALTO & $\begin{array}{l}\text { AE Lt } 4 \text { e } 6 \text { - } \\
\text { Distrito SLU }\end{array}$ & Rosival & $8440-8894$ & $\begin{array}{l}1 \text { prensa e } 1 \\
\text { caminhão vide } \\
\text { CDT }\end{array}$ & $\begin{array}{l}\text { Área de Transbordo do } \\
\text { SLU } \\
\text { Sobradinho tendas }\end{array}$ & 45 \\
\hline 20 & COOPERDIFE & $\begin{array}{l}\text { AE Lt } 4 \text { e } 6 \text { - } \\
\text { Distrito SLU }\end{array}$ & Gilmar & $9278-1983$ & $\begin{array}{l}1 \text { prensa, } 1 \text { esteira, } \\
1 \text { Camihão }\end{array}$ & $\begin{array}{l}\text { Área de Transbordo do } \\
\text { SLU Sobradinho } \\
\text { tendas }\end{array}$ & 30 \\
\hline \multicolumn{8}{|c|}{ Riacho Fundo I } \\
\hline 21 & 100 DIMENSÃO & $\begin{array}{l}\text { QN } 16 \text { Conj. } 5 \text { lote } \\
2\end{array}$ & Sônia & $8530-0616$ & $\begin{array}{l}1 \text { prensa módulo } \\
\text { de processamento } \\
\text { p montagem. }\end{array}$ & $\begin{array}{l}3 \text { Galpões fechados } \\
\text { área total } 1.800 \mathrm{~m}^{2}\end{array}$ & sem registro \\
\hline
\end{tabular}

Quadro 3.8 - Organizações de catadores de materiais recicláveis no Distrito Federal (continuação). 


\begin{tabular}{|c|c|c|c|c|c|c|c|}
\hline Ordem & Instituição & Endereço & \multicolumn{2}{|c|}{ Contato } & Equipamento & Terreno & $\begin{array}{l}\text { Número de } \\
\text { Catadores }\end{array}$ \\
\hline \multicolumn{8}{|c|}{ Recanto das Emas } \\
\hline 22 & SUPERAÇÃO & $\begin{array}{l}\text { Qd. } 200 \text { Cj. } 04 \\
\text { Lote } 17 \text { ProdDF }\end{array}$ & Leda & $8431-8921$ & $\begin{array}{l}\text { sem equipamentos } \\
\text { vide CDT }\end{array}$ & $\begin{array}{l}\text { sem área, sem atuação } \\
\text { regular }\end{array}$ & 10 \\
\hline 23 & RECICLO & $\begin{array}{l}\text { Av. Monjolo AE } \\
\text { Complexo Educac. } \\
\text { Cidad. dos } \\
\text { Meninos Q. } 300 \\
\end{array}$ & Nívea & $8569-4581$ & $\begin{array}{l}2 \text { prensas, } 1 \\
\text { balança, } 1 \\
\text { caminhão vide } \\
\text { CDT }\end{array}$ & $\begin{array}{l}\text { Galpão fechado } \\
\text { SEDEST } 220 \mathrm{~m}^{2}\end{array}$ & 20 \\
\hline \multicolumn{8}{|c|}{ Samambaia } \\
\hline 24 & FLOR DO CERRADO & Não informado & Marcos & - & Prensa e caminhão & $\begin{array}{l}\text { Ocupação próxima do } \\
\text { late Clube }\end{array}$ & 28 \\
\hline \multicolumn{8}{|c|}{ Ceilândia } \\
\hline 25 & CATAMARE & $\begin{array}{l}\text { QNR } 03 \text { Cj. G } \\
\text { Casa 15 P Norte }\end{array}$ & Antônia & $9514-5112$ & sem equipamentos & $\begin{array}{l}\text { Galpão fechado } \\
\text { Terracap } 375 m^{2}\end{array}$ & 10 \\
\hline 26 & RECICLE A VIDA & $\begin{array}{l}\text { QNM } 28 \text { Md. B } \\
\text { Ceilândia }\end{array}$ & Cláudia/Taisa & $3373-1810$ & $\begin{array}{l}2 \text { prensas, } 1 \\
\text { caminhão, } 1 \\
\text { empilhadeira, } 1 \\
\text { esteira, }\end{array}$ & $\begin{array}{l}\text { Galpão fechado } \\
\text { SEDEST } 1.000 \mathrm{~m}^{2}\end{array}$ & 134 \\
\hline 27 & APCORC & $\begin{array}{l}\text { QNP } 28 \text { AE Usina } \\
\text { do P Sul }\end{array}$ & Cléia & $3378-6125$ & $\begin{array}{l}2 \text { prensas vide } \\
\text { CDT }\end{array}$ & $\begin{array}{l}\text { Usina P Sul e Galpão } \\
\text { SLU de } 2.500 \mathrm{~m}^{2}\end{array}$ & 115 \\
\hline 28 & CATAGUAR & $\begin{array}{l}\text { QNP } 28 \text { AE Usina } \\
\text { do P Sul }\end{array}$ & Graça & $3585-7742$ & vide CDT & $\begin{array}{l}\text { Usina P Sul e Galpão } \\
\text { SLU de } 2.500 \mathrm{~m}^{2}\end{array}$ & 45 \\
\hline \multicolumn{8}{|c|}{ Brazlândia } \\
\hline 29 & ACOBRAZ & $\begin{array}{l}\text { Vila São José Km } \\
01 \text { (Saída p/ } \\
\text { Rodeador) }\end{array}$ & Marconi & $8597-8964$ & $\begin{array}{l}3 \text { prensas, vide } \\
\text { CDT }\end{array}$ & $\begin{array}{l}\text { Área de transbordo do } \\
\text { SLU Brazlândia Galpão } \\
253 \mathrm{~m}^{2} \text { tendas }\end{array}$ & 25 \\
\hline \multicolumn{8}{|c|}{ Gama } \\
\hline 30 & COOPERFENIX & $\begin{array}{l}\text { QI } 6 \text { It } 460 \text { S. } \\
\text { Indústria - Gama } \\
\text { Leste }\end{array}$ & Raimunda & $3385-3132$ & vide CDT & sem atividade & sem registro \\
\hline
\end{tabular}

Quadro 3.8 - Organizações de catadores de materiais recicláveis no Distrito Federal (continuação). 


\begin{tabular}{|c|c|c|c|c|c|c|c|}
\hline \multicolumn{8}{|c|}{ Santa Maria } \\
\hline 31 & ASTRADASM & $\begin{array}{l}\text { Av. Alagados - ch. } \\
06 \text { - }\end{array}$ & Lindon J. & $9284-8953$ & vide $\mathrm{CDT}$ & $\begin{array}{l}\text { sem registro de } \\
\text { atividade }\end{array}$ & 15 \\
\hline 32 & VIDA NOVA & $\begin{array}{l}\text { QE } 30 \text { Bloco B lj. } \\
15 \text { Guará II }\end{array}$ & Osmero & 8463-3216 & $\begin{array}{l}\text { sem registro de } \\
\text { atividade }\end{array}$ & $\begin{array}{l}\text { sem registro de } \\
\text { atividade }\end{array}$ & 12 \\
\hline \multicolumn{8}{|c|}{ Planaltina } \\
\hline 33 & FUNDAMENTAL & Q. 18 Cj. F Lote 18 & Fernando & $3029-3465$ & $\begin{array}{l}1 \text { prensa, } 1 \\
\text { caminhão vide } \\
\text { CDT }\end{array}$ & Galpão $375 \mathrm{~m}^{2}$ alugado & sem registro \\
\hline 34 & & & & & & & \\
\hline
\end{tabular}

Quadro 3.8 - Organizações de catadores de materiais recicláveis no Distrito Federal (conclusão).

Fonte: Distrito Federal (2015). 
Cidade Ocidental, Goiás

A CS foi implantada no município de Cidade Ocidental, no ano de 2011, a partir de uma parceria entre o governo municipal, a Cooperativa Esperança e a Fundação Alphaville. Antes do início da CS, colaboradores do programa realizaram campanhas porta-a-porta para informar a população sobre a importância da CS. Nestas campanhas foram distribuídos panfletos com informações sobre o funcionamento da coleta e com orientações para a separação adequada dos resíduos sólidos. As instituições parceiras do projeto realizaram oficinas de capacitação para os catadores, inclusive para aqueles que trabalhavam dispersos no aterro da cidade.

Os resíduos sólidos domiciliares são separados por tipo, entre secos e orgânicos. O projeto forneceu sacos retornáveis para o armazenamento dos resíduos secos, que são recolhidos duas vezes por semana pelo caminhão da CS. Os resíduos orgânicos são coletados por caminhões da coleta convencional. A cidade possui um Posto de Entrega Voluntária (PEV) para o complemento da coleta dos materiais recicláveis.

Após à recolha, os resíduos sólidos recicláveis são encaminhados para o galpão da cooperativa Esperança onde são separados, prensados e embalados. O galpão possui duas esteiras para a triagem dos materiais. Além do benefício ambiental, a CS gera uma renda mensal entre 700 e 1.000 reais para os 23 cooperados da associação.

Formosa, Goiás

O município de Formosa (GO) iniciou a CS em 2012 por meio de uma parceria entre o governo municipal e a cooperativa Recicla Formosa. Para o início do programa, a cidade recebeu cerca de 1.000 lixeiras, que foram instaladas em praças e escolas municipais, totalizando 34 ecopontos. Campanhas e oficinas de capacitação para os catadores e de sensibilização para a comunidade são realizadas com frequência na cidade. A iniciativa precedeu o Plano Municipal de Gestão Integrada de Resíduos Sólidos de Formosa, que foi

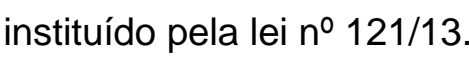

A CS é executada pela associação de catadores, que conta com 500 cooperados. A cooperativa é responsável pela coleta porta-a-porta dos resíduos sólidos secos e pela coleta dos resíduos secos depositados nos ecopontos. Atualmente a cooperativa passa por um processo de reestruturação do galpão de triagem, que foi atingido por um incêndio. 
Luziânia, Goiás

Em Luziânia, o programa de CS iniciou-se em 2014. A prefeitura da cidade e a cooperativa de catadores Cooperluz foram responsáveis pela implantação da CS. Os moradores devem separar os Resíduos Sólidos Domésticos (RDOs) entre secos e orgânicos. Aproximadamente 50 PEVs foram instalados nas escolas municipais. Os catadores receberam um curso de capacitação com duração de 60 horas/aula.

Índice de sustentabilidade

O índice de sustentabilidade da CS, calculado por meio de dois métodos para cada localidade, é apresentado na Tabela 3.3, a seguir.

Tabela 3.3 - Índices de sustentabilidade da Coleta Seletiva.

\begin{tabular}{lcccc}
\hline \multicolumn{1}{c}{ Cidade/Estado } & Besen (2011) & $\begin{array}{c}\text { Tendência à } \\
\text { Sustentabilidade }\end{array}$ & Fechine (2014) & $\begin{array}{c}\text { Tendência à } \\
\text { Sustentabilidade }\end{array}$ \\
\hline $\begin{array}{l}\text { Distrito Federal } \\
\text { Cidade Ocidental } \\
\text { (GO) }\end{array}$ & 0,34 & Desfavorável & 4,6 & Baixa \\
Cristalina (GO) & 0,35 & Desfavorável & 4,5 & Baixa \\
Formosa (GO) & 0,26 & Desfavorável & 3,14 & Baixa \\
Luziânia (GO) & 0,35 & Desfavorável & 4,8 & Baixa \\
Santo Antônio do & 0,28 & Desfavorável & 5,1 & Média \\
Descoberto (GO) & 0,17 & Muito desfavorável & 4,3 & Baixa \\
Buritis (MG) & 0,1 & Muito desfavorável & 3,8 & Baixa \\
\hline
\end{tabular}

Fonte: Da autora.

De acordo com o índice desenvolvido por Besen (2011), os programas de coleta seletiva com menor tendência à sustentabilidade são o de Buritis (MG) e o de Santo Antônio do Descoberto (GO). A nota de ambos faz parte do intervalo classificado como "muito desfavorável". Ainda de acordo com o índice de Besen (2011), as demais localidades obtiveram a segunda categoria de notas mais baixas, que é classificada como "desfavorável".

Pelo índice elaborado por Fechine (2014), apenas o programa de CS realizado em Luziânia (GO) apresentou nota mediana, classificado como "média sustentabilidade". Os demais locais estudados obtiveram a segunda categoria de notas mais baixas, que é classificada como "baixa sustentabilidade". 
A partir da comparação, verificou-se que a utilização de duas metodologias distintas, para a análise do mesmo conjunto de dados, gerou resultados distintos.

As diferenças encontradas nos resultados podem ser explicadas pela maneira de atribuição de notas aos indicadores. No método de Besen (2011) a tendência mais baixa de sustentabilidade recebe nota 0 . No método de Fechine (2014) a menor sustentabilidade recebe nota 1. Outra diferença observada é a ponderação de notas desenvolvida por Besen (2011), onde cada indicador possui um peso diferente para determinação do índice. No caso do índice desenvolvido por Fechine (2014), os indicadores não possuem pesos, ou seja, são considerados de importância igual para a definição da sustentabilidade da CS.

Abrangência da Coleta Seletiva

A abrangência da CS foi avaliada por meio de indicadores sobre a população atendida (Besen: Ind. 2; Fechine: Ind. 4) e sobre a área de prestação do serviço (Fechine: Ind. 5).

Tabela 3.4 - Abrangência da Coleta Seletiva.

\begin{tabular}{lccccc}
\hline Cidade/Estado & $\begin{array}{c}\text { População } \\
\text { atendida pela } \\
\text { CS (\%) }\end{array}$ & Nota Besen & Nota Fechine & $\begin{array}{c}\text { Área de } \\
\text { abrangência } \\
\text { da CS }\end{array}$ & Nota Fechine \\
\hline Distrito Federal & 67,60 & 0,45 & 3 & $\begin{array}{c}\text { Parte da área } \\
\text { urbana }\end{array}$ & 1 \\
$\begin{array}{l}\text { Cidade } \\
\text { Ocidental (GO) }\end{array}$ & 63,58 & 0,45 & 3 & $\begin{array}{l}\text { Parte da área } \\
\text { urbana }\end{array}$ & 1 \\
Cristalina (GO) & 9,57 & 0 & 1 & $\begin{array}{l}\text { Parte da área } \\
\text { urbana }\end{array}$ & 1 \\
$\begin{array}{l}\text { Formosa (GO) } \\
\text { Luziânia (GO) }\end{array}$ & 27,17 & 0 & 1 & $\begin{array}{l}\text { Parte da área } \\
\text { urbana }\end{array}$ & - \\
$\begin{array}{l}\text { Santo Antônio } \\
\text { do Descoberto } \\
\text { (GO) }\end{array}$ & - & - & - & - & - \\
\begin{tabular}{l} 
Buritis (MG) \\
\hline
\end{tabular} & 25,36 & - & 1 & Parte da área \\
urbana
\end{tabular}

Fonte: Da autora.

A maior parcela da população atendida foi no DF $(67,60 \%)$ seguido de Cidade Ocidental (63,58\%). Este percentual corresponde à nota mediana, no quesito atendimento da população, para os dois métodos utilizados. Cristalina (GO) apresentou o menor atendimento à população $(9,57 \%)$, recebendo as notas mais baixas dos dois métodos. Os municípios de Luziânia (GO) e Santo Antônio do Descoberto (GO) não forneceram estas informações. A área atendida pelo serviço de CS, em todas as localidades estudadas, 
abrangia apenas parte da área urbana, resultando na nota mais baixa pelo método Fechine (2014).

Eficiência ambiental

Dentre os indicadores ambientais destacaram-se a massa recuperada em relação ao total gerado (Besen: Ind. 3; Fechine: Ind. 16); a massa recuperada por habitante (Fechine: Ind. 13); taxa de rejeitos (Besen: Ind.4; Fechine: Ind 14). 
Tabela 3.5 - Indicadores ambientais.

\begin{tabular}{|c|c|c|c|c|c|c|c|c|}
\hline Cidade/Estado & $\begin{array}{c}\text { Massa } \\
\text { recuperada } \\
\text { em relação } \\
\text { ao total } \\
\text { gerado (\%) }\end{array}$ & Nota Besen & $\begin{array}{c}\text { Nota } \\
\text { Fechine }\end{array}$ & $\begin{array}{c}\text { Massa } \\
\text { recuperada } \\
\text { por } \\
\text { habitante } \\
\text { (kg/hab/ano) }\end{array}$ & $\begin{array}{c}\text { Nota } \\
\text { Fechine }\end{array}$ & $\begin{array}{l}\text { Taxa de } \\
\text { rejeito (\%) }\end{array}$ & Nota Besen & $\begin{array}{l}\text { Nota } \\
\text { Fechine }\end{array}$ \\
\hline Distrito Federal & 1,29 & 0 & 1 & 7,64 & 3 & 56,6 & 0 & 1 \\
\hline $\begin{array}{l}\text { Cidade Ocidental } \\
\text { (GO) }\end{array}$ & 4,55 & 0 & 1 & 9,77 & 3 & 22,5 & 0,435 & 1 \\
\hline Cristalina (GO) & 1,11 & 0 & 1 & 6,5 & 1 & 0 & Erro & Erro \\
\hline Formosa (GO) & 0,16 & 0 & 1 & 0,79 & 1 & 48,7 & 0 & 1 \\
\hline Luziânia (GO) & 5,09 & 0 & 3 & 17,89 & 5 & - & - & - \\
\hline $\begin{array}{l}\text { Santo Antônio do } \\
\text { Descoberto (GO) }\end{array}$ & 6,94 & 0 & 3 & 16,14 & 5 & 0 & Erro & Erro \\
\hline Buritis (MG) & 2,32 & 0 & 1 & 16,89 & 5 & 0 & Erro & Erro \\
\hline
\end{tabular}

Fonte: Adaptado a partir de dados do SNIS (2016). 
Do ponto de vista ambiental, a quantidade de resíduos sólidos recuperados representou baixa sustentabilidade quando avaliado pelo método elaborado por Besen (2011). De acordo com os critérios de avalição de Fechine (2014), para o indicador correspondente, os municípios de Luziânia (GO) e Santo Antônio do Descoberto (GO) apresentaram nota mediana para taxa de materiais recuperados. As demais localidades receberam a nota mais baixa.

A taxa de rejeitos é um indicador importante para avaliar a eficiência da CS, pois esta taxa auxilia a estimar a adesão da população ao programa de CS. Quanto maior é a taxa de rejeito encontrada, provavelmente, menor é a participação efetiva da população.

A efetividade da participação vai além da adesão ao programa de CS. A efetividade avalia, também, se a segregação dos resíduos sólidos é realizada de forma correta. Uma ferramenta muito utilizada para avaliar a participação efetiva da população na CS é a aplicação de questionários. Entretanto, os dados obtidos por meio de questionários tendem a superestimar a participação da população. A combinação entre os dados obtidos nos questionários e a taxa de rejeitos pode resultar em dados mais próximos à realidade sobre a adesão da população.

No caso das localidades estudadas, o Distrito Federal (DF) e o município de Formosa (GO) apresentaram elevadas taxas de rejeitos (56,6\% e 48,7\% respectivamente). Ambos obtiveram as notas mais baixas de sustentabilidade, segundo os dois métodos utilizados. Para Cidade Ocidental (GO), a taxa de rejeitos informada foi de $22,5 \%$ do total coletado seletivamente. Este valor representou o valor mediano de sustentabilidade para o método Besen (2011) e o valor mais baixo de sustentabilidade segundo o método de Fechine (2014).

Os municípios de Cristalina (GO), Santo Antônio do Descoberto (GO) e de Buritis (MG) informaram que a quantidade de materiais recuperados pela reciclagem é igual à quantidade total de resíduos sólidos coletados seletivamente, o que implicaria em uma taxa de rejeitos nula, representando um erro na informação dos dados. A cidade de Luziânia (GO) não forneceu dados para o cálculo da taxa de rejeitos.

\section{Aspectos sociais}

A tabela a seguir contempla os seguintes aspectos sociais: Existência de organizações/cooperativas de catadores (Fechine: Ind. 22); Número de catadores; Parcerias entre as organizações (Fechine: Ind. 6) e Campanhas de educação/divulgação (Besen: Ind. 10; Fechine: Ind. 18). 
Tabela 3.6 - Aspectos sociais.

\begin{tabular}{|c|c|c|c|c|c|c|c|c|c|}
\hline Cidade/Estado & $\begin{array}{c}\text { Quantidade } \\
\text { de } \\
\text { associações } \\
\text { de catadores }\end{array}$ & $\begin{array}{c}\text { Nota } \\
\text { Fechine }\end{array}$ & $\begin{array}{l}\text { Número de } \\
\text { Catadores }\end{array}$ & Educação/Divulgação & $\begin{array}{l}\text { Nota } \\
\text { Besen }\end{array}$ & $\begin{array}{l}\text { Nota } \\
\text { Fechine }\end{array}$ & $\begin{array}{c}\text { Tipo de } \\
\text { parceria do } \\
\text { governo com } \\
\text { as } \\
\text { associações }\end{array}$ & $\begin{array}{c}\text { Nota } \\
\text { Fechine }\end{array}$ & $\begin{array}{c}\text { Presença } \\
\text { de } \\
\text { catadores } \\
\text { dispersos } \\
\text { na cidade }\end{array}$ \\
\hline Distrito Federal & 30 & 3 & 2.362 & Anual/Pontual & 0 & 1 & Assistencialista & 1 & Sim \\
\hline $\begin{array}{l}\text { Cidade } \\
\text { Ocidental (GO) }\end{array}$ & 1 & 1 & 23 & Bimestral e Trimestral & 0,395 & 3 & - & - & - \\
\hline Cristalina (GO) & 1 & 1 & 25 & Anual/Pontual & 0 & 1 & Assistencialista & 1 & Sim \\
\hline Formosa (GO) & 1 & 1 & 500 & Permanente/Quinzenal/Mensal & 0,79 & 5 & - & - & Sim \\
\hline Luziânia (GO) & 1 & 1 & 206 & Bimestral e Trimestral & 0,395 & 3 & Assistencialista & 1 & Sim \\
\hline $\begin{array}{l}\text { Santo Antônio } \\
\text { do Descoberto } \\
\text { (GO) }\end{array}$ & 1 & 1 & 20 & Anual/Pontual & 0 & 1 & Assistencialista & 1 & Sim \\
\hline Buritis (MG) & - & - & - & Anual/Pontual & 0 & 1 & - & - & - \\
\hline
\end{tabular}

Fonte: Da autora. 
Os aspectos sociais indicam que a CS promoveu a inclusão social de catadores na maioria das localidades estudadas. A renda mensal média variou de 400 a 1.200 reais. Observou-se que a renda é influenciada pela produtividade mensal, que pode cair pela metade quando o funcionamento de equipamentos como a esteira de triagem é interrompido. Todos os municípios informaram que existem catadores que preferem trabalhar de forma autônoma, muitas vezes dispersos pela cidade.

A cooperativa Recicla Formosa apresentou a melhor campanha de educação e de divulgação da CS, desenvolvendo atividades com uma boa frequência. O Distrito Federal, Cristalina (GO), Santo Antônio do Descoberto (GO) e Buritis (MG) desenvolveram poucas atividades de divulgação e incentivo da CS, concentradas no início dos programas, na fase de implantação da CS.

Aspectos econômicos

A avaliação dos aspectos econômicos da CS foi a etapa mais complexa, devido a pouca informação dos dados por parte dos municípios. A maior parte dos indicadores econômicos precisou ser excluída da avaliação.

O questionário do SNIS não aborda aspectos econômicos essenciais como custo do serviço de CS por tonelada, a renda mensal média dos catadores e a taxa de autofinanciamento da CS. É imprescindível que estas informações sejam adicionadas no questionário do SNIS, para que os dados sejam mais completos e para que seja possível a análise da evolução da CS ao longo dos anos de desenvolvimento dos programas.

Os aspectos econômicos contemplados na série histórica do SNIS que trazem dados relevantes sobre a gestão dos RSUs nas localidades estudadas são apresentados na Tabela 3.7, a seguir. 
Tabela 3.7 - Aspectos econômicos sobre a gestão dos Resíduos Sólidos Urbanos.

\begin{tabular}{lcccc}
\hline Cidade/Estado & $\begin{array}{c}\text { Despesas totais } \\
\text { com o manejo de } \\
\text { RSU (reais) }\end{array}$ & $\begin{array}{c}\text { Despesas com o } \\
\text { serviço de coleta } \\
\text { (reais) }\end{array}$ & $\begin{array}{c}\text { Despesas com o } \\
\text { serviço de coleta } \\
\text { (\%) }\end{array}$ & $\begin{array}{c}\text { Autofinanciamento } \\
\text { do manejo de } \\
\text { RSUs (\%) }\end{array}$ \\
\hline Distrito Federal & $378.088 .216,27$ & $103.863 .029,8$ & 27,47 & 34,59 \\
Cidade Ocidental & 4.930 .000 & 3.600 .000 & 73,02 & - \\
(GO) & & & & - \\
Cristalina (GO) & 8.659 .404 & 3.894 .787 & 44,97 & 14,23 \\
Formosa (GO) & 5.017 .320 & 1.000 .000 & 19,93 & 36,59 \\
Luziânia (GO) & 4.991 .677 & 4.051 .741 & 81,16 & - \\
Santo Antônio do & - & - & - & - \\
Descoberto (GO) & & - & & - \\
Buritis (MG) & - & - & & - \\
\hline
\end{tabular}

Fonte: Adaptado a partir de dados do SNIS (2016).

Os custos com a coleta de RSUs em Luziânia (GO) e na Cidade Ocidental (GO) corresponderam a $81,16 \%$ e a $73,02 \%$ do total, respectivamente. Isto significa que uma parcela muito pequena foi utilizada para outras atividades essenciais como o tratamento dos resíduos sólidos e a disposição final.

Dentre as localidades estudadas, apenas o DF, Formosa (GO) e Luziânia (GO) informaram o percentual de autofinanciamento do manejo dos RSUs. Este percentual foi menor em Formosa (14,23\%) e maior em Luziânia (36,59\%). Ainda assim, os valores apresentados são baixos. Os recursos para o manejo dos RSUs são oriundos de taxa específica no Imposto Predial e Territorial Urbano (IPTU).

No DF, segundo dados do SLU (DISTRITO FEDERAL, 2015), a coleta convencional custou $R \$ 77,00 /$ tonelada, enquanto a CS teve o valor de $R \$ 204,00 /$ tonelada, no ano de 2014. O custo da CS não foi informado pelos municípios estudados.

Resíduos da saúde

Os Resíduos Sólidos da Saúde (RSSs) requerem coleta e tratamento especial devido ao alto grau de risco que oferecem. Entre os locais estudados, apenas Cidade Ocidental (GO) declarou não realizar a coleta diferenciada dos resíduos da saúde (vide Tabela 3.8, a seguir). 
Tabela 3.8 - Custo da coleta diferenciada de Resíduos Sólidos da Saúde.

\begin{tabular}{lcc}
\hline \multicolumn{1}{c}{ Cidade/Estado } & Quantidade de RSS coletados & Custo coleta de RSS (R\$/ton) \\
\hline Distrito Federal & $2.800,10$ & $1.376,61$ \\
Cidade Ocidental (GO) & - & - \\
Cristalina (GO) & 95 & $1.000,00$ \\
Formosa (GO) & - & $1.700,00$ \\
Luziânia (GO) & 120 & - \\
Santo Antônio do Descoberto (GO) & - & - \\
Buritis (MG) & 365 & $6.500,00$ \\
\hline
\end{tabular}

Fonte: Adaptado a partir de dados do SNIS (2014).

Quanto à coleta de RSSs observou-se que os gastos são elevados devido à complexidade deste serviço. Outro fator que aumenta os custos da coleta é o fato de não existir centros de tratamento de resíduos da saúde em todas as cidades. O maior custo da coleta dos RSSs foi em Buritis (MG). Os resíduos da saúde, gerados nesta cidade, são encaminhados para o município de Patos de Minas (MG).

Educação Ambiental: campanhas e divulgação da Coleta Seletiva

A Educação Ambiental (EA) tem um papel muito importante na construção de valores que levam a sociedade a adotar práticas cotidianas mais sustentáveis. Um programa bem conduzido de EA, com atividades contínuas, pode aumentar a taxa de recuperação de materiais recicláveis ao incentivar a população a participar efetivamente da CS.

No caso do Distrito Federal, observou-se que as campanhas de promoção da CS limitaram-se, basicamente, ao início do programa. A divulgação foi realizada por meio do rádio e da TV, além da distribuição de panfletos. As rotas dos caminhões que realizam a CS foram pouco divulgadas, ficando disponíveis apenas para consulta na internet, no endereço eletrônico do SLU. A falta de informação e de campanhas frequentes e o descumprimento do horário das rotas resultaram na baixa participação da comunidade na CS.

Os municípios de Cristalina (GO), Santo Antônio do Descoberto (GO) e Buritis (MG) também realizaram campanhas de divulgação e incentivo da CS apenas durante a fase inicial do programa. Formosa (GO) foi a cidade que promoveu mais campanhas desde a implantação da CS, realizando cursos, oficinas e seminários com frequência. Apesar de uma boa campanha de divulgação, a taxa de recuperação de materiais recicláveis foi a mais baixa $(0,16 \%)$ dentre as cidades estudadas. 
Em outros estados, novas ferramentas estão sendo desenvolvidas para incentivar a CS. A Original Games, em parceria com a prefeitura de Curitiba e o Instituto Pró Cidadania, desenvolveram o jogo virtual Clean City Curitiba, onde o jogador deve depositar cada tipo de resíduo na lixeira correta (Prefeitura Municipal de Curitiba, 2016). O Clean City Curitiba pode ser jogado em qualquer computador com acesso à internet e pode ser uma ferramenta complementar, utilizada no ambiente escolar.

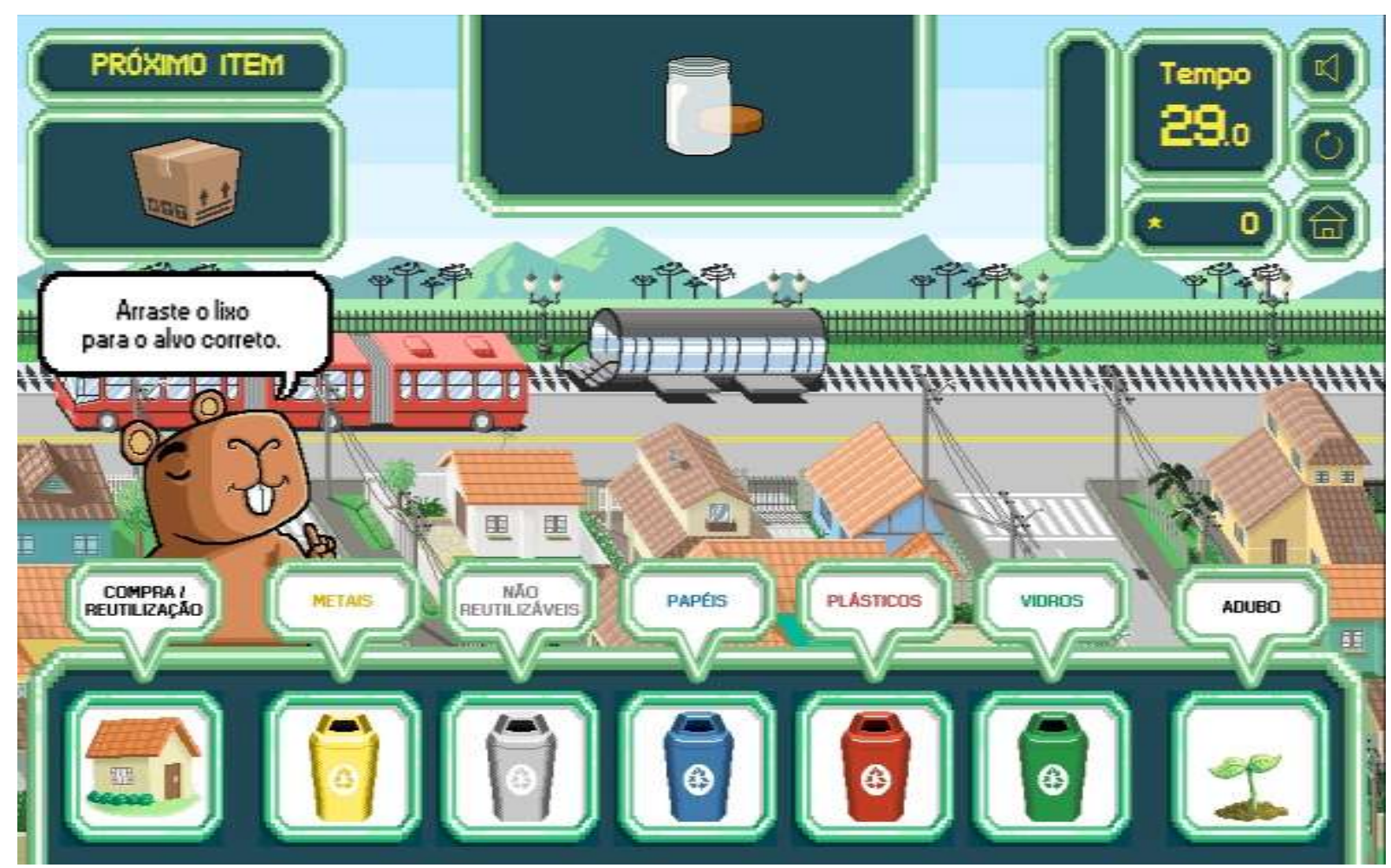

Figura 3.4 - Imagem do jogo Clean City Curitiba.

Fonte: Original Games (2016).

Outras formas de incentivos também conferem resultados positivos, como descontos para moradores que praticam a CS. A Companhia Energética do Ceará (COELCE) elaborou um programa que permite a troca de resíduos sólidos recicláveis por descontos na conta de energia elétrica. A iniciativa teve boa recepção pela população e, em 2014, já era desenvolvida em 80 ecopontos distribuídos em 30 municípios cearenses (COELCE, 2014).

O incentivo de práticas mais sustentáveis com o fornecimento de bônus é, no entanto, um mecanismo discutível, pois o fim do fornecimento do benefício leva também ao fim da prática em questão, como a participação na coleta seletiva. As campanhas de incentivo devem, então, sensibilizar para a importância das mudanças de comportamento, indicando os benefícios ambientais, sociais e econômicos que o novo hábito possibilita. 


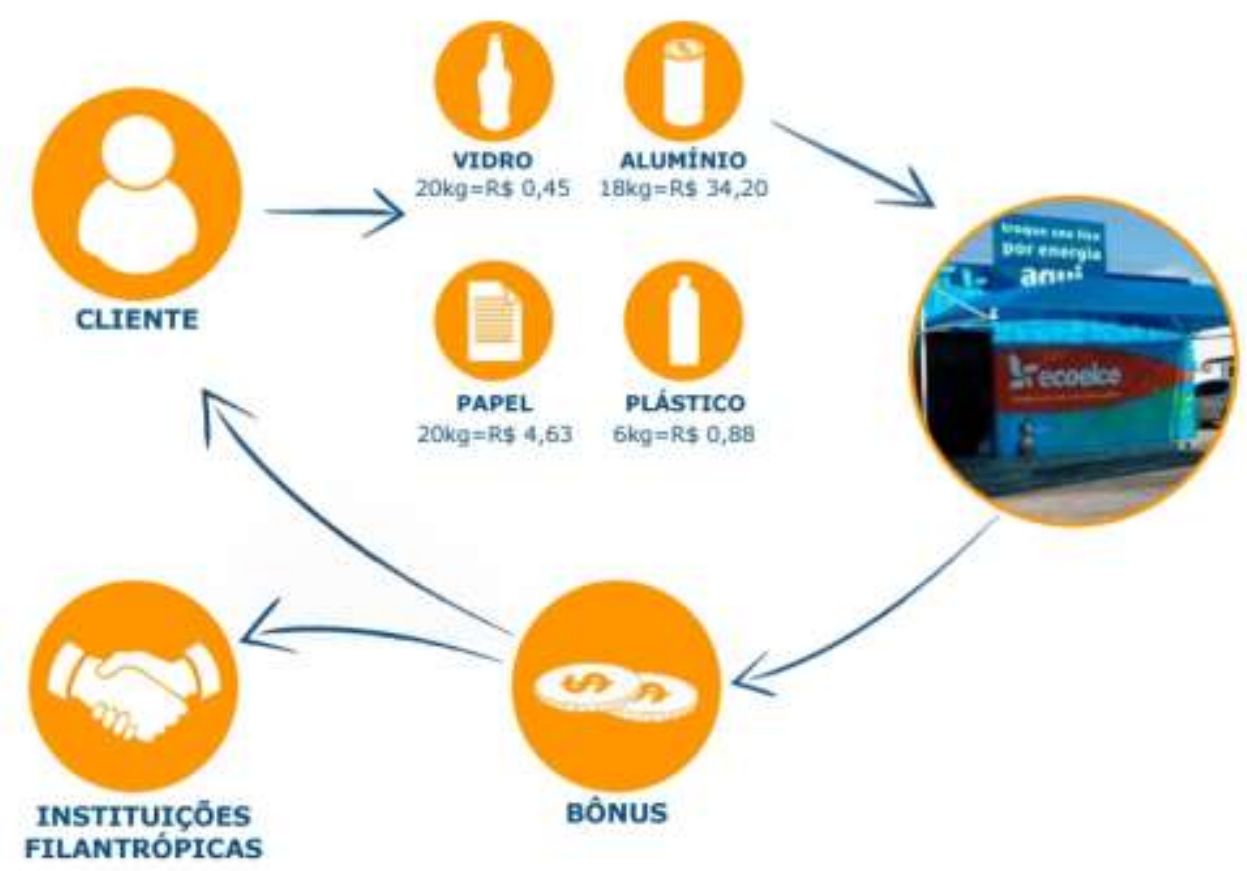

Figura 3.5 - Funcionamento do programa ECOELCE.

Fonte: COELCE (2014).

CONCLUSÃO

A avaliação da Coleta Seletiva (CS) a partir de dados secundários foi possível, com algumas limitações. Os dados que compõem a série histórica do Sistema Nacional de Informações sobre Saneamento (SNIS) são informados pelos próprios municípios, o que pode levar à divulgação de alguns dados errôneos. Outra dificuldade encontrada foi a falta de fornecimento de alguns dados por parte dos municípios. Apesar destas dificuldades, os erros foram identificados e desconsiderados e, desta maneira, não afetaram os resultados finais do capítulo.

A análise dos aspectos econômicos da CS foi abreviada devido à ausência destas informações no SNIS. É imprescindível que um item sobre o custo da CS/tonelada seja adicionado à série histórica para uma melhor avaliação dos critérios econômicos. Ainda assim, as séries históricas, inclusive a do SNIS, continuam sendo uma boa ferramenta para a análise da evolução de fenômenos ou de variáveis ao longo do tempo. A partir destas séries também é possível fazer previsões e traçar metas de planejamento. Como vantagens da utilização de dados secundários, destacaram-se o baixo custo econômico do método e o menor tempo para a execução da análise. Além disso, a análise in loco pode ser realizada para complementar os dados já fornecidos. 
No geral, todos os programas de CS desenvolvidos na Região Integrada de Desenvolvimento do Distrito Federal e Entorno (RIDE-DF), no ano de 2014, obtiveram baixa tendência à sustentabilidade. Entretanto, a utilização de dois índices diferentes gerou resultados distintos para o mesmo conjunto de dados. A maioria das localidades analisadas recebeu dois resultados diferentes para o mesmo programa de CS.

A taxa de recuperação de resíduos é um dos principais indicadores ambientais para a avaliação da CS. Todos os municípios estudados obtiveram baixo desempenho neste quesito, apresentando taxas inferiores a 10\%. Os municípios que apresentaram as maiores taxas de recuperação de resíduos recicláveis foram, respectivamente, Santo Antônio do Descoberto (GO) e Luziânia (GO). O município de Formosa (GO), que desenvolveu o melhor programa de divulgação e informação sobre o serviço de CS apresentou a pior taxa de recuperação de materiais recicláveis.

A criação de um índice a cada vez que se avalia a gestão dos RSUs num local diferente pode resultar no surgimento de diversos índices, mas sem nenhum mecanismo de comparação entre eles. A padronização de um índice de sustentabilidade, que seja constantemente aprimorado, pode resultar numa ferramenta mais precisa para a análise da gestão dos RSUs, bem como trazer a possibilidade da realização de análises comparativas.

As taxas de recuperação de materiais recicláveis foram baixas em todos os locais estudados. Em Formosa (GO) foi encontrada a menor taxa de recuperação $(0,16 \%$ do total produzido). O município de Santo Antônio do Descoberto (GO) apresentou a maior taxa de recuperação $(6,94 \%$ do total produzido), no entanto, obteve o segundo menor índice de sustentabilidade pelo método Besen (2011), classificado como "muito desfavorável".

Desde a instituição da PNRS houve um aumento no número de iniciativas de CS, o que pode indicar uma preocupação maior dos municípios com a gestão dos Resíduos Sólidos Urbanos (RSUs). No caso da RIDE-DF, nenhum dos programas de coleta seletiva desenvolvidos no ano de 2014 representou melhorias significativas na gestão dos RSUs.

\section{REFERÊNCIAS}

ASSOCIAÇÃO BRASILEIRA DE EMPRESAS DE LIMPEZA PUBLICA E RESIDUOS ESPECIAIS - ABRELPE. Panorama dos Resíduos Sólidos no Brasil 2009. São Paulo, $2009 . \quad 202 \quad$ p. Disponível em: <http://www.wtert.com.br/home2010/arquivo/noticias_eventos/Panorama2009.pdf >. Acesso em: 10/06/2015.

Panorama dos Resíduos Sólidos no Brasil 2014. São Paulo, 2014. 202 p. Disponível em: <http://www.abrelpe.org.br/Panorama/panorama2014.pdf>. Acesso em: 
29/09/2015.

BESEN, G. R. Coleta seletiva com inclusão de catadores: construção participativa de indicadores e índices de sustentabilidade. 2011. Tese (Doutorado em Saúde) - PósGraduação em Saúde Pública, Universidade Estadual de São Paulo, 2011.

BRASIL. Decreto n. 7.404, de 23 de dezembro de 2010. Regulamenta a Lei n. 12.305, de 2 de agosto de 2010, que institui a Política Nacional de Resíduos Sólidos, cria o Comitê Interministerial da Política Nacional de Resíduos Sólidos e o Comitê Orientador para a Implantação dos Sistemas de Logística Reversa, e dá outras providências. Brasília, 2010a. Disponível em: <http://www.planalto.gov.br/ccivil_03/_ato20072010/2010/decreto/d7404.htm>. Acesso em: 26/02/2016.

Lei n. 12.305, de 2 de agosto de 2010. Institui a Política Nacional de Resíduos Sólidos; altera a Lei n. 9.605, de 12 de fevereiro de 1998; e dá outras providências. Brasília, 2010b. Disponível em: <http://www.planalto.gov.br/ccivil_03/_ato20072010/2010/lei/l12305.htm>. Acesso em: 26/02/2016.

Ministério do Meio Ambiente. Logística reversa. 2016. Disponível em: <http://www.mma.gov.br/cidades-sustentaveis/residuos-perigosos/logistica-reversa $>$. Acesso em: 16/07/2015.

BUQUE, L. I. B.; RIBEIRO, H. Panorama da coleta seletiva com catadores no município de Maputo, Moçambique: desafıos e perspectivas. Saúde e Sociedade, São Paulo, v. 24, n. 1, p. 298-307, jan./mar. 2015.2 Disponível em: <http://www.scielo.br/scielo.php?script=sci_arttext\&pid=S0104$12902015000100298 \& \operatorname{lng}=$ en\&nrm=iso\&tlng=pt\&ORIGINALLANG=pt>. Acesso em: $16 / 07 / 2015$.

CORDEIRO, L. D.; FRANÇA, M. O. M. A dinâmica migratória na área metropolitana de Brasília - AMB entre 1991 e 2010. In: Anais do XVIII Encontro Nacional de Estudos Populacionais, ABEP, Águas de Lindóia, SP, de 19 a 23 de novembro de 2012. Disponível em: <http://www.abep.nepo.unicamp.br/xviii/anais/files/POSTER[407]ABEP2012.pdf>. Acesso em: 1\%09/2015.

COMPANHIA ENERGÉTICA DO CEARÁ - COELCE. ECOELCE: Troca de resíduos por bônus na conta de energia elétrica. 2014. Disponível em: <http://praticaeventos.com/wpcontent/uploads/2013/07/Ecoelce-2014.pdf>. Acesso em: 07/03/2016.

CONKE, L. S. Barreiras ao desenvolvimento da coleta seletiva no Brasil. 2015. Tese (Doutorado) - Centro de Desenvolvimento Sustentável, Universidade de Brasília, Brasília.

CURITIBA. Prefeitura Municipal. Pró-Cidadania lança game que incentiva boas práticas e preservação do meio ambiente. In: Prefeitura Municipal de Curitiba, 2015. Disponível em: $<$ http://www.curitiba.pr.gov.br/noticias/pro-cidadania-lanca-game-que-incentiva-boaspraticas-e-preservacao-do-meio-ambiente/38144>. Acesso em: 07/03/2016. 
DISTRITO FEDERAL. Vice-Governadoria do Distrito Federal. Secretaria de Infraestrutura e Serviços Públicos. Serviço de Limpeza Urbana. Relatório do Diagnóstico de Resíduos Sólidos do Distrito Federal (2014). Brasília, 2015. Disponível em: <http://www.agenciabrasilia.df.gov.br/images/agencia_brasilia/2015/04-

ABRIL/Relatorio_diagnostico_residuos_solidos_SLU_2014.pdf>. Acesso em: 1\%/07/2015.

EIGENHEER, E. M.; FERREIRA, J. A. Três décadas de coleta seletiva em São Francisco (Niterói/RJ): lições e perspectivas. Eng. Sanit. Ambient, v. 20, n. 4, p. 677-684, out./dez. 2015. Disponível em: <http://www.scielo.br/pdf/esa/v20n4/1413-4152-esa-20-04-00677.pdf>. Acesso em: 07/03/2016.

FECHINE, R. Indicadores de sustentabilidade como instrumentos para avaliação dos programas de coleta seletiva na cidade de Salvador-BA. 2014. Dissertação (Mestrado em Meio Ambiente, Águas e Saneamento) - Escola Politécnica, Universidade Federal da Bahia, Salvador. Disponível em: <http://www.maasa.eng.ufba.br/sites/maasa.eng.ufba.br/files/Disserta\%C3\%A7\%C3\%A30\% 20Roberta\%20Fechine.pdf>. Acesso em: 07/03/2016.

RIBEIRO, H.; BESEN, G. R. Panorama da coleta seletiva no Brasil: desafios e perspectivas a partir de três estudos de caso. OINTERFACEHS - Revista de Gestão Integrada em Saúde do Trabalho e Meio Ambiente, v. 2, n. 4, ago. 2007. Disponível em: <http://www.revistas.sp.senac.br/index.php/ITF/article/viewFile/138/166>. Acesso em: 07/03/2016. 


\section{CONCLUSÃO GERAL}

A análise da gestão dos Resíduos Sólidos Urbanos (RSUs) adotada na Região Integrada de Desenvolvimento do Distrito Federal e Entorno (RIDE-DF) foi realizada em três etapas: a geração de resíduos, a gestão e a coletiva seletiva. A maioria dos dados utilizados no estudo faz parte da série histórica do Sistema Nacional de Informação sobre Saneamento (SNIS) e são autodeclaratórios, ou seja, são informados pelos próprios municípios. A utilização destes dados possui algumas limitações devido à existência de erros nas informações prestadas. A existência de erros é explicada, em parte, pela falta de conhecimento para o correto preenchimento do questionário do SNIS. Ainda assim, os dados constantes no SNIS representam o maior conjunto de informações sobre os resíduos sólidos, necessitando de aprimoramentos.

O aumento na geração de RSUs é um fenômeno observado nas cidades brasileiras e também foi constatado nas cidades da RIDE-DF contempladas neste estudo. Este aumento sugere que a política dos resíduos sólidos, conforme amplamente propagada, é pouco praticada nestes locais, principalmente a ação de reduzir a produção de resíduos sólidos, mas também a de reutilizar e reciclar. Zaneti, Sá e Almeida (2009) apontam que é de fundamental importância que a gestão pública atue com o propósito de consolidar processos coletivos, atuantes sobre as dimensões cultural e educacional da sustentabilidade, que possibilitem alterar os padrões sociais de produção e consumo.

O crescimento da geração de RSUs é consequência de diversos fatores socioeconômicos. A renda, a densidade demográfica e o consumo possuem relação diretamente proporcional com a quantidade de resíduos sólidos gerados, ou seja, o aumento destes fatores resulta no aumento do volume de resíduos sólidos produzidos.

O crescimento da geração de resíduos sólidos urbanos é consequência de diversos fatores socioeconômicos. A renda, a densidade demográfica e o consumo possuem relação diretamente proporcional com a quantidade de resíduos sólidos gerados, ou seja, o aumento destes fatores resulta no aumento do volume de resíduos sólidos produzidos.

Outro fator importante a ser considerado na análise da geração de RSUs é a mudança da faixa etária da população. Silva et. al. (2012), ao estudarem fatores socioeconômicos que influenciaram a geração de RSUs em Belo Horizonte (MG), constataram que a população com idade igual ou superior a 60 anos tende a apresentar uma geração per capita de RSUs maior do que a de outros grupos etários. Este fenômeno pode ser uma tendência em todo o Brasil, que observa mudanças na composição populacional classificada quanto à faixa etária. 
No Distrito Federal (DF) observou-se que o aumento da geração de Resíduos Sólidos Domésticos (RDOs) esteve, sobretudo, relacionado ao crescimento do Produto Interno Bruto (PIB) durante os anos 2003 a 2014. É interessante observar se esta relação será mantida nos próximos anos, nos quais o PIB deve sofrer uma retração. A tendência seria, então, de um pequeno decrescimento na geração de RDOs. É importante ressaltar que a geração de RDOs no DF está muito acima da atual capacidade de gerenciamento e, por isso, a pequena diminuição esperada não trará efeitos expressivos. Além disso, é provável que a geração de RDOs volte a crescer à medida que a economia se recupere.

A eficiência ambiental do manejo dos RSUs adotado nas cidades estudadas foi muito baixa. O maior impacto calculado foi a emissão de gás carbônico devido ao aterramento dos RSUs sem qualquer tratamento. Esta prática, difícil de ser modificada, foi observada nos Municípios e também no DF, mostrando que o desafio de se adequar à Política Nacional de Resíduos Sólidos (PNRS) é complexo para os Municípios. Os menores porque apresentam poucos recursos financeiros, e no caso dos maiores, que apresentam orçamento superior, lidam com um contingente populacional maior, maior desordenamento urbano e, em geral, renda superior o que resulta numa quantidade maior de RSUs gerada.

A infraestrutura para o gerenciamento dos RSUs disponível nos municípios da RIDEDF é insuficiente até mesmo para a realização da atividade mais básica deste processo, a coleta convencional. Em algumas cidades, como Padre Bernardo, Goiás (GO), a área de cobertura do serviço de coleta convencional diminuiu durante o período estudado, indicando que o gerenciamento dos resíduos sólidos tem piorado no Município.

Outro ponto constatado é que a maior parte dos recursos investidos é destinada ao serviço de coleta convencional. Em alguns municípios cerca de $80 \%$ do total investido é relativo à coleta dos RSUs, mostrando que uma parcela pequena de recursos é utilizada para outras atividades fundamentais como o tratamento dos resíduos e a disposição final.

A reciclagem de materiais, realizada no DF e nos Municípios que declararam a realização da Coleta Seletiva (CS), representa uma fração muito pequena do total produzido, tendo pouca eficácia no desvio de materiais dos lixões. Dessa forma, observa-se uma perda considerável de recursos que poderiam ser transformadas em renda.

Em relação à sustentabilidade, todos os programas de CS estudados apresentaram-se pouco sustentáveis dos pontos de vista econômico, social e ambiental. A baixa taxa de recuperação de materiais e a grande quantidade de rejeitos no material coletado seletivamente podem indicar falhas na execução da CS bem como uma baixa participação da população na coleta dos materiais. No ano de 2014 nenhum dos programas de CS executados na RIDE-DF eram realizados em toda a cidade, estando limitados à parte da área urbana. 
Os programas de coleta seletiva apresentaram diversos problemas como: A falta de informação sobre a correta separação dos resíduos, o descumprimento das rotas e da frequência de coleta dos materiais recicláveis e o alto índice de contaminação dos materiais recicláveis.

Todas as iniciativas de CS estudadas apresentaram baixa sustentabilidade. Sugere-se que estes programas sejam reavaliados e que passem por ajustes. É imprescindível que haja um planejamento das ações de Educação Ambiental (EA) para estimular a adesão efetiva da população à CS. O planejamento adequado da CS deve conter etapas de diagnóstico, implantação, divulgação e avaliação do programa. Devido ao pouco sucesso da CS, observa-se que o investimento de recursos para a o fechamento dos lixões traria mais benefícios ambientais do que a CS implantada atualmente.

Dados sobre a compostagem de matéria orgânica não são disponibilizados na série histórica de RS do Sistema Nacional de Informação sobre Saneamento (SNIS). É necessário que informações sobre a compostagem passem a integrar o questionário elaborado pelo sistema, com o intuito de poder avaliar a situação do tratamento dos resíduos sólidos orgânicos no Brasil.

A conclusão é de que a situação é deplorável. A produção de resíduos sólidos tem crescido sem que os serviços de coleta, tratamento e disposição final acompanhem este crescimento. Há, contudo, uma esperança de que a situação venha a melhorar. O Consórcio Público de Manejo dos Resíduos Sólidos e das Águas Pluviais da Região Integrada do Distrito Federal e Goiás (CORSAP-DF/GO) encontra-se em fase de consolidação e deve dar início às mudanças no manejo dos resíduos sólidos no DF e nos municípios goianos do entorno do DF a partir da elaboração do Plano Intermunicipal de Gestão Integrada de Resíduos Sólidos (PIGIRS), previsto na Lei 12.305/2010. 


\section{REFERÊNCIAS}

AGÊNCIA NACIONAL DE ENERGIA ELÉTRICA - ANEEL. Consumo de energia elétrica no Brasil. $\quad S$ d. $\quad$ Disponível em: <http://relatorios.aneel.gov.br/RelatoriosSAS/Forms/Allttems.aspx>. Acesso em: 1\%/09/2015.

ASSOCIAÇÃO BRASILEIRA DE EMPRESAS DE LIMPEZA PUBLICA E RESIDUOS ESPECIAIS - ABRELPE. Panorama dos Resíduos Sólidos no Brasil 2009. São Paulo, $2009 . \quad 202$ p. Disponível <http://www.wtert.com.br/home2010/arquivo/noticias_eventos/Panorama2009.pdf>. Acesso em: 10/06/2015.

Panorama dos Resíduos Sólidos no Brasil 2014. São Paulo, 2014. 202 p. Disponível em: <http://www.abrelpe.org.br/Panorama/panorama2014.pdf>. Acesso em: 29/09/2015.

BESEN, G. R. Coleta seletiva com inclusão de catadores: construção participativa de indicadores e índices de sustentabilidade. 2011. Tese (Doutorado em Saúde) - PósGraduação em Saúde Pública, Universidade Estadual de São Paulo, 2011.

BRAGA, N. C.; DIAS, N. C. Gestão de resíduos sólidos urbanos. Curitiba, 2008. Disponível

em: <http://www.administradores.com.br/_resources/files/_modules/academics/academics_1079 _201002281825303644.pdf>. Acesso em: Acesso em: 1\%/09/2015.

BRASIL. Decreto n. 7.404, de 23 de dezembro de 2010. Regulamenta a Lei n. 12.305, de 2 de agosto de 2010, que institui a Política Nacional de Resíduos Sólidos, cria o Comitê Interministerial da Política Nacional de Resíduos Sólidos e o Comitê Orientador para a Implantação dos Sistemas de Logística Reversa, e dá outras providências. Brasília, 2010a. Disponível em: <http://www.planalto.gov.br/ccivil_03/_ato20072010/2010/decreto/d7404.htm>. Acesso em: 26/02/2016.

Lei n. 11.445, de 5 de janeiro de 2007. Estabelece diretrizes nacionais para o saneamento básico; altera as Leis ns 6.766, de 19 de dezembro de 1979, 8.036, de 11 de maio de 1990, 8.666, de 21 de junho de 1993, 8.987, de 13 de fevereiro de 1995; revoga a Lei n. 6.528, de 11 de maio de 1978; e dá outras providências. Brasília, 2007. Disponível em: <http://www.planalto.gov.br/ccivil_03/_ato2007-2010/2007/lei//11445.htm>. Acesso em: 29/09/2015.

Lei n. 12.305, de 2 de agosto de 2010. Institui a Política Nacional de Resíduos Sólidos; altera a Lei n. 9.605, de 12 de fevereiro de 1998; e dá outras providências. Brasília, 2010b. Disponível em: <http://www.planalto.gov.br/ccivil_03/_ato20072010/2010/lei//12305.htm>. Acesso em: 26/02/2016. 
Lei n. 6.938, de 31 de agosto de 1981. Dispõe sobre a Política Nacional do Meio Ambiente, seus fins e mecanismos de formulação e aplicação, e dá outras providências. Brasília, 1981. Disponível em: <http://www.planalto.gov.br/ccivil_03/leis/L6938.htm>. Acesso em: 29/09/2015.

Ministério do Meio Ambiente. Logística reversa. 2016. Disponível em: <http://www.mma.gov.br/cidades-sustentaveis/residuos-perigosos/logistica-reversa>. Acesso em: $16 / 07 / 2015$.

BUQUE, L. I. B.; RIBEIRO, H. Panorama da coleta seletiva com catadores no município de Maputo, Moçambique: desafıos e perspectivas. Saúde e Sociedade, São Paulo, v. 24, n. 1, p. 298-307, jan./mar. 2015.2 Disponível em: <http://www.scielo.br/scielo.php?script=sci_arttext\&pid=S0104-

$12902015000100298 \& \operatorname{lng}=\mathrm{en} \& \mathrm{nrm}=\mathrm{iso} \& \mathrm{t} \mathrm{ng}=\mathrm{pt} \& O R I G I N A L L A N G=p t>$. Acesso em: $16 / 07 / 2015$.

COMPANHIA ENERGÉTICA DO CEARÁ - COELCE. ECOELCE: Troca de resíduos por bônus na conta de energia elétrica. 2014. Disponível em: <http://praticaeventos.com/wpcontent/uploads/2013/07/Ecoelce-2014.pdf>. Acesso em: 07/03/2016.

CONKE, L. S. Barreiras ao desenvolvimento da coleta seletiva no Brasil. 2015. Tese (Doutorado) - Centro de Desenvolvimento Sustentável, Universidade de Brasília, Brasília.

CORDEIRO, L. D.; FRANÇA, M. O. M. A dinâmica migratória na área metropolitana de Brasília - AMB entre 1991 e 2010. In: Anais do XVIII Encontro Nacional de Estudos Populacionais, ABEP, Águas de Lindóia, SP, de 19 a 23 de novembro de 2012. Disponível em: <http://www.abep.nepo.unicamp.br/xviii/anais/files/POSTER[407]ABEP2012.pdf>. Acesso em: 1\%09/2015.

CURITIBA. Prefeitura Municipal. Pró-Cidadania lança game que incentiva boas práticas e preservação do meio ambiente. In: Prefeitura Municipal de Curitiba, 2015. Disponível em: <http://www.curitiba.pr.gov.br/noticias/pro-cidadania-lanca-game-que-incentiva-boaspraticas-e-preservacao-do-meio-ambiente/38144>. Acesso em: 07/03/2016.

DISTRITO FEDERAL. Lei n. 3.232, de 3 de dezembro de 2003. Dispõe sobre a Política Distrital de Resíduos Sólidos e dá outras providências. Brasília, 2003. Disponível em: $<\mathrm{http}: / /$ www.tc.df.gov.br/SINJ/Arquivo.ashx?id_norma_consolidado=51180>. Acesso em: $1 \% / 01 / 2016$.

Vice-Governadoria do Distrito Federal. Secretaria de Infraestrutura e Serviços Públicos. Serviço de Limpeza Urbana. Relatório do Diagnóstico de Resíduos Sólidos do Distrito Federal (2014). Brasília, 2015. Disponível em: <http://www.agenciabrasilia.df.gov.br/images/agencia_brasilia/2015/04-

ABRIL/Relatorio_diagnostico_residuos_solidos_SLU_2014.pdf>. Acesso em: 1\%/07/2015. 
EIGENHEER, E. M.; FERREIRA, J. A. Três décadas de coleta seletiva em São Francisco (Niterói/RJ): lições e perspectivas. Eng. Sanit. Ambient, v. 20, n. 4, p. 677-684, out./dez. 2015. Disponível em: <http://www.scielo.br/pdf/esa/v20n4/1413-4152-esa-20-04-00677.pdf>. Acesso em: 07/03/2016.

EMPRESA DE PESQUISA ENERGÉTICA - EPE. Nota Técnica DEN 06/08. Avaliação preliminar do aproveitamento energético dos Resíduos Sólidos Urbanos de Campo Grande, MS. Rio de Janeiro, 2008. (Série Recursos Energéticos). Disponível em: <http://www.epe.gov.br/mercado/Documents/S\%C3\%A9rie\%20Estudos\%20de\%20Energia/2 0081208_1.pdf>. Acesso em: 1\%/01/2016.

FECHINE, R. Indicadores de sustentabilidade como instrumentos para avaliação dos programas de coleta seletiva na cidade de Salvador-BA. 2014. Dissertação (Mestrado em Meio Ambiente, Águas e Saneamento) - Escola Politécnica, Universidade Federal da Bahia, Salvador. Disponível em: <http://www.maasa.eng.ufba.br/sites/maasa.eng.ufba.br/files/Disserta\%C3\%A7\%C3\%A30\% 20Roberta\%20Fechine.pdf>. Acesso em: 07/03/2016.

GADELHA, E. P. Avaliação de inóculos metanogênicos na aceleração do processo de degradação da fração orgânica dos Resíduos Sólidos Urbanos. 2005. Dissertação (Mestrado em Tecnologia Ambiental e Recursos Hídricos) - Departamento de Engenharia Civil e Ambiental, Faculdade de Tecnologia, Universidade de Brasília, Brasília. Disponível em: <http://livros01.livrosgratis.com.br/cp095915.pdf>. Acesso em: 1\%/07/2015.

GALLARDO, A.; CARLOS, M.; PERIS, M.; COLOMER, F. J. Methodology to design a municipal solid waste pre-collection system. A case study. Waste Management, v. 36, p. 111, fev. 2015.

GETAHUN, T.; MENGISTIE, E.; HADDIS, A.; WASIE, F.; ALEMAYEHU, E.; DADI, D.; VAN GERVEN, T.; VAN DER BRUGGEN, B. Municipal solid waste generation in growing urban areas in Africa: current practices and relation to socioeconomic factors in Jimma, Ethiopia. Environmental monitoring and assessment, v. 184, n. 10, p. 6337-6345, out. 2012.

GOIÁS. Lei n. 14.248, de 29 de julho de 2002. Dispõe sobre a Política Estadual de Resíduos Sólidos e dá outras providências. Goiânia, 2002. Disponível em: <http://www.gabinetecivil.goias.gov.br/leis_ordinarias/2002/lei_14248.htm>. Acesso em: $1 \% / 01 / 2016$.

GROVER, P.; SINGH, P. An analytical study oif effect of family income and size on per capita household solid waste generation in developing countries. Review of Arts and Humanities March, v. 3, n. 1, p. 127-143, 2014. Disponível em: <http://aripd.org/journals/rah/Vol_3_No_1_March_2014/11.pdf>. Acesso em: 1\%/09/2015.

INSTITUTO BRASILEIRO DE GEOGRAFIA E ESTATÍSTICA - IBGE. Produto Interno Bruto dos Municípios 2010-2013. 2014. Disponível em: <http://www.ibge.gov.br/home/estatistica/economia/pibmunicipios/2010_2013/default.shtm>. Acesso em: 1\%09/2015. 
INSTITUTO BRASILEIRO DE GEOGRAFIA E ESTATÍSTICA - IBGE. Séries Históricas e Estatísticas. Disponível em: <http://seriesestatisticas.ibge.gov.br/lista_tema.aspx?op=0\&no=2>. Acesso em: 1\%/11/2015.

JACOBI, P. R.; BESEN, G. R. Gestão de resíduos sólidos em São Paulo: desafios da sustentabilidade. Estudos Avançados, São Paulo, v. 25, n. 71, p. 135-158, jan./abr. 2011. Disponível em: <http://www.scielo.br/pdf/ea/v25n71/10.pdf>. Acesso em: 1\%/11/2015.

KAMRAN, A.; CHAUDHRY, M. N.; BATOOL, S. A. Effects of socio-economic status and seasonal variation on municipal solid waste composition: a baseline study for future planning and development. Environmental Sciences Europe, v. 27, n. 16, p. 1-8, dez. 2015. Disponível em: <http://link.springer.com/article/10.1186/s12302-015-0050-9>. Acesso em: $1 \% / 11 / 2015$.

KAWAI, K.; TASAKI, T. Revisiting estimates of municipal solid waste generation per capita and their reliability. Journal of Material Cycles and Waste Management, v. 18, n. 1, p. 113, jan. 2016. Disponível em: <http://link.springer.com/article/10.1007/s10163-015-0355-1>. Acesso em: 1\%02/2016.

KHAN, D.; KUMAR, A.; SAMADDER, S. R. Impact of socioeconomic status on municipal solid waste generation rate. Waste Management, n. 49, p. 15-25, mar. 2016.

LI, L.; GE, X.; ZHANG, J.; WANG, J. Long-term relationship among the generation of municipal solid waste, urbanization, affluence and prosperity of tertiary industry. Metallurgical and Mining Industry, n. 6, p. 206-212, 2015. Disponível em: <http://www.metaljournal.com.ua/assets/Journal/MMI-6/025-Li-Li.pdf>. Acesso em: $1 \% / 02 / 2016$.

LIU, C.; WU, X. W. Factors influencing municipal solid waste generation in China: a multiple statistical analysis study. Waste Management \& Research, v. 29, n. 4, abr. 2011.

RIBEIRO, H.; BESEN, G. R. Panorama da coleta seletiva no Brasil: desafios e perspectivas a partir de três estudos de caso. CINTERFACEHS - Revista de Gestão Integrada em Saúde do Trabalho e Meio Ambiente, v. 2, n. 4, ago. 2007. Disponível em: <http://www.revistas.sp.senac.br/index.php/ITF/article/viewFile/138/166>. Acesso em: 07/03/2016.

SAMUEL, O. O. Socio-economic correlates of household solid waste generation: evidence from Lagos metropolis, Nigeria. Management Research and Practice, v. 7, n. 1, p. 44, 2015.

SANKOH, F. P.; YAN, X.; CONTEH, A. M. H. A situational assessment of socioeconomic factors affecting solid waste generation and composition in Freetown, Sierra Leone. Journal of Environmental Protection, n. 3, p. 563-568, jul. 2012. Disponível em: <http://file.scirp.org/pdf/JEP20120700002_99280824.pdf>. Acesso em: 1\%/02/2016. 
SHARHOLY, M.; AHMAD, K.; VAISHYA, R. C.; GUPTA, R. D. Municipal solid waste characteristics and management in Allahabad, India. Journal of Waste Management, n. 27, p. 490-496, 2007. Disponível em: <http://www.seas.columbia.edu/earth/wtert/sofos/Sharholy_MSW\%20Characteristics\%20and \%20Management\%20in\%20Allahabad,\%20India.pdf>. Acesso em: 1\%/09/2015.

SILVA, F. C.; SANTOS, F. F. Destinação final ambientalmente adequada para os Resíduos da Construção Civil. In: Anais do XXVI Congresso Regional de Iniciação Científica e Tecnológica em Engenharia - 2014, Alegrete, RS, Brasil. 2014.

SILVA, H., BARBIERI, A. F., \& MONTE-MÓR, R. L. (2012). Demografia do consumo urbano: um estudo sobre a geração de resíduos sólidos domiciliares no município de Belo Horizonte. RBEP-Eletrônica, 29(2), 421-449.

SISTEMA NACIONAL DE INFORMAÇÕES SOBRE SANEAMENTO - SNIS. 2016. Disponível em: <http://www.snis.gov.br/>. Acesso em: 1\%/04/2014.

SOLTANI, A.; HEWAGE, K.; REZA, B.; SADIG, R. Multiple stakeholders in multi-criteria decision-making in the context of Municipal Solid Waste Management: a review. Waste Management, v. 35, p. 318-328, jan. 2015.

ZAMAN, A. U.; LEHMANN, S. The zero waste index: a performance measurement tool for waste management systems in a 'zero waste city'. Journal of Cleaner Production, v. 50, p. 123-132, jul. 2013.

ZANETI, I. C. B. B.; SÁ, L. M.; ALMEIDA, V. G. Insustentabilidade e produção de resíduos: a face oculta do sistema do capital. Sociedade e Estado, Brasília, v. 24, n. 1, p. 173-192, jan./abr. 2009. Disponível em: <http://www.scielo.br/pdf/se/v24n1/a08v24n1.pdf>. Acesso em: 1\%/01/2016.

ZANTA, V. M.; FERREIRA, C. F. A. Gerenciamento integrado de Resíduos Sólidos Urbanos. In: BORGES, A. C. (Coord.). Resíduos sólidos urbanos: aterro sustentável para municípios de pequeno porte. 1. ed. São Carlos, SP: Rima Artes e Textos, 2003. v. 1. 